\title{
FRAPCON-2 Developmental Assessment
}

Prepared by G. A. Berna, Idaho National Engineering Laboratory

D. D. Lanning, Pacific Northwest Laboratory

W. N. Rausch, Pacific Northwest Laboratory

Pacific Northwest Laboratory

Operated by

Battelle Memorial Institute

Prepared for

U.S. Nuclear Regulatory

Commission 


\title{
NOTICE
}

This report was prepared as an account of work sponsored by an agency of the United States Government. Neither the United States Government nor any agency thereof, or any of their employees, makes any warranty, expressed or implied, or assumes any legal liability or responsibility for any third party's use, or the results of such use, of any information, apparatus product or process disclosed in this report, or represents that its use by such third party would not infringe privately owned rights.

\author{
Available from \\ GPO Sales Program \\ Division of Technical Information and Document Control \\ U. S. Nuclear Regulatory Commission \\ Washington, D. C. 20555 \\ Printed copy price: $\$ 4.75$
}

and 


\section{FRAPCON-2 Developmental Assessment}

Marusctina Completed: June 1981

Date Published: Jul 1981

papared by

G. . B. Berna, Idaho National Engineering Laboratory

D. D. Lanning, Pacific Northwest Laboratory

W. N. Rajusch, Pacific Northwest Laboratory

Pacific Northwast Laboratory

Richiand. WA 9935 ?

\section{Prepared for}

Division of Accident Evaluation

Office of Nuclear Pegulatory Research

U.S. Nuclear Regulatory Commission

Washington, D.C. 20555

NRC FIN' A6050, B2043 



\section{ACKNOWLEDGMENTS}

The authors acknowledge Dr. G. P. Marino of the U.S. Nuclear Regulatory Commission (NRC) for his guidance in conducting this assessment. We aiso acknowledge $S$. Watson and $W$. Bennett for their technical assistance. 



\section{ABSTRACT}

FRAPCON-2 calculations using all mechanical and gas release options are compared with well-characterized experimental data and with calculations of generic fuel rod response by FRAPCON-1. These comparisons indicate that FRAPCON-2 is capable of analyzing the fuel rod response for the wide range of cases for which the code was designed and compares well with experimental data. 



\section{CONTENTS}

ACKNOWLEDGMENTS

ABSTRACT

1.0 INTROOUCTION

2.0 OVERVIEN OF FRAPCON-2 + . + . + . + . . .

2.1 FRAPCON-2 SOLUTION SCHEME + $+.+.+. \quad+3$

2.2 FRAPCON-2 FUEL ROO THERMAL RESPONSE * + * + . 4

2.3 FRAPCON-2 FUEL ROO MECHANICAL RESPONSE , * . * . 4

2.3.1 FRACAS Mechanical Response * . . * . . 4

2.3 .2 PELET/RADIAL Mechanica) Response . . . . . 5

2.3 .3 AXISYM Local Deformation Model . . . . . . 6

2.4 FRAPCON-2 FUEL ROO GAS PRESSURE RESPONSE * . , * 6

3.0 GENERIC POWER REACTOR CALCULATIONS $\quad . \quad . \quad . \quad * \quad . \quad . \quad 9$

3.1 PRESSURIZED WATER REACTOR CALCULATIONS,$\quad . \quad * \quad * \quad 9$

3.2 BOLLING WATER REACTOR CALCUEATIONS * * * * . 16

4.0 EXPERIMENTAL DATA COMPARISONS . . . . . . . . . 21

4. EFFECT OF POWER AND GAP SIZE ON FUEL

4.1.1 Trends of Major Code Options . . . . . 23

4.1.2 Experiment Description for GC 2 Tests . . . 23

4.1.3 Comparison of FRAPCQN-z to GC 2 Test Data . * . 25

4.1 .4 Discussion $\times .+. \times+.+32$

4.2 EFFECT OF AS-FABRICATEO FUEL OENSITY
ON BEGINANG-OF-LIFE FUEL TEMPERATURE * + * . . . * 35

4.2.1 Comparison of FRAPCon-? to GC z Test Data. . . . 35

$4.2,2$ 0iscussion . . . . . . . . . . 39 
4.3 POWER AND GAP SIZE EFFECTS ON CLADDING

DEFORMATION AT BEgINNING OF LIFE $\cdot$. $\quad . \quad \cdot \quad \cdot \quad \cdot \quad 39$

4.3.1 Trends fron the Major Code Options . . . . 42

4.3.2 Comparison of Code Calculations to Data from IFA-508 . 42

4.3.3 Comparison of Code Calculations to Data from Rod 3 of IFA-431 . $\quad . \quad . \quad . \quad . \quad . \quad . \quad 52$

4.3.4 Comparison of Code Calculations to Data from Rod 15 of PCM-4 .

4.3.5 Discussion of Cladding Deformation Results _ . $\quad 67$

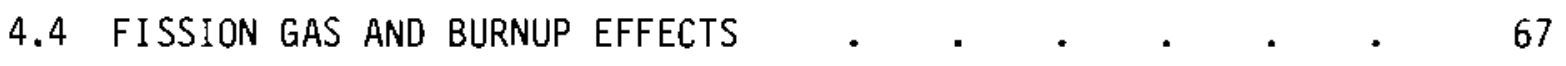

4.4.1 Comparison of Code Calculations to Data from the

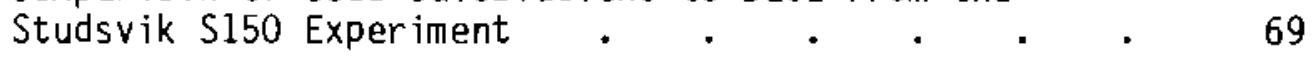

4.4.2 Comparison of Code Calculations to Experimental Data from Rod 1 of IFA-432 . . . . . . . 74

4.4.3 Comparison of Code Calculations to Experimental Data from Rod K-4 of H. B. Robinson Assembly B05 . . 83

4.4.4 Discussion of Burnup Effects . . . . . . . $\quad$ B7

5.0 SUMMARY OF EFFECTS .

5.1 EFFECTS OF AS-FABRICATED FUEL-CLADDING GAP . . . . 91

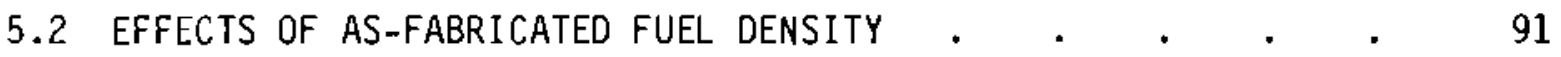

5.3 EFFECTS OF POWER AND AS-FABRICATED GAP SIZE
UPON BEGINNING-DF-LIFE CLADDING DEFORMATION

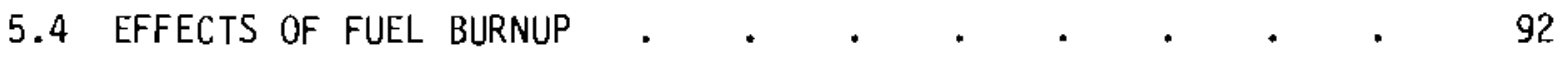

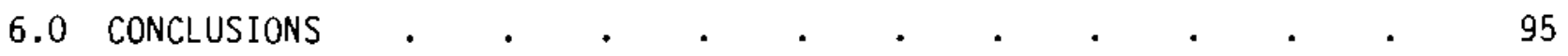

7.0 REFERENCES $\quad . \quad$. $\quad . \quad$.

APPENDIX - DEVELOPMENTAL ASSESSMENT CASES OUTPUT . . . . . . . . A.1 


\section{FIGURES}

1 FRAPCON-1 and FRAPCON-2 Center line Temperature Calculations for the Generic PtR Case . * . * . * 12

2 FRAPCON-I and FRAPCON-2 ROd Internal Presstire Calculations for the Generic Pink case . . . . * . 13

3 FRAPCON-1 and FRAPCON-2 Gap Heat Transfer Coefficient Calculations for the Generic PWR Case . . . . . . * 14

4 FRAPCON-1 and FRAPCON-2 Center line Temperature Calculations for the Generic BwR Case * . . . * . 17

5 FRAPCON-1 and FRAPCON-2 Rod Internal Pressure Calculations for the Generic BwR Case . . . * . . 18

6 FRAPCON-1 and FRAPCON-2 Gap heat Transfer Coefficient Calculations for the Generic BWR Case . . . * . . 19

7 Demonstration of Gap Size Effect Using 60 2-1 and GC $2-2$ Test Rod Data . * * * * * . . * 22

8 Representative Axial Power Profile for the Gap conductance Tests GC $2 \mathrm{~m}$, GC $2-2$, and GC $2-3.3 .+25$

9 Power-Tine History of the PBF Core During the Power Caltbration

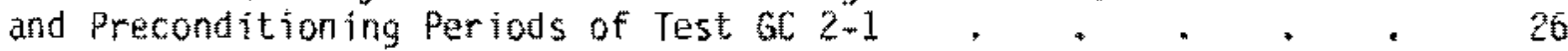

10 Power-Tine History of the PBF Core During the Power Calloration and Preconditioning Periods of Test GC $2-2 .+. \quad \cdot \quad 27$

1 Power-Tine History of the PBF Core During the Fower Calibration and Preconditioning Periods of Test 6C $2-3 . . .28$

12 Comparison of PELET, FRACAS-I, and FRACAS-11 Calculations and lod $522-3$ of $6 C 2-2$ Center line Temperature 0ata . * . 29

13 Comparison of PELET, FRACAS-I, and FRACAS-II Calculations and Rod 503 of 60 2 -1 Centerline Temperature Data . . . 30

14 Comparison of PELET, FRACAS-I, and FRACAS-II Calculations and Rod 522-4 of GC 2-2 Centerline Temperature Data . . . 31

15 Comparison of FRAPCON-2 (PELET) Thermal Resistance Trends

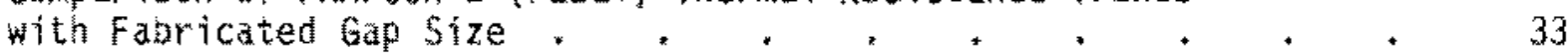

16 Demonstration of Fuel Density Effect Using Two $\mathrm{GC} 2$ Test Rods wth Helium Fill Gas and 100-um Dianetral Fabricated Gaps 
17 Predicted Fuel Density Effect Using the Major Code Options . . $\quad 37$

18 Comparison of PELET, FRACAS-1, and FRACAS-II Calculations and Rod 523-1 of GC 2-3 Centerline Temperature Data . . . 38

19 Demonstration of Gap Size Effect on Axial Elongation

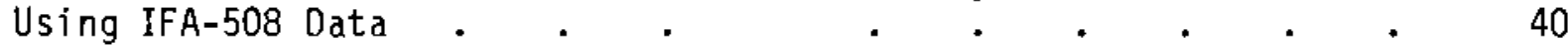

20 Demonstration of Gap Size Effect on Diametral Strain Using IFA-508 Data . . . . . . . . . . . .

21 Predicted Gap Size Effect on Axial Elongation Using FRACAS-II

22 Predicted Gap Size Effect on Axial Elongation Using PELET . . 44

23 Step Power Ramp in the First Cycle for IFA-508 . . . . . 45

24 Beginning-of-Life Centerline Temperature Data for Rods 11 and 13 of IFA-508 Compared to PELET Calculations . . . . .

25 Beginning-of-Life Axial Elongation Data for Rods 11 and 13 of IFA-508 Compared to PELET Calculations . . . . 48

26 Beginning-of-Life Diametral Strain Data for Rods 11 and 13 of IFA-508 Compared to PELET Calculations . . . . . 49

27 Beginning-of-Life Centerline Temperature Data for Rods 11 and 13 of IFA-508 Compared to FRACAS-II Calculations . . . 50

28 Beginning-of-Life Cladding Deformation Data for Rods 11 and 13 of IFA-508 Compared to FRACAS-II Calculations . . .

29 Beginning-of-Life Centerline Temperature Data for Rods 11 and 13 of IFA-508 Compared to FRACAS-I Calculations . . .

30 Beginning-of-Life Cladding Deformation Data for Rods 11 and 13 of IFA-508 Compared to FRACAS-I Calculations

31 Arrangement of Temperature Sensors, Neutron Detectors, and Fuel Relative to Reference Axial Thermal Flux Prof $i l e$ for IFA-432 and IFA-431

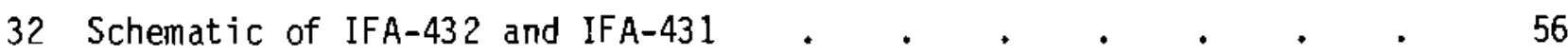

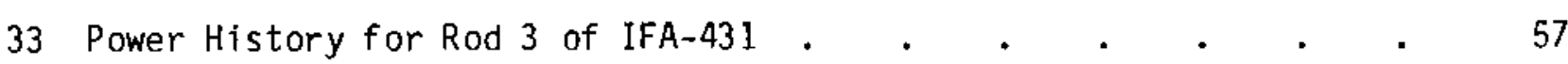


34 Measured and Calculated Beginning-of-Life Fuel Centerline Temperatures for Rod 3 of IFA-431 Using PELET, FRACAS-I,

35 Measured and Calculated Fuel Rod Elongation on First Rise to Power for Rod 3 of IFA-431 Using PELET, FRACAS-I, and FRACAS-I I

36 Measured and Calculated Rod Axial Elongation Versus Burnup for Rod 3 of IFA-431 . . . . . .

37 Axial Power Profile for Test PCM-4, Determined from Cobalt Wire Activation . . . . . . . . .

38 Typical Fuel Rod Peak Power and Coolant Mass Flux During the Fuel Rod Power Calibration Phase . . . .

39 Comparison of PELET, FRACAS-I, and FRACAS-II Calculations and Rod 15 of PCM-4 Centerline Temperature Data . . . . 65

40 Calculated and Measured Cladding Elongation Versus Peak Rod Power for Rod 15 of PCM-4 Using FRAPCON-2 With PELET, FRACAS-I, and FRACAS-II

41 Representation of Burnup Effects Upon Fuel Temperatures

for an Unpressurized BWR Rod . . . . . . . .

42 Representation of Burnup Effects Upon Fuel Temperatures for a Pressurized PWR Rod

43 Axial Flux Variation for the Studsvik S150 Experiment . . . 71

44 Power History for Rod 11 of the Studsvik S150 Experiment . . 72

45 Measured and Calculated Fuel Centerline Temperature and Gas Release for Rod 11 of the S150 Experiment Using PELET, FRACAS-I, and FRACAS-II

46 Power History for Rod 1 of IFA-432 Using PELET, FRACAS-I,

47 Inferred Gas Release for Rod 1 of IFA-4.32 . . . . 77

48 Measured Fuel Centerline Temperature at Constant Power for the Lower Thermocouple Location of Rod 1 of IFA-432 . . .

49 Measured and Calculated Fuel Centerline Temperature Versus Burnup for the Lower Thermocouple Location of Rod 1 of IFA-432 Using PELET 
50 Measured and Calculated Fuel Caterline Temperature Versus Power Versus Burnup for the Lower Thermocouple Location of Rod 1 of IFA-432 Using FRACAS-I and FRACA5-II

51 Comparison of PELET, FRAOAS-I, and FRACAS-II Calculations with Rod 1 of IFA.432 Center Iine Temperature Data . . . . . 81

52 Comparison of PELET, FRACAS-I, and FRACAS-II Calculations with Rod 1 of IFAm 42 Centerline Temperature Data * * . . 32

53 Beginingmof-Life Axial Power Profile for Assembly But from the H. Robinson Reactor

54 End-of-Life Axial Power Profile for Assembly bos from the H. B. Robinson Reactor

55 Input and Actual Power Histories for H. B. Robinson PWR Rod

SE Calculated pellet Surface and Center Temperatures Versus Irradiation Time for $H$. B. Robinson PWR Rod Using PE.ET, FRACAS-1, and FRACAS-II

\section{TABLES}

I Integrated Thermal-Mechanical Models

2 Gas Release Models

3 Generic PWR Input to FRAPCON-1 and FRAPCON-2

4 PNR Axial Poher Profile . . . . . . . . . . . 10

5 Generic BWR Input to FRAPCON-1 and FRAPCON-2 * * . * 11

6 BHR Axia Power Profile . . . . . . . . . . . . 11

7 Representative Calculated and Measured Themal Resistances Snowing Gap Size Effects

8 Design Characteristics of Selected Fuel Rots from the

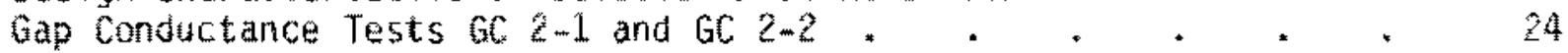

9 Design Characteristics of Several Halden and PBF Test Roos . . 34

10 Measured and Calculated Resistances for Rods 1 and 6 of 1 RA 431 Using PELT . . . . . . . . . 39

li H. B. Rooinson Assembly gos power History + . + . . . B4 


\subsection{INTRODUCTION}

FRAPCON-2 is a computer code for calculating the steady-state thermal and mechanical behavior of a single light water reactor (LWR) fuel rod. This report presents comparisons of the code calculations with experimental data from a few well-characterized and heavily instrumented irradiated test hul rods. The code is aso conpared wh FRACON-1 calculations for generic fuel rods taken to extended burnup. These comparisons illustrate the range of conditions and rod designs over which FRAPCon-2 may be applied and famlliarize the reader with the code's operation, capabilities, and linltations.

A detailed description of the code and its modeling options may be found in the FRAPCON-2 code Description and User's Manual. (1) The results of an "independent assessment" of FRAPCON-2 based on comparison with a large number of tes* rod data are presented in a report by Lats et a (2) $^{(2)}$

Development of the FRAPCON code series is funded by the U.S. Nuclear Regulatory Commssion (NRC), which, prior to 1977 , funded development of both FRAP $-5(3)$ at I daho National Engineering Laboratory (INEL) and GAPCON-THERMAL (4) at Pacific Northwest Laboratory (PNL). In 1977 funding for these singlem rod steady-state fuel code series was teminated, and the FRAPCon series was established to conbine the best elements of the two previous codes into an advanced code for audit calculations in licensing proceedings as well as for bestestimate calculations. The NRC decided to combine the mechanics pack age fron FRAP-S (FRACAS-1) ${ }^{(5)}$ with the gap conductance and pellet heat conduction routines from the GAPCON-THERMAL sertes, and this combination was released by laEL as FRAPCONm 1 (6) The ARC then encouraged INEL and PNL to develop a second, improved verstion of the code jointly. which was to include nore closely coupled thermal and mechanical models developed at each 1 aboratory as well as a variety of ass release models. The best combination bf models was to be chosen as a result of compartson to the large number of irradiation experiments detafled ir Reference 2.

The fint version of FRAPCON-2 contains three coup?ed thermal and mechanical model options (see Table 1) and fue fission gas release models (see Table 2). In adotion, the code can be linked to the fully intercomected, 
TAGLE 1. Integrated Therma 1-Mechanical Models

\begin{tabular}{|c|c|c|c|}
\hline $\begin{array}{l}\text { Mechanical } \\
\text { Model }\end{array}$ & $\begin{array}{r}\text { Associated Fuel } \\
\text { Relocation Model }\end{array}$ & $\begin{array}{l}\text { Associated Fuel } \\
\text { Conductivity } \\
\text { Factor Mode1 }\end{array}$ & $\begin{array}{l}\text { Brief } \\
\text { Model Description }\end{array}$ \\
\hline $\begin{array}{l}\text { FRACAS-1 } \\
\text { ERACAS-II } \\
\text { PELET/RADIAL }\end{array}$ & $\begin{array}{l}\text { Coleman } \\
\text { Carlson } \\
\text { Constant contact }\end{array}$ & $\begin{array}{l}\text { Eoleman } \\
\text { Modified coleman } \\
\text { Williford }\end{array}$ & $\begin{array}{l}\text { Rigid Pellet } \\
\text { Deformable Pel1 } \\
\text { Cracked Pellet }\end{array}$ \\
\hline
\end{tabular}

detailed half mellet finite element model AxISYM, which can calculate cladding localized defomation (ridging).

Section 2 of this report provides a brief overview of the code and its options. Section 3 presents FRAPCON-2 versus FRAPCON-1 calculations for generic fue 1 rods taken to extended burnup. Section 4 presents code calculations compared with experinental data for in-reactor data on fuel center and of $f$ center temperatures, cladding elongation, fission gas release, and radial defomation. This is done on a case-by-case basis, and the cases are grouped by general emphasis-utemperature response, cladding response, and fission gas release. A sumary of the various effects on fuel rod response observed in in-reactor experimental data (such as the effect of initial pellet density) is presented in Section 5, and the conclusions drawn from this developmental assessment and recommendations for future FRAPCON-2 development are presented in Section 6 .

TABLE 2. Gas Release Models

Gas Release Model
Beyer-Hann $(7)$
Booth $(8)$
MacDonald-Weisman $(9)$
ANS $-5.4(10)$
FASTGRASS(11)
GRASS(12)

Model Basis
Empirical
Diffusion theory using empirical constant
Release and trapping probability using
empirical constants
Detailed diffusion
Mechanistic approach
Mechanistic approach

Originating Laboratory

PNL (a) $\operatorname{AECL}(b)$ INEL $(t)$

PNL. (d)

ANL.

(a) Pacific Northwest Laboratory, Richland, Washington.

(b) Atomic Energy of Canada, Ltd.

(c) Idaho National Engineering Laboratory, Idaho Falls, Idaho.

(d) Argonne National Laboratory. Argonne, Illinois. 


\subsection{OVERVIEW OF FRAPCON-2}

FRAPCON-2 is an analytical tool that calculates LWR fuel rod behavior when power and boundary condition changes are sufficiently slow so that a series of steady-state analyses (no time derivatives) can be used to model rod behavior. Such situations would include long periods at constant power and slow power ramps that are typical of nomal power reactor operations. The code calculates the variation with time of all significant fuel rod variables, including fuel and cladding temperatures, cladding hoop strain, cladding oxidation, fuel irradiation swelling, fuel densification, fission gas release, and rod internal gas pressure. In addition, the code is designed to generate initial conditions for transient fuel rod analysis by either FRAP-T6 ${ }^{(13)}$-- the companion transient fuel rod analysis code--or RELAP4/MOD7 ${ }^{(14)}$--a thermal-hydraulic code for transient analys is of LWR systems.

\subsection{FRAPCON-2 SOLUTION SCHEME}

Calculating the variables listed above begins with processing of input data; and the initial fuel rod state is detemined through a self-initialization calculation. Time is advanced according to user-specified time increments, a steady-state solution is performed, and the new fuel rod state is determined. The new fuel rod state provides the initial state conditions for the next time step. The calculations are cycled in this manner for the user-specified number of time steps.

The solution for each time step consists of calculations of:

- the temperature of the fuel and the cladding

- fuel and cladding deformation

- the fission gas generation, void volume, and fuel rod internal gas pressure.

Each of these calculations is made in a separate subcode. The fuel rod response for each time step is determined by repeated cycling through two nested loops of calculations until the fuel rod temperature, deformation, and internal gas pressure data converge. 


\subsection{FRAPCON-2 FUEL ROD THERMAL RESPDNSE}

The models used in the fuel rod temperature calculations assume a cylindrical fuel rod surrounded by coolant. User-supplied boundary conditions (coolant imlet temperature, coolant channel equivalent heated diameter, and coolant mass flux) and the user-supplied axial linear heat generation rate are used to calculate the coolant bulk temperature with a single channel coolant enthalpy rise model. A film temperature rise is then calculated from the coolant to the surface of the fuel rod through any crud layer that may exist. The temperature of the inside surface of the cladding is found by calculating the temperature rise across the zirconium oxide and the cladding using Fourier's Law. The temperature rise to the fuel surface is determined from an annular gap conductance model, thereby establishing the fuel surface temperature. Finally, the temperature distribution in the fuel is calculated accounting for fuel cracking effects and using the fuel surface temperature and assumed symmetry at the centerline as boundary conditions.

\subsection{FRAPCON-2 FUEL ROD MECHANICAL RESPONSE}

An accurate calculation of fuel and cladding deformation is necessary in any fuel rod response analysis because the heat transfer coefficient (HTC) across the fuel-cladding gap is a function of both the effective gap size and the interfacial pressure. An accurate calculation of cladding stresses is also needed so that an accurate determination of the onset of cladding failure (and subsequent release of fission products) can be made.

FRAPCON-2 has four mechanical modeling options: FRACAS-I, FRACAS-II, PELET/RADIAL, and AXISYM. Each model is briefly discussed below (see Reference 1 for detailed descriptions).

\subsubsection{FRACAS Mechanical Response}

Two FRACAS models can calculate the small displacement deformation of the fuel and cladding. The more simplified model, FRACAS-I, neglects the stressinduced deformation of the fuel and is called the rigid pellet model. The second model, FRACAS-II, includes stress-induced fuel deformation and is called the deformable pellet model. 
In andyzing the deformation of fuel rods, one of two physical situations is assumed to exist:

- fuel and cladding are not in contact - Here the prablem of a cylindrical she 11 (the cladoing) with specifled internal and external pressures and a specified cladding temperature distribution must be solved; called the open gap regine.

- fuel and cladding are in contact - occurs when the fuet (whtch is considerably hotter than the clatding) has expanded; further heating of the fuel results in "driving" the cladding ottward; called the closed gap regine. This regime can occur due to creep of the cladding onto the fuel from elevated cladding temperatures and a high coolant pressure.

\subsubsection{PELET/RADIAL. Mechanica Response}

The PELET finte element mode i from CAPCON-THERMAL-3(i5) has been modified for use in FRAPCON-2 by addition of the RAOLAL fodel, which changes the effective elastic modulus of the fuel elements to simulate the mechanical behavior of cracked fuel. (16) This "softer" fuel elastic modulus is then used in the finfe elenent calculation to determine ciadding elastic-plastic deformation.

RADIAL is also the prinary link between thertal and mechanical portions of the computer program. The thermal effect of fuel cracking reduces the effective themal conductivity of the fuel. The theral conductivity of the fill gas is much less than that of the solid fuel; and since there are cracks in the fuel, some of the heat transfer will take place via this less conductive medutur.

RADIAL assutes that as the fuel cracks, the pieces tend to shift position and change orientation relative to one another. Themal expansion of the fuei will result in these pieces of fuel applying loads on each other and on the cladding; Mikic has shown such a relationship betwen crack with and applied stress. (17) The assumption is made by the subroutine that the stress across 
the cracks in the fuel is the same as the stress present in the interface between the fuel and cladding. Using Mikic's formulation, the stresses as well as the width of the cracks and the size of the gap can be determined.

The amount of free area within the cladding that is not occupied by fuel can be determined by accounting for the thermal expansion of the fuel and cladding and the deformation of the cladding due to interral and external loads. The gap size solved for earlier can be used to determine the apportionment of the free area that is gap area or crack area. These percentages have been correlated with the effective elastic modulus of the fuel. The resolved stress is used to calculate the effective themal conductivity. In this manter, the mechanical and thermal models have been made fully interdependent and, in fact, are not separable.

\section{3 .3 AXISYM Loca Deformation Mode 1}

Local strain concentrations in the cladoing of nuclear fuel rods are known to be potential sites for fallure initiation. Assessment of such strain concentrations requires a two-dimensional analysis of stress and strain in both the fuel and the cladding during pelletwcladding mechanical interaction (PCMI). AxISYM-a finite element mode 1 developed at IMEL--was modified to provide this capability in the FRAPCON-2 cote.

AxIsm uses constant strain, axisymetric, triangular elements and a standard finite element displacement formulation. The model can accomodate temperature-dependent material properties and has full elastic-plastic creep capabillties. AXISw has been modified for PCMI analysis by the addition of fuel-cladding gap elements and special cladding boundary constraints and provides for a detalled mechanical analysis for examination of local strains.

\subsection{FRAPCON-2 FUEL ROD GAS PRESSURE RESPONSE}

After the fuel rod temperature and deformation calculations have been completed, the pressure of the gas in the fuel rod is computed. The fuel rod internal gas pressure model is based on the perfect gas law modified to permit different volumes of gas at different temperatures. The gas pressure is calculated using the gas temperature, void volumes, and gas inventory. The thermal 
models discussed earlier provide the temperature of the gas in the fuel rod plenum, fuel-cladding gap, and fuel voids. The fuel rod deformation models calculate information for computing the volume of the fuel rod plenum, fuelcladding gap, and other fuel voids. The initial fill gas and the gas release mode Is-which include ANS-5.4, (10) MacDonald-Weisman, (9) Beyer-Hann, (7) Booth Diffusion, ${ }^{(8)}$ and FASTGRASS (11) --provide the gas inventory. 



\subsection{GEMERIC POWER REACTOR CALCULATIONS}

Two generic power reactor fuel rods were analyzed with fRAFon-z and FRAPCON-1 to proyide code comparis ons for conmercial fuel rods through extended burnup and to assess the reasonabieness of the calculations. The fuel rods chosen for these comparisons correspond to a comercial pressurized water reactor (PWR) 15 by 15 design and a comercial bolling water reactor (BWR) 7 by 7 design. While these cases are not data comparisons, they provide information whereby the code can be benchmarked for extended burmup of commercial tuel rods.

For these comparisons, as-fabricated fuel rod parameters, reactor operating conditions, and power history for the wwo cases were input to frapcon-1 and FRAPCON-2. The FRACAS-1, FRACAS-11, and PELET mechanics options as well as the MacDonald-We sman, FASTGRASS, and Beyer-Hann gas release nodels were used. The input parameters for the PWR fuel rod are shown in Table 3 . For these calculations, the rod average power was $23.06 \mathrm{~kW} / \mathrm{m}$ and the conlant inlet temperature, mass flow rate, and pressure were $526 \mathrm{~K}, 1937.5 \mathrm{~kg} / \mathrm{s}-\mathrm{m}^{2}$, and $15.5 \mathrm{MPa}$, respectively. The axial power profile that was provided to FRAPCON-1 and FRAPCon- 2 for the PWR case is shown in Table 4 . The BWR input fuel rod paraneters are shown in Table 5. For these calculations, the rod average power was $24.25 \mathrm{~kW} / \mathrm{t}$ and the coolant inlet temperature, mass flow rate, and pressure were $522 \mathrm{~K}, 1007.5 \mathrm{~kg} / \mathrm{sm} \mathrm{m}^{2}$ and $7.14 \mathrm{MPa}$, respectively. The axial profile that was used is shown in Tables.

\subsection{PRESSURIZED WATER REACTOR CALCULATIONS}

The FRAPCON-2 options included in these comparisons are FRACAS-I with MacDonald-Weisman, FRACAS-II with MacDonald-weisman, FRACAS-II with FASTGRASS, PELET with Maclonaldweisman, and PELET with Beyer-Hann. Centerline temperam ture, internal gas pressure, and gap Hic plots are shown for the generic PwR case in Figures 1,2 , and 3 , respectively.

The generic PWR comparisons of FRAPCON-1 versus FRAPCON-2 show some important differences. The fuel centerline tenperature (Flgure 1) calculated by FRAPCON-2 is lower than that using FRAPCON-1 by approximately $170 \mathrm{~K}$ at beginning 
TABLE 3. Generic PUR InPut to FRAPCON-1 and FRAPCON-2

\begin{tabular}{|c|}
\hline Rod Parameter \\
\hline 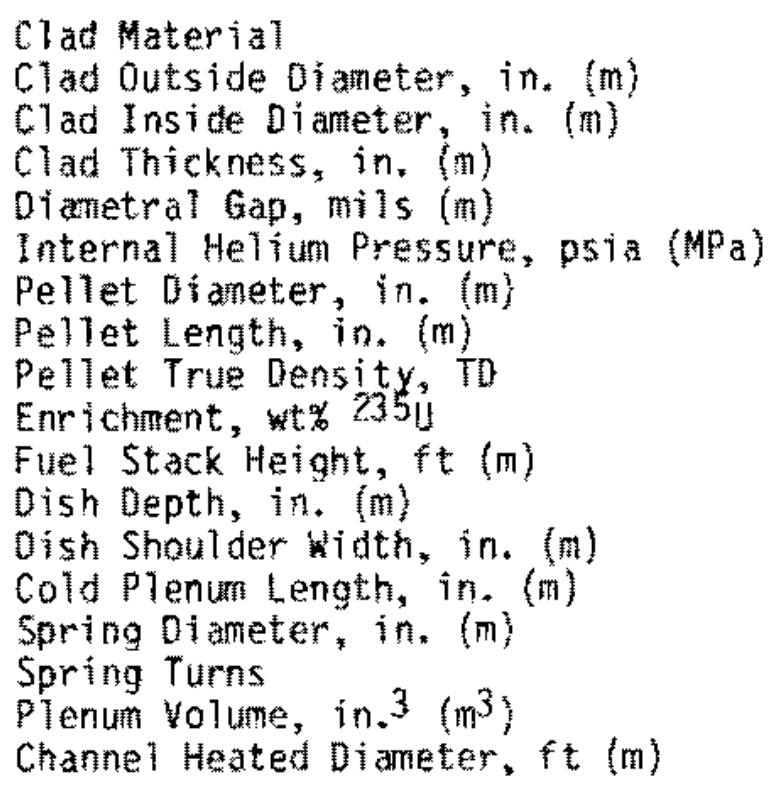 \\
\hline
\end{tabular}

\begin{tabular}{l}
$\frac{1}{\text { Design Value }}$ \\
\hline Zircaloy-4 \\
$0.422(0.0107)$ \\
$0.374(0.0095)$ \\
$0.024(0.00061)$ \\
$7.5(0.0019)$ \\
$345(2.379)$ \\
$0.3665(0.0093)$ \\
$0.6(0.0152)$ \\
$94 \%$ \\
2.8 \\
$12.0(3.65)$ \\
$0.015(0.000381)$ \\
$0.043(0.00109)$ \\
$6.8(0.173)$ \\
$0.35(0.00889)$ \\
28 \\
$0.638(1.05 \times 10.5)$ \\
$0.0445(0.01357)$
\end{tabular}

\section{TABLE 4. PWR Axial Power Profile}

Increment

1

2

3

4

5

6

8

9
Axial Station.

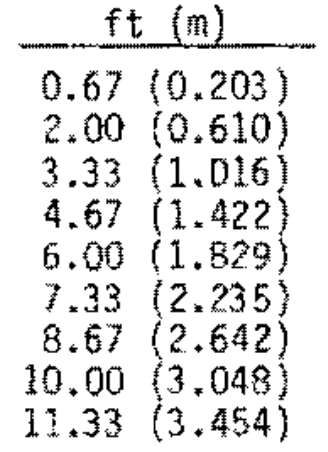

Normal ized Heat F lux

0.457

0.858

1.152

1.326

1.386

1.326

1.152

0.858

0.457 
TABLE 5. Generic BWR Input to FRAPCON-1 and FRAPCON-2

\begin{tabular}{ll}
\multicolumn{1}{c}{ Parameter } & \multicolumn{1}{c}{ Design Value } \\
\cline { 1 - 1 } Clad Material & Zircaloy-2 \\
Clad Outside Diameter, in. (m) & $0.567(0.0144)$ \\
Clad Inside Diameter, in. (m) & $0.499(0.0127)$ \\
Clad Thickness, in. (m) & $0.034(0.00086)$ \\
Diametral Gap, mils (m) & $12.0\left(0.3048 \times 10^{-3}\right)$ \\
Internal Helium Pressure, psia (MPa) & $15.0(0.1034)$ \\
Pellet Diameter, in. (m) & $0.487(0.0124)$ \\
Pellet Length, in. (m) & $0.365(0.00927)$ \\
Pellet True Density, To & $94 \%$ \\
Enrichment, wt\% 235U & 2.2 \\
Fuel Stack Height, ft (m) & $12.0(3.66)$ \\
Dish Depth, in. & 0.00 \\
Dish Shoulder Width, in. (m) & $0.2435(0.00619)$ \\
Cold Plenum Length, in. (m) & $16.0(0.406)$ \\
Spring Diameter, in. (m) & $0.48(0.0122)$ \\
Spring Turns & 64 \\
Plenum Volume, in. ${ }^{3}$ (m $\left.{ }^{3}\right)$ & $2.76\left(0.452 \times 10^{-4}\right)$ \\
Channel Heated Diameter, ft (m) & $0.0583(0.0178)$
\end{tabular}

TABLE 6. BWR Axial Power Profile

\begin{tabular}{|c|c|c|}
\hline Increment & $\begin{array}{c}\text { Axial Station, } \\
\mathrm{ft}(\mathrm{m}) \\
\end{array}$ & Normalized Heat Flux \\
\hline $\begin{array}{r}1 \\
2 \\
3 \\
4 \\
5 \\
6 \\
7 \\
8 \\
9 \\
10 \\
11\end{array}$ & $\begin{array}{r}0.546(0.166) \\
1.636(0.499) \\
2.727(0.831) \\
3.818(1.422) \\
4.909(1.496) \\
6.000(1.829) \\
7.091(2.161) \\
8.182(2.494) \\
9.273(2.826) \\
10.364(3.159) \\
11.455(3.491)\end{array}$ & $\begin{array}{l}0.416 \\
0.760 \\
1.034 \\
1.231 \\
1.348 \\
1.348 \\
1.389 \\
1.348 \\
1.231 \\
0.760 \\
0.416\end{array}$ \\
\hline
\end{tabular}




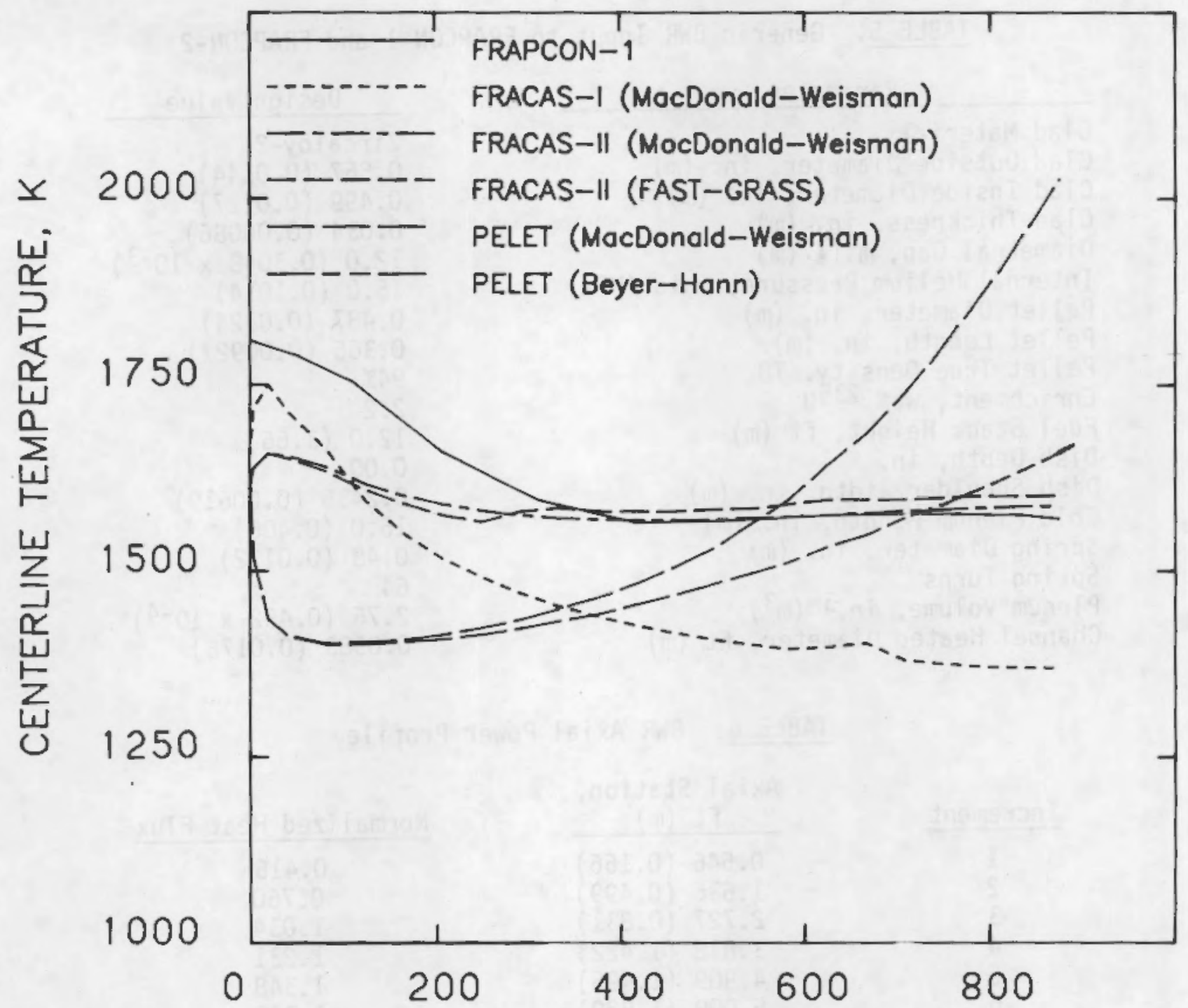

TIME, days

FIGURE 1. FRAPCON-1 and FRAPCON-2 Centerline Temperature Calculations for the Generic PWR Case 


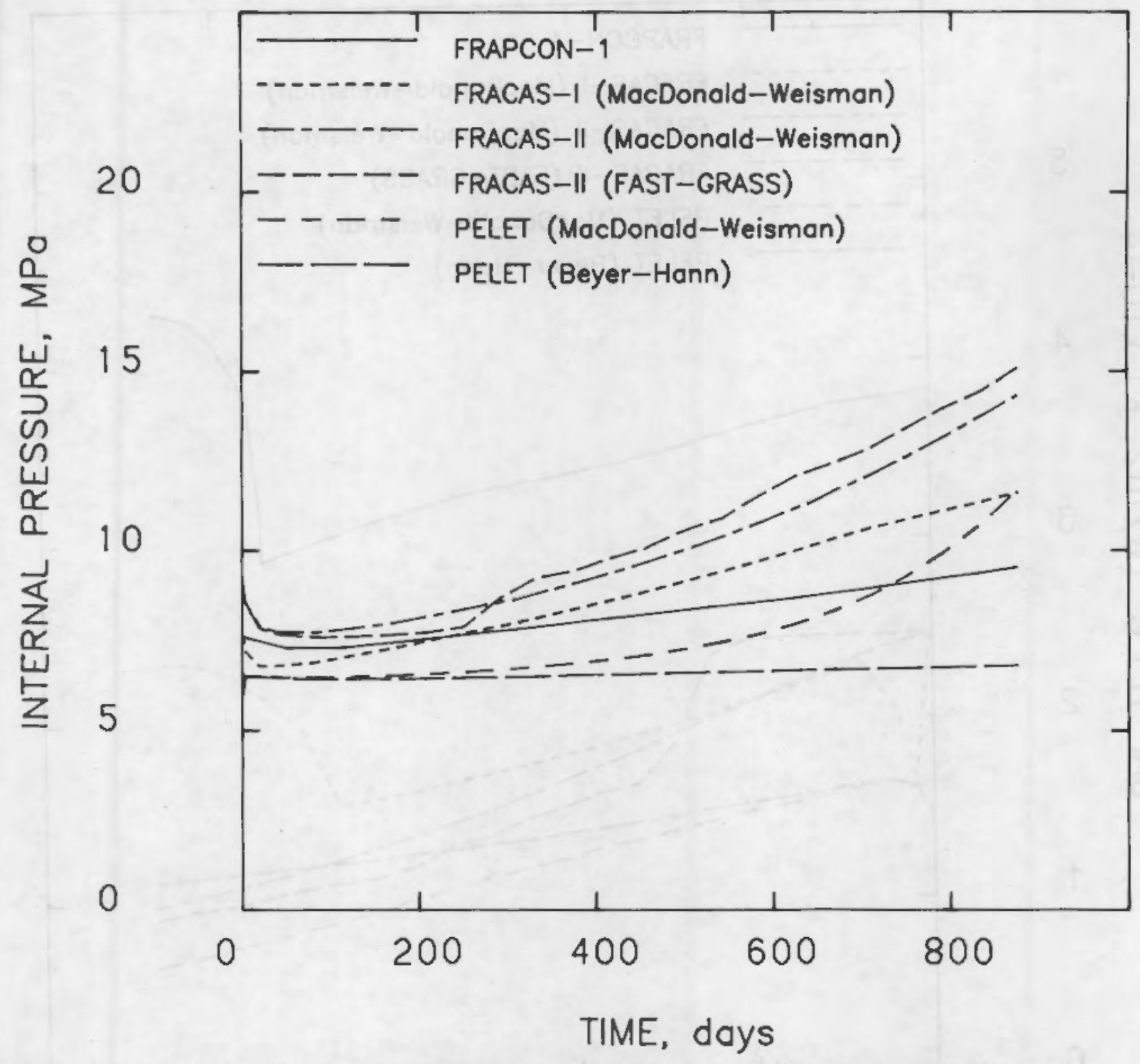

FIGURE 2. FRAPCON-1 and FRAPCON-2 Rod Internal Pressure Calculations for the Generic PWR Case 


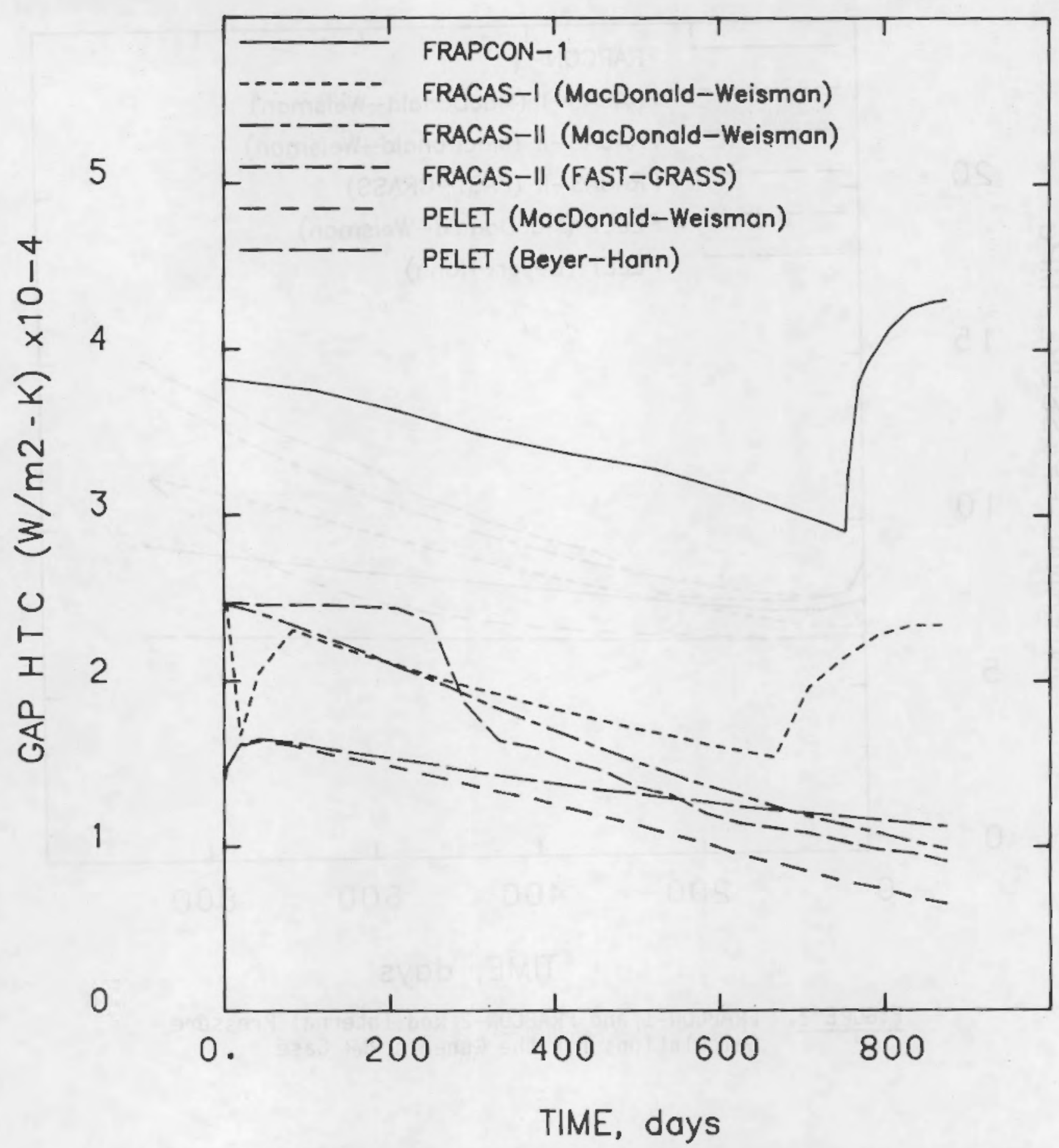

FIGURE 3. FRAPCON-1 and FRAPCON-2 Gap Heat Transfer Coefficient Calculations for the Generic PWR Case 
of life (BOL) for all options that are presented. This difference is due in part to an improper treatment of the crack void temperature in FRAPCON-1 and in an improved feedback of density effects and cracking effects in the fuel conductivity in FRAPCON-2. At end of iife (EOL), however, the calculations of fuel centerline temperature differ significantly due to differences in the application of the effective fuel thermal conductivity models. The sudden drop in temperature exhibited by the PELET options has been tentatively attributed to improper modeling of the densification. The trend of the lower BOL fuel temperature is in the desired direction as discussed in the independent assessment of FRAPCON-2. (2)

The fission gas production in FRAPCON-1 was incorrectly modeled and was low by a factor of four, which resulted in the lower internal gas pressure at EOL as calculated by FRAPCON-1 when compared with the FRACAS-I and FRACAS-II calculations from FRAPCON-2 (see Figure 2). The PELET calculation of a lower gas pressure at EOL results from differences in the assumed void volume distribution within the fuel rod.

The gap HTC comparison shown in Figure 3 demonstrates the various modeling assumptions. The basic gap conductance model changed between FRAPCON-1 and FRAPCON-2, resulting in a slight lowering of the peak power conductance values. Among the FRAPCON-2 model options, all the FRACAS calculations correspond at BOL, as do the two PELET combinations; but the two sets differ from each other. The FRACAS models assume conventional pellet surface roughness but instantaneous significant relocation, which at high power ( $33 \mathrm{~kW} / \mathrm{m}$ in this case) results in a nearly total closure of the thermal gap. Mechanical contact, with consequent interfacial pressure and further increase in gap conductance, is not assumed, however, until fuel swelling equals the volume change caused by initial relocation. This finally happens at about 650 days in the FRACAS-I (MacDonald-Weisman) case and at about 700 days in the FRAPCON-1 case (see Figure 3). PELET assumes mechanical and thermal contact at all times but assigns a macroroughness to the fuel surface that is quite large (and depends upon as-fabricated gap size). For these nominal gap rods, the roughness is on the order of 20 microns. Hence, the initial PELET gap conductance is slightly lower than the FRACAS value (at high power); but it is less power and burnup dependent. 
The trends represented by Figures 1 through 3 represent generally realistic fuel rod behavior. The initial increase in the fuel temperature (Figure 1) is due to early-in-life densification; the slow decrease in fuel temperature, to cladding creep and fuel swelling; and the leveling off and slight increase of the fuel temperature, to the fission gas increase within the fuel rod. In Figure 2, the initial gas pressure decrease is due to initial fuel densification. The ever-increasing gas inventory, however, reverses that trend; and the gas pressure monotonically increases. The gap HTC decrease with time is due to the increased fission gas inventory, which degrades the conductivity of the gas in the fuel-cladding gap. These data indicate that FRAPCON-2 is calculating reasonable generic PWR fuel rod behavior.

\subsection{BOILING WATER REACTOR CALCULATIONS}

The generic BWR comparisons of FRAPCON-1 versus FRAPCON-2 show notable differences due to increased fission gas production, as was the case for the PWR comparisons. The centerline temperature, internal gas pressure, and gap HTC for the BWR fuel rod are shown in Figures 4,5 , and 6 , respectively.

As shown in Figure 4, the FRAPCON-1 calculation of centerline temperature at EOL is approximately 100K higher than that of FRAPCON-2 using FRACAS-II. BOL centerline temperature differences are small and cannot be attributed to any specific model change. The initial rise in temperature (except for PELET; see Section 3.1) is due to fuel densification while the general decrease in temperature from that point is due to cladding creepdown. The increased fission gas inventory results in a significant increase in the internal gas pressure. This is more prominent than in the generic PWR case because the amount of initial fill gas in the BWR rod is small compared with the fission gas that is released.

The difference in the gap HTC between that calculated by FRAPCON-1 and FRAPCON-2 (see Figure 6) is due to a change in the gap HTC model.

The trends shown in Figures 4,5 , and 6 are again as expected. The centerline temperatures calculated by the FRACAS options increase early in life 


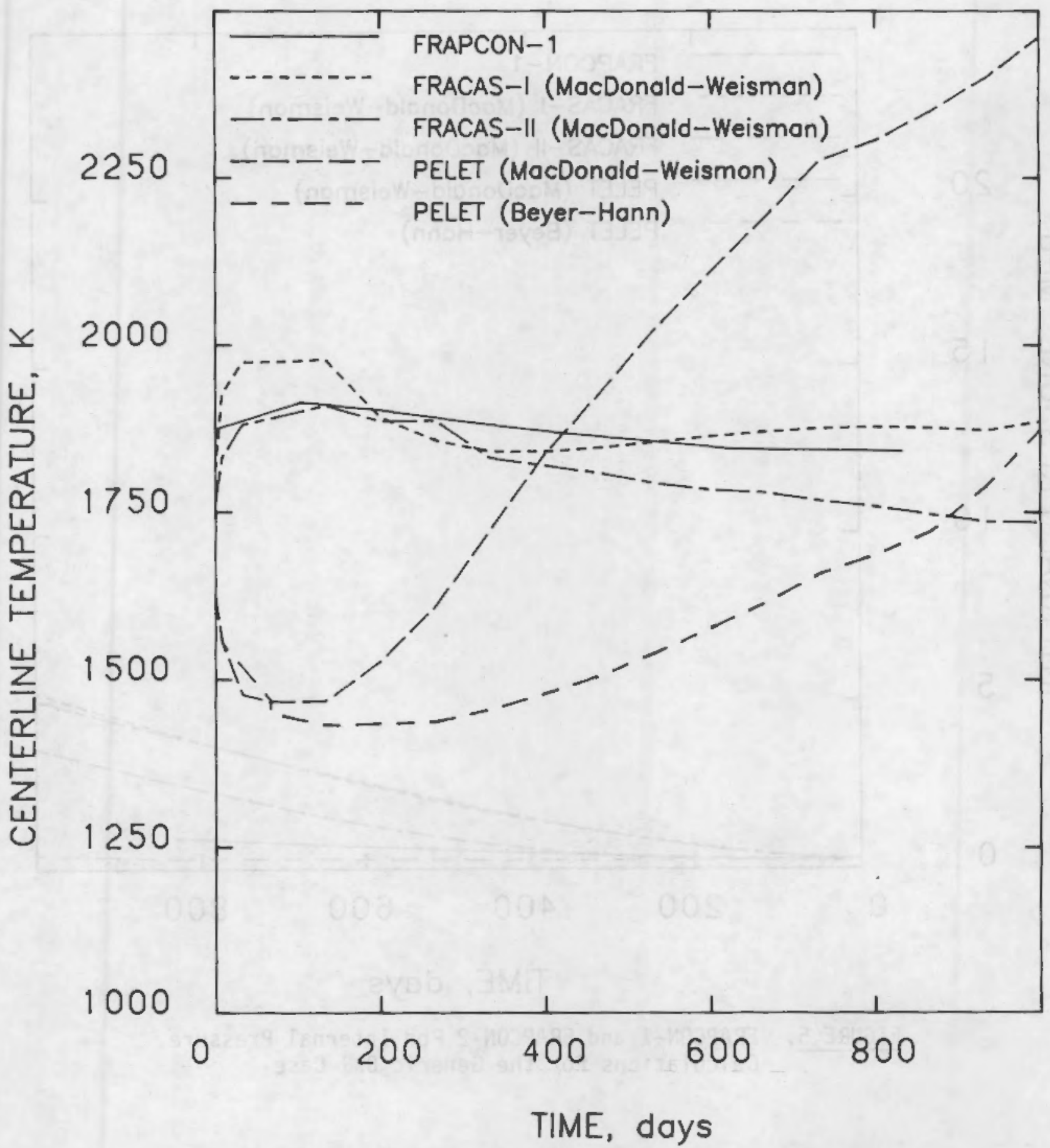

FIGURE 4. FRAPCON-1 and FRAPCON-2 Centerline Temperature Calculations for the Generic BWR Case 


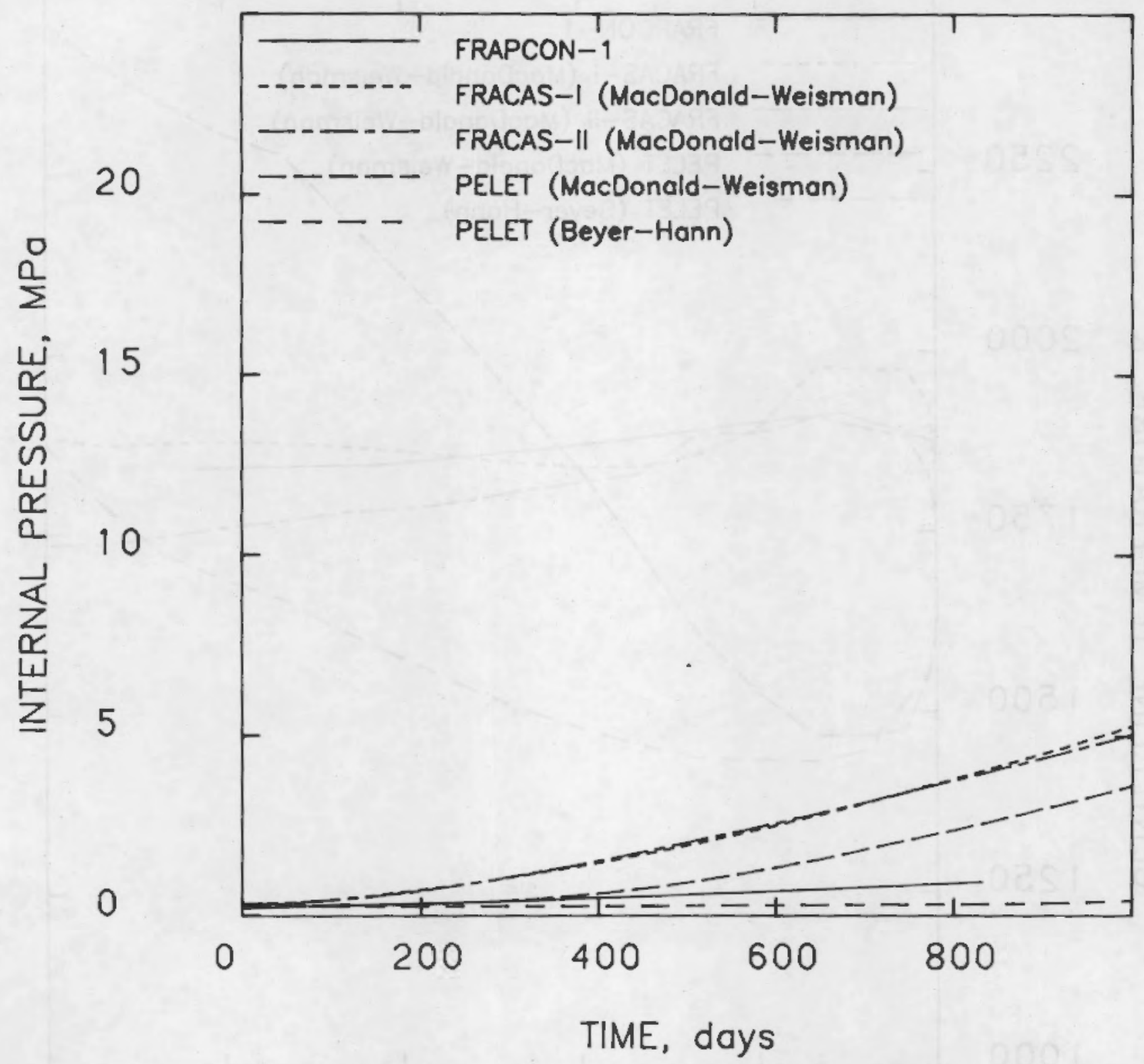

FIGURE 5. FRAPCON-1 and FRAPCON-2 Rod Internal Pressure Calculations for the Generic BWR Case 


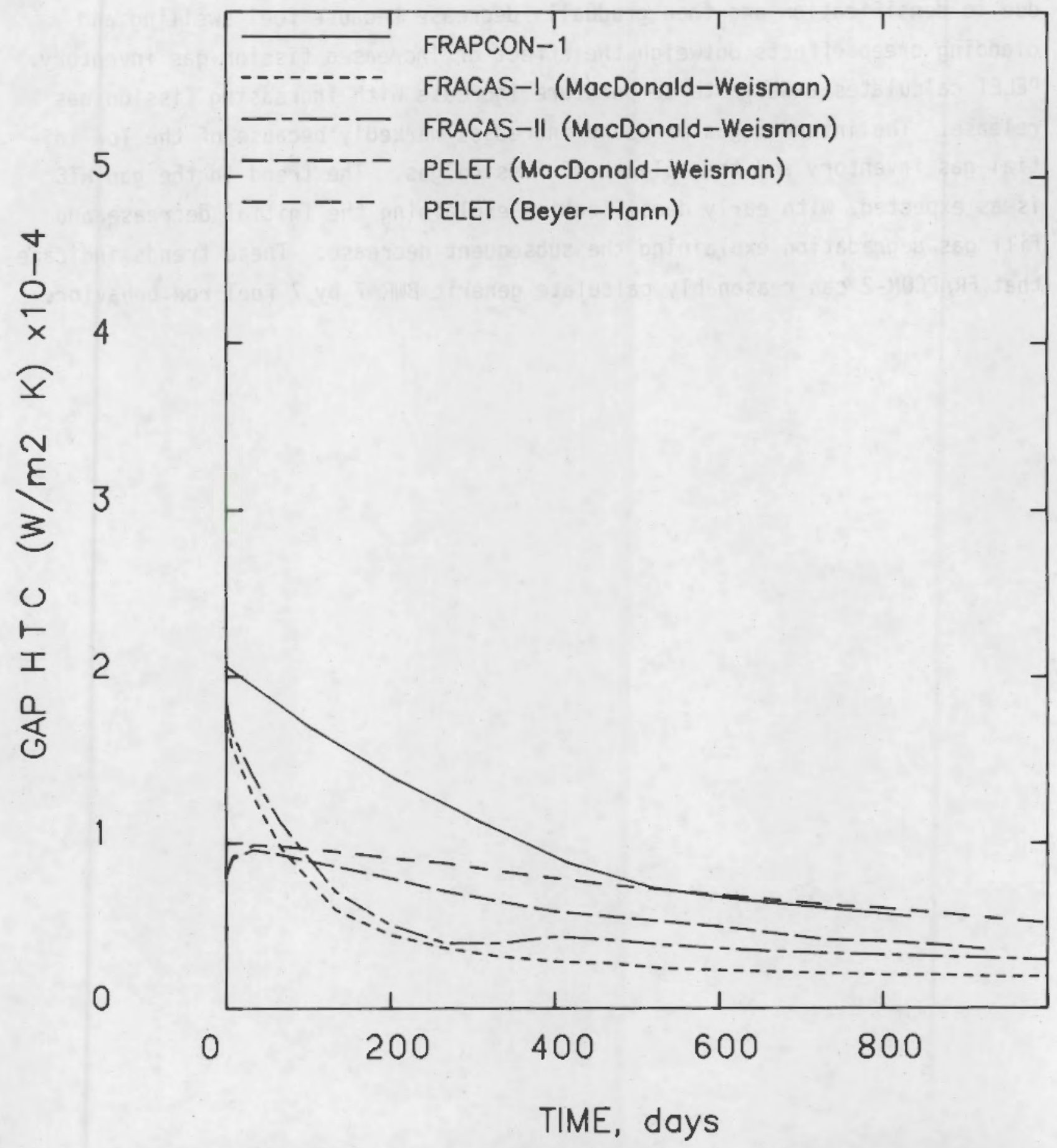

FIGURE 6. FRAPCON-1 and FRAPCON-2 Gap Heat Transfer Coefficient Calculations for the Generic BWR Case 
due to densification and then gradually decrease because fuel swelling and cladding creep effects outweigh the effect of increased fission gas inventory. PELET calculates a definite temperature increase with increasing fission gas release. The internal gas pressure increases markedly because of the low initial gas inventory and the release of fission gas. The trend in the gap HTC is as expected, with early densification explaining the initial decrease and fill gas degradation explaining the subsequent decrease. These trends indicate that FRAPCON-2 can reasonably calculate generic BWR 7 by 7 fuel rod behavior. 


\subsection{EXPERIMENTAL DATA COMPARISONS}

The following sections present FRAPCON-2 calculations of fuel rod response for selected experimental fuel rods irradiated in the Halden Boiling Water Reactor (HBWR), Halden, Norway; the Power Burst Facility (PBF), Idaho Falls, Idaho; and the Studsvik reactor, Sweden, and for a commercial fuel rod irradiated in the H. B. Robinson plant. Many combinations of the model options are tested using the cases chosen.

The purpose of these data comparisons is to verify that the code reproduced observed trends. Specifically, the following areas were examined:

- effect of rod power and the as-fabricated fuel-cladding gap size on thermal response

- effect of as-fabricated fuel density on thermal response

- effect of power and as-fabricated gap size on cladding deformation

- effect of fuel burnup and fission gas release on fuel temperatures.

The general format of the subsections that follow is: (a) statement of the observed effect, portrayed by data trends; (b) indication that the major code options reproduce the observed trends; (c) description of the experiments, including reactor and test conditions, power history, and design parameters; and (d) comparison of code calculations to data and a brief discussion. Overall discussion of the comparison of code calculations to data is reserved for Section 5.0.

\subsection{EFFECT OF POWER AND GAP SIZE ON FUEL TEMPERATURE AT BEGINNING OF LIFE}

At BOL the slope of fuel temperature plotted versus local power becomes progressively steeper with increasing as-fabricated fuel-cladding gap size for fuel rods of otherwise identical design. This is illustrated in Figure 7 , where centerline temperature versus power data are shown for varying gap sizes for three fresh instrumented rods from the PBF gap conductance tests GC 2-1 and 2-2. (19) The slopes (Kelvin per $\mathrm{kW} / \mathrm{m}$ ) of the data trends in the figure are nearly constant. We refer to this slope as the "thermal resistance," and such trends have also been observed in many tests at the Halden reactor. 


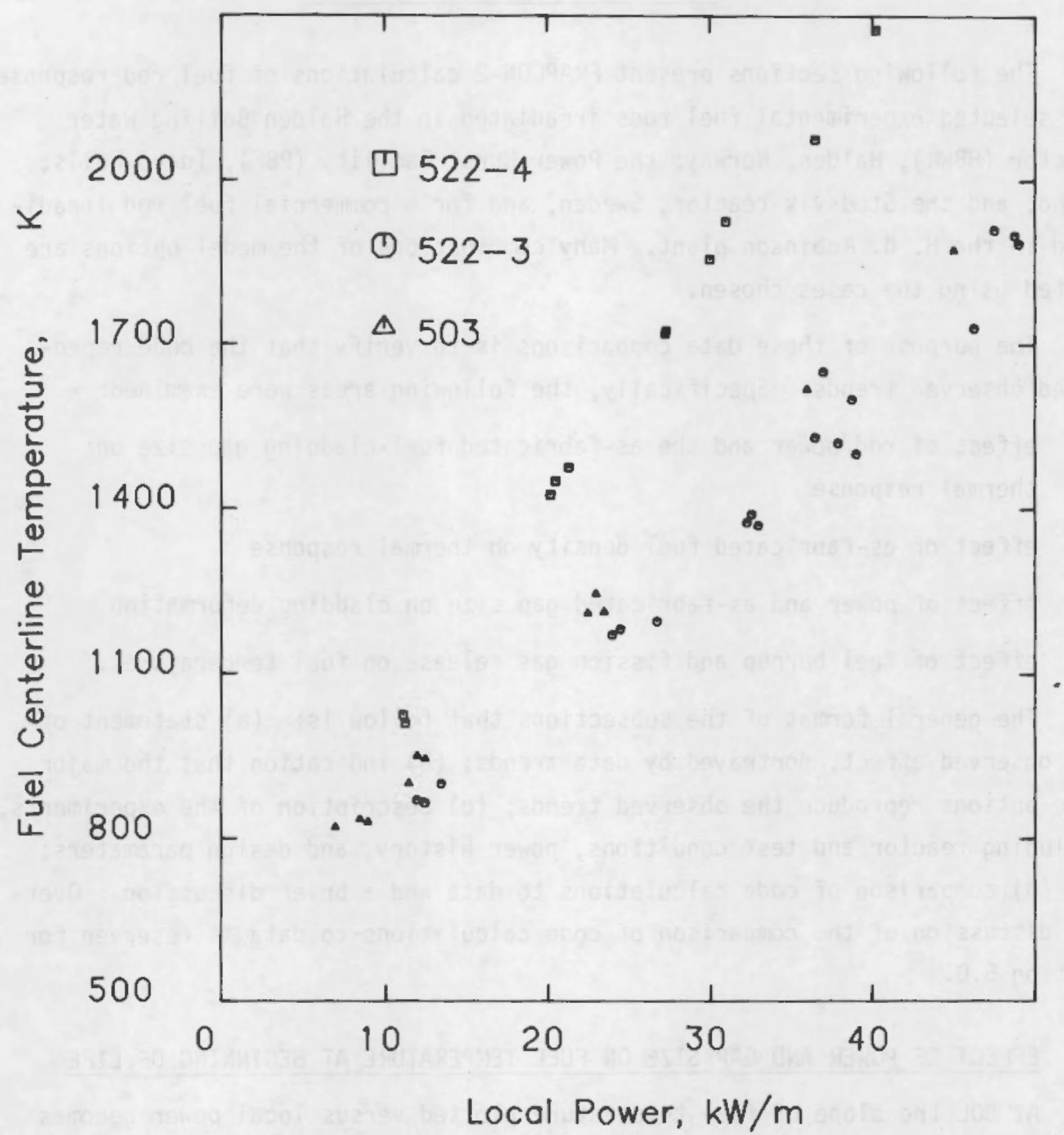

FIGURE 7. Demonstration of Gap Size Effect Using GC 2-1 and GC 2-2 Test Rod Data (as-fabricated gap sizes: $100 \mu \mathrm{m}$ for rod 522-3; $220 \mathrm{\mu m}$ for rod 503; and $350 \mu \mathrm{m}$ for rod 522-4) 


\subsubsection{Trends of Major Code Options}

All major thermal-mechanical options in the code produce the same trend-the BOL resistance increases with increasing fabricated gap size. Table 7 shows calculated resistance for the same three rods by the FRACAS-I, FRACAS-II, and PELET options. Notice that all three options, while having the right trend with respect to the gap size effect, undercalculate the thermal resistance in each case.

\subsubsection{Experiment Description for GC 2 Tests}

The gap conductance test GC 2 was conducted using a series of four-rod instrumented fuel assemblies (IFAs) in the PBF. $(19,20)$ The experimental matrix initially consisted of 20 rods featuring variations in gap size, fill gas composition, and fuel density. Table 8 lists the important parameters from the three helium-filled rods selected from this test to demonstrate the effect of gap size.

The PBF reactor operates with natural circulating unpressurized light water coolant. The test region is an in-pile tube that houses the four Zircaloy-shrouded test rods. The inlet coolant temperature to the in-pile tube was $538 \mathrm{~K}$ during the power calibration and preconditioning periods and 478K during the power oscillation period with a coolant pressure of $7.17 \mathrm{MPa}$. The coolant flow was 2.5 to $10 \mathrm{~m} / \mathrm{s}$ during the power calibration and preconditioning periods and $5 \mathrm{~m} / \mathrm{s}$ during the oscillation period.

The instrumentation on these rods included a fuel centerline thermocouple (titanium-sheathed tungsten-rhenium), three off-center thermocouples (Inconelsheathed chromel-alumel), five cladding surface thermocouples (titanium-sheathed chromel-alumel), and one bellows-type strain gauge (see Appendix A of Reference 19 for additional instrumentation information).

The power history for the various rods can be deduced from the PBF core power during the power calibration and preconditioning periods using appropriate power factors ( $\mathrm{kW} / \mathrm{m}$ peak power per megawatt of core power). The axial power profile that was used for the entire GC 2 test is shown in Figure 8. Note that the thermocouple plane lies in the peak power region. The power histories of each test are shown in Figures 9, 10, and 11. 
TABLE 7. Representative Calculated and Measured Thermal Resistances Showing Gap Size Effects

\begin{tabular}{|c|c|c|c|}
\hline $\begin{array}{ll} & G C \\
\text { Rod Number } & \text { Numb } \\
\end{array}$ & $\underset{\mu \mathrm{m}}{\text { Gap Size, }}$ & $\begin{array}{l}\text { Measured } \\
\text { Resistance, } \\
\mathrm{K}-\mathrm{m} / \mathrm{kW} \\
\end{array}$ & $\begin{array}{c}\text { FRAPCON-2(a) } \\
\text { Calculated } \\
\text { Resistance, } \mathrm{K}-\mathrm{m} / \mathrm{kW} \\
\end{array}$ \\
\hline $\begin{array}{l}522-3 \\
503 \\
522-4\end{array}$ & $\begin{array}{l}100 \\
220 \\
360\end{array}$ & $\begin{array}{l}26 \\
31 \\
43\end{array}$ & $\begin{array}{l}22 \\
27 \\
33\end{array}$ \\
\hline
\end{tabular}

(a) Representative of all three options; generally the calculations ranged in the order FRACAS-I, PELET, and FRACAS-II (highest to lowest) but did not diverge by more than $1.5 \mathrm{~K}-\mathrm{m} / \mathrm{kW}$.

TABLE 8. Design Characteristics of Selected Fuel Rods(a) from the Gap Conductance Tests GC 2-1 and GC 2-2

Rod Parameter

Cladding Outside Diameter, mm

$\mathrm{Cl}$ adding Inside Diameter, $\mathrm{mm}$

Wall Thickness, mm

Fuel Material

Cladding Material

Pellet Diameter, mm

Diametral Gap, $\mu m$

Pellet Shape

Rod Overall Length, mm

Fuel Stack Length, mm

Plenum Length, mm

Internal Pressure, $\mathrm{MPa}$

Pellet Enrichment, wt\% $235 \mathrm{U}$

Fill Gas

Fuel Density, \%TD

\begin{tabular}{l}
\multicolumn{1}{c}{ Design Value } \\
\hline 12.50 \\
10.79 \\
0.86 \\
U02 \\
Zircaloy-2 \\
Rod $522-3=10.69$ \\
Rod $503=10.57$ \\
Rod $522-4=10.43$ \\
Rod $522-3=100$ \\
Rod $503=220$ \\
Rod $522-4=360$ \\
Flat ends \\
$990.6 \quad$ \\
914.4 \\
55.12 \\
2.58 \\
10.0 \\
Helium \\
95.0
\end{tabular}

(a) Rods differing only in gap size 


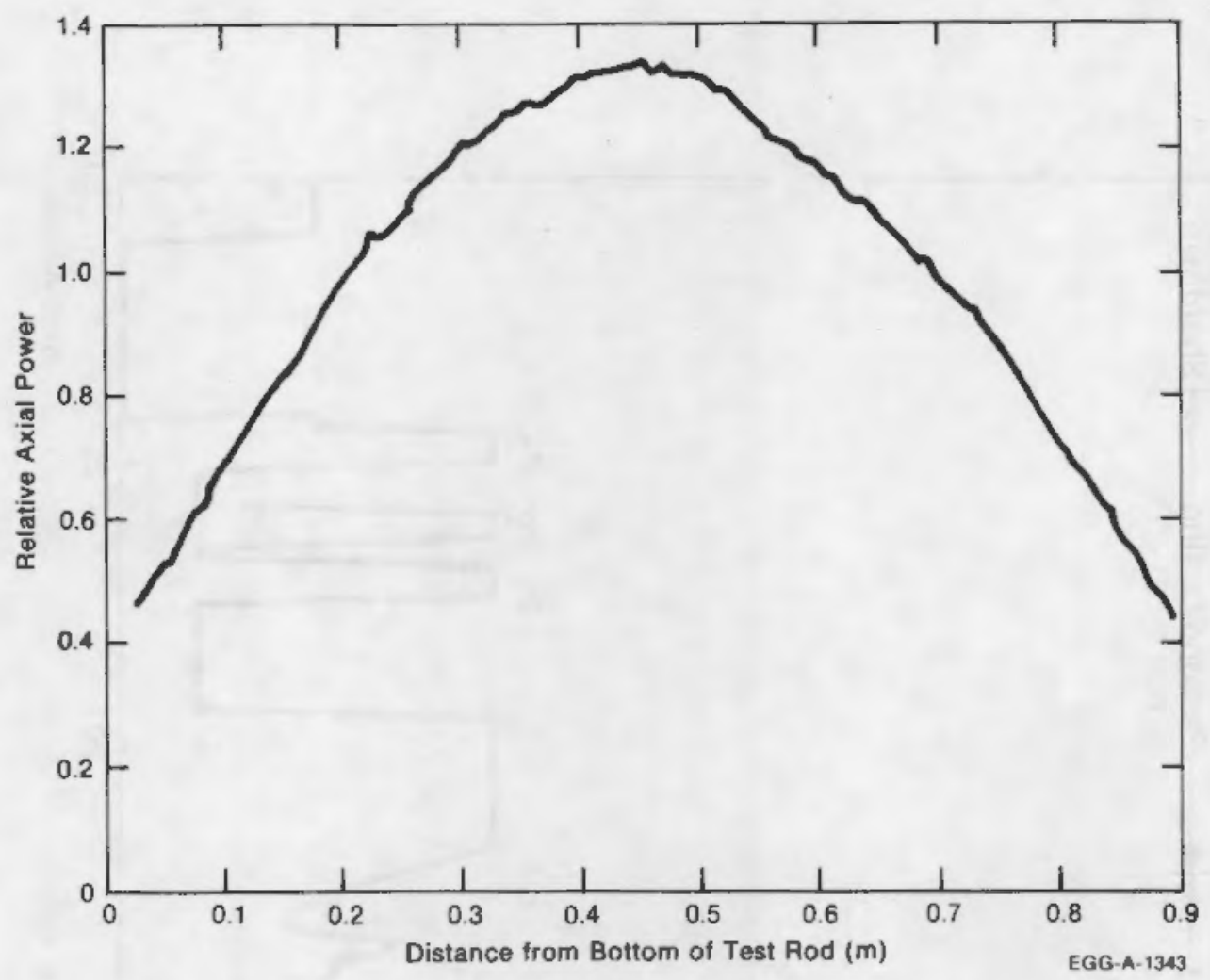

FIGURE 8. Representative Axial Power Profile for the Gap Conductance Tests GC 2-1, GC 2-2, and GC 2-3

\subsubsection{Comparison of FRAPCON-2 to GC 2 Test Data}

Figure 12 compares calculated fuel centerline temperatures for rod 522-3 (the 100- $\mu \mathrm{m}$ diametral gap rod) using the FRACAS-I, FRACAS-II, and PELET options with preconditioning period data. All options tend to be low relative to thosc data; the discrepancy amounts to about 50 to $75 \mathrm{~K}$ at $30 \mathrm{~kW} / \mathrm{m}$. The same comparis on was made for rod 503, the 200- $\mu \mathrm{m}$ gap rod (see Figure 13); the FRACAS-I option is within $\pm 10 \mathrm{~K}$ of the data mean while the other two options are only 5 to 50K low at any point. However, a large difference can be noted between rod 522-4 data (360- $\mathrm{mm}$ gap) and code calculations (see Figure 14). Calculations by all three options were several hundred Kelvin degrees below the indicated data in the 30 to $45 \mathrm{~kW} / \mathrm{m}$ power range. If rod $522-4$ is representative of the thermal performance of all rods having fabricated gaps greater than $\sim 3 \%$ of the pellet diameter, then FRAPCON gives unacceptably low fuel temperature calculations for that range of gap sizes. 


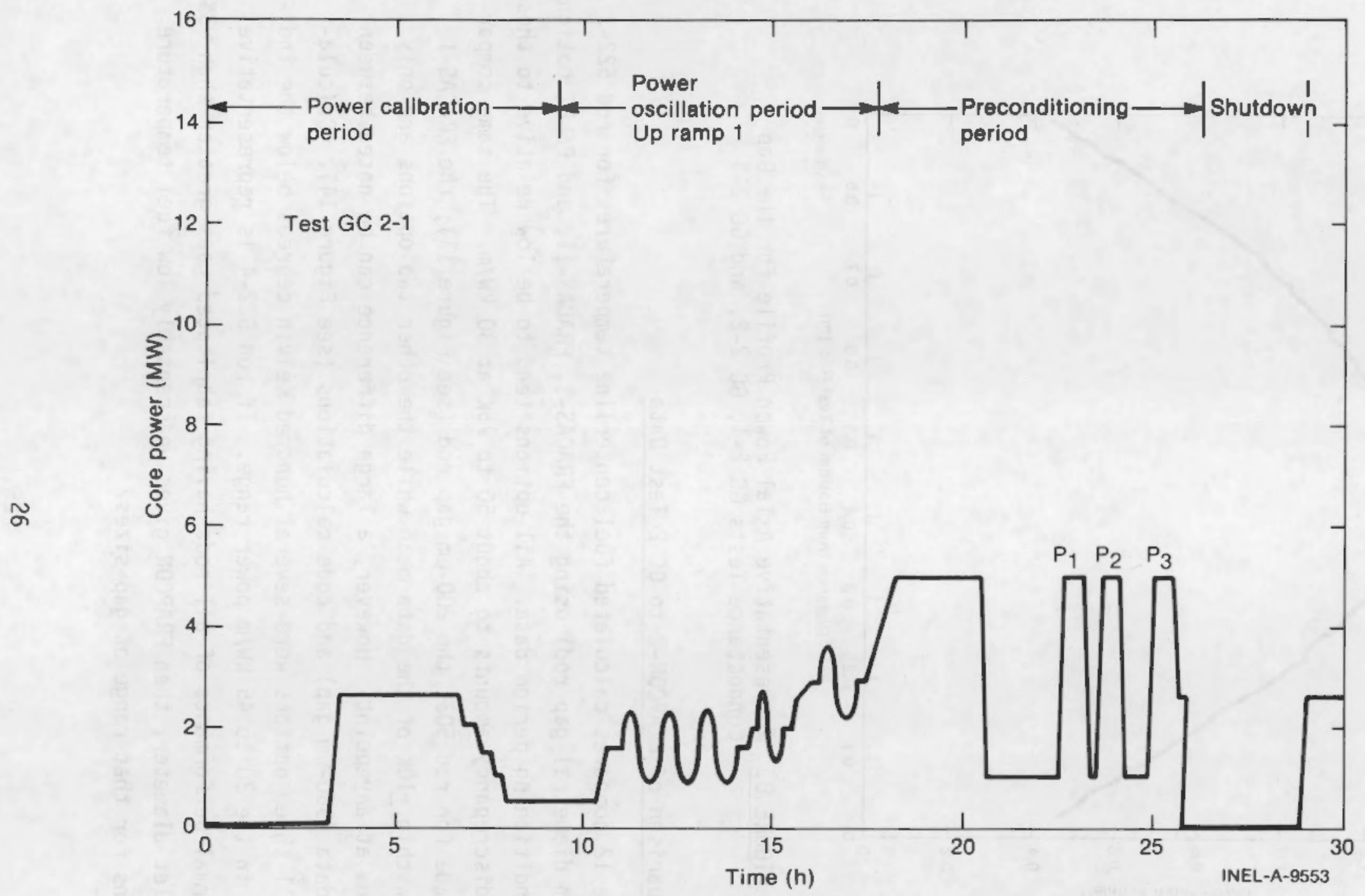

FIGURE 9. Power-Time History of the PBF Core During the Power Calibration and Preconditioning Periods of Test GC 2-1 (applies to rod 503 peak power using a factor of $5.2 \mathrm{~kW} / \mathrm{m}-\mathrm{MW}$ ) 


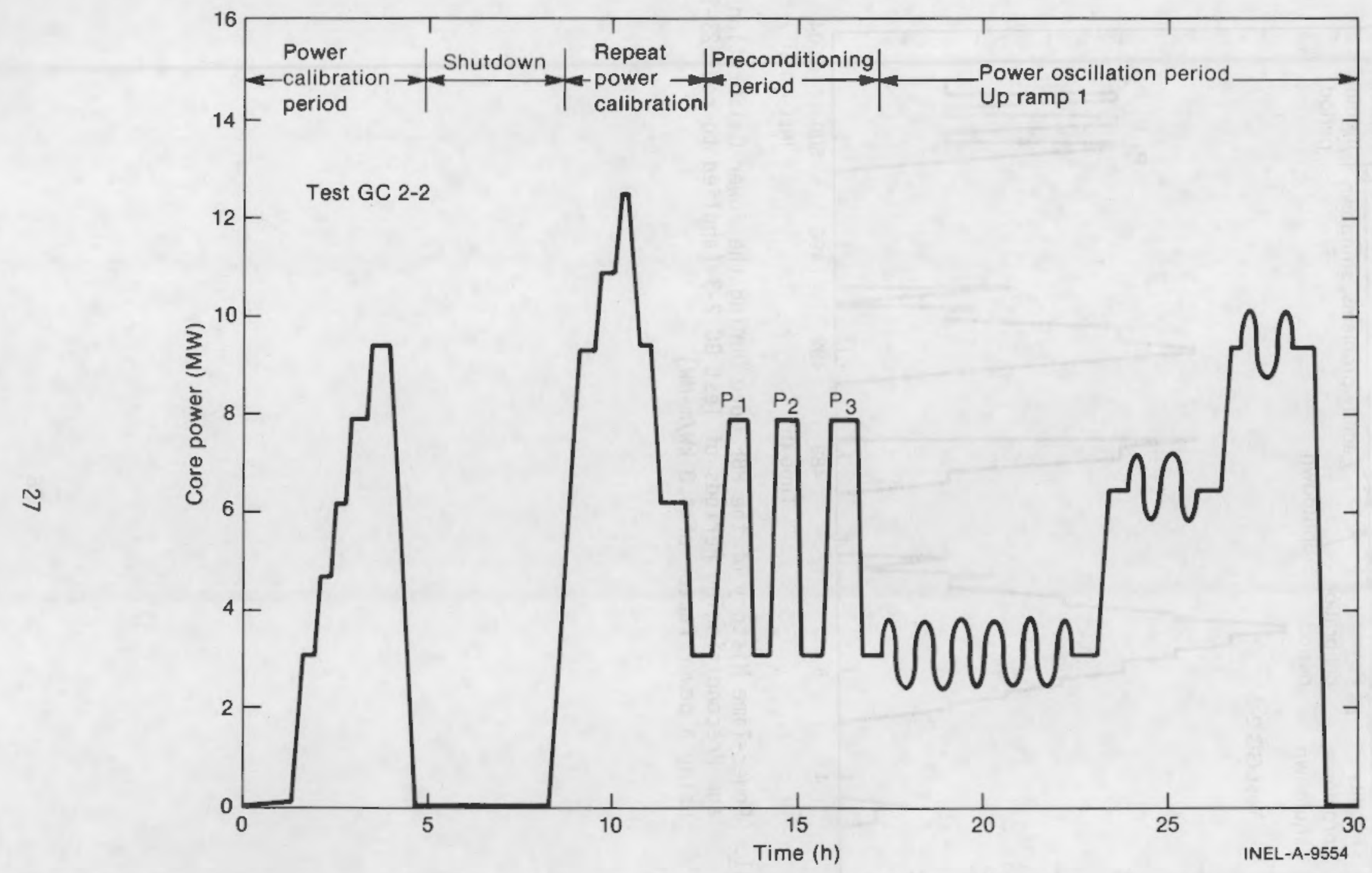

FIGURE 10. Power-Time History of the PBF Core During the Power Calibration and Preconditioning Periods of Test GC 2-2 (applies to rod 522-3 peak power using a factor of $4.2 \mathrm{~kW} / \mathrm{m}-\mathrm{MW}$ and to rod $522-4$ using a power factor of 3.5 ) 


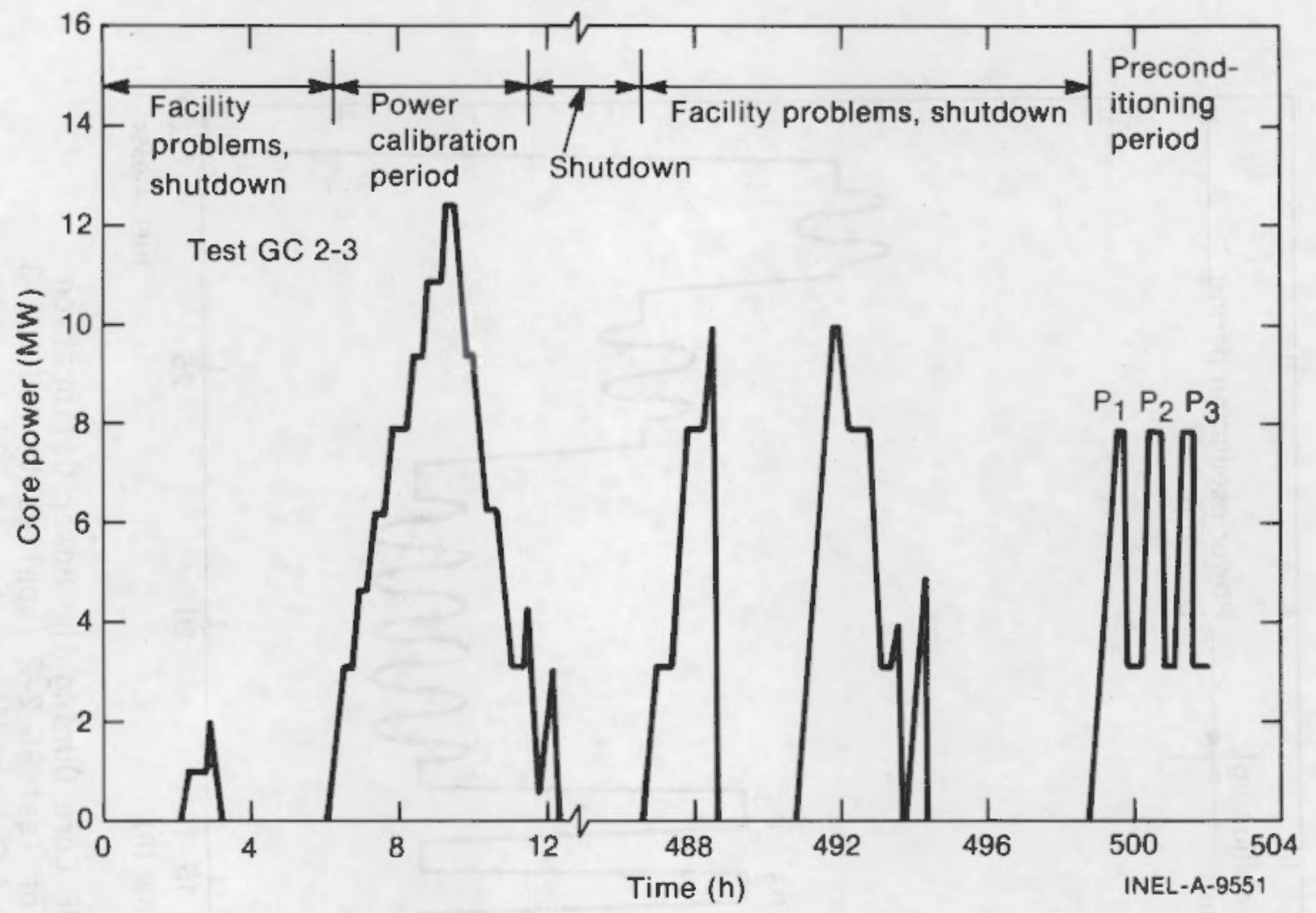

FIGURE 11. Power-Time History of the PBF Core During the Power Calibration and Preconditioning Periods of Test GC 2-3 (applied to rod 523-1 using a power factor of $4.0 \mathrm{~kW} / \mathrm{m}-\mathrm{MW}$ ) 


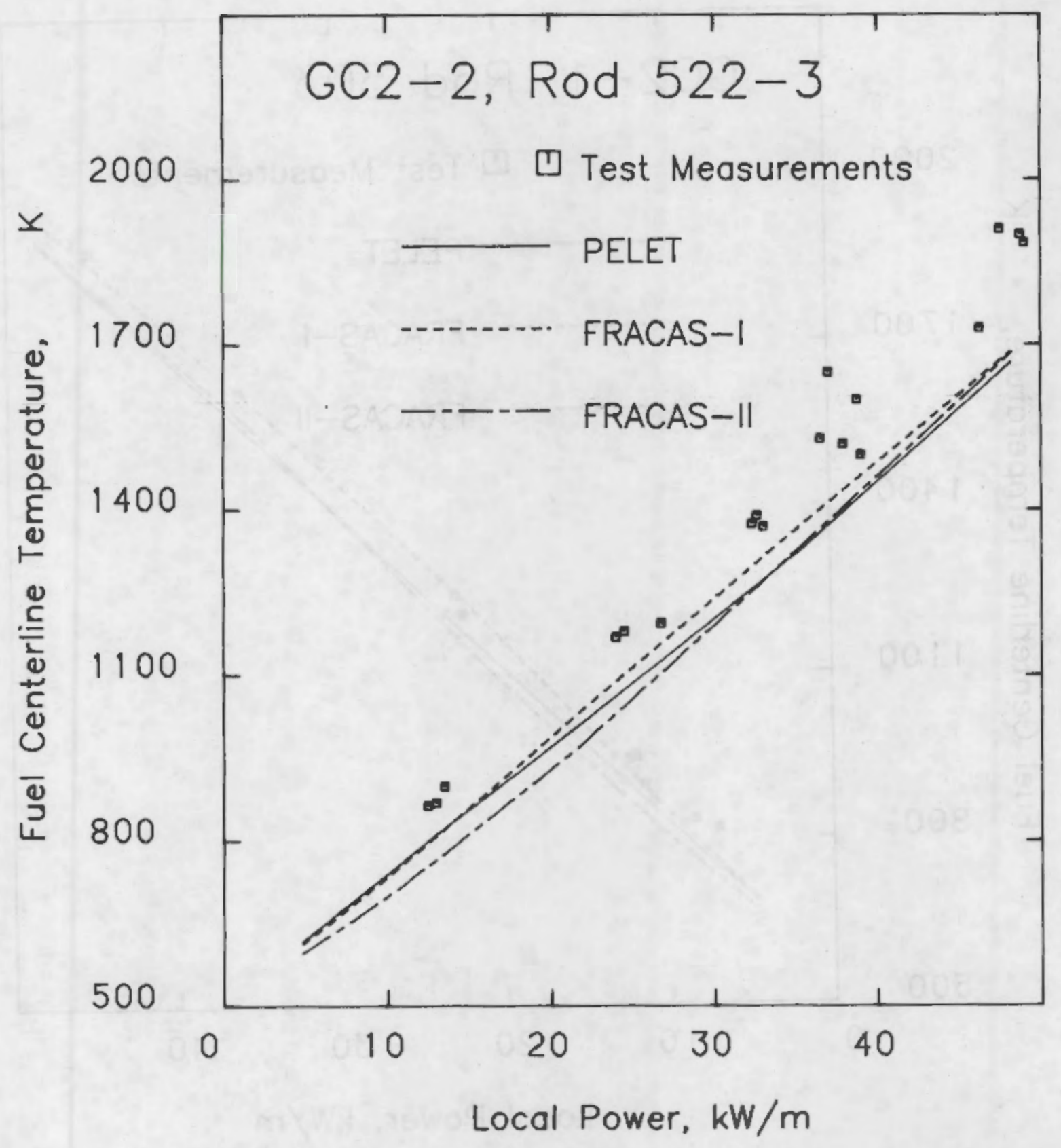

FIGURE 12. Comparison of PELET, FRACAS-I, and FRACAS-II Calculations and Rod 522-3 of GC 2-2 Centerline Temperature Data 


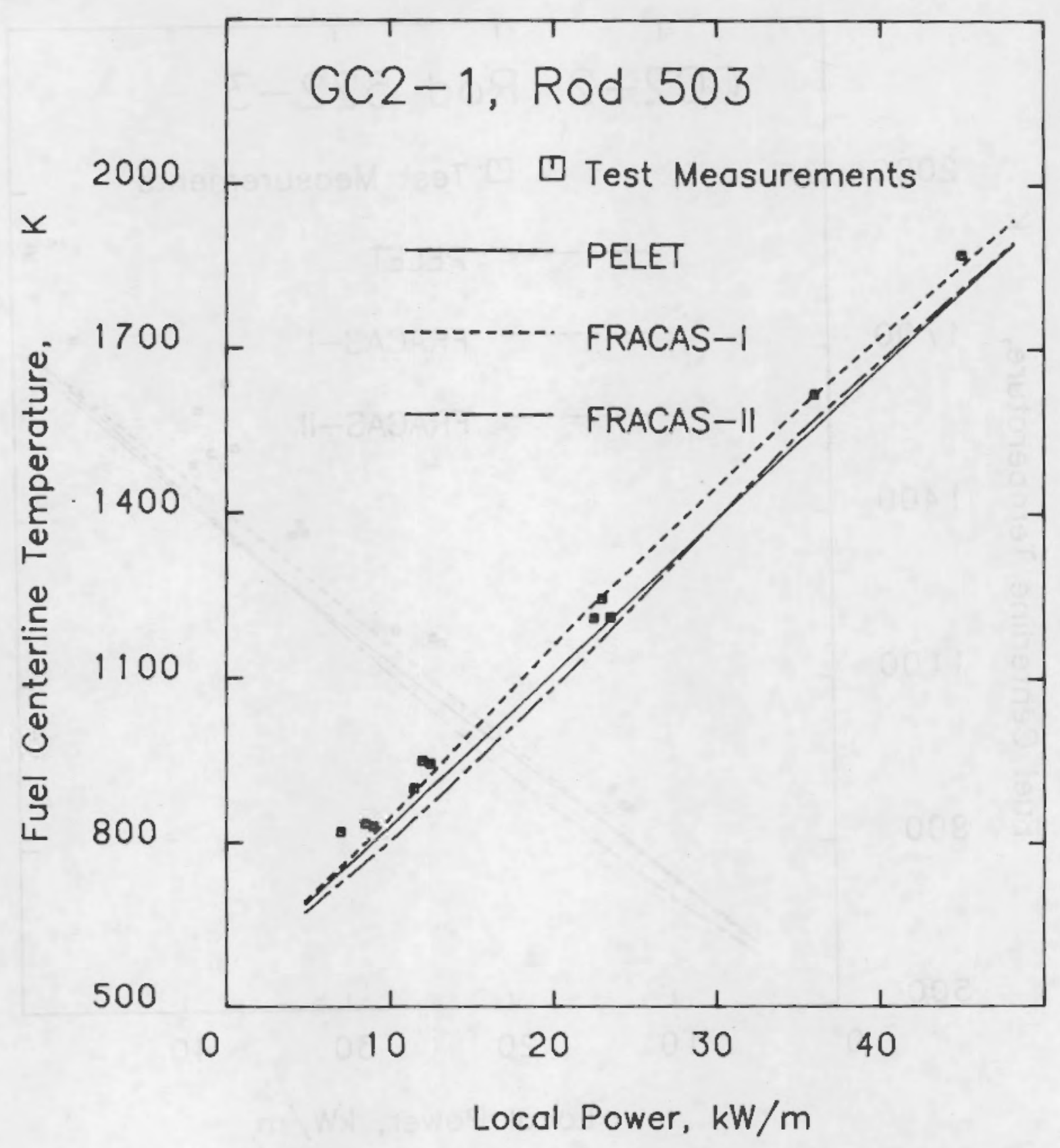

FIGURE 13. Comparison of PELET, FRACAS-I, and FRACAS-II Calculations and Rod 503 of GC 2-1 Centerline Temperature Data 


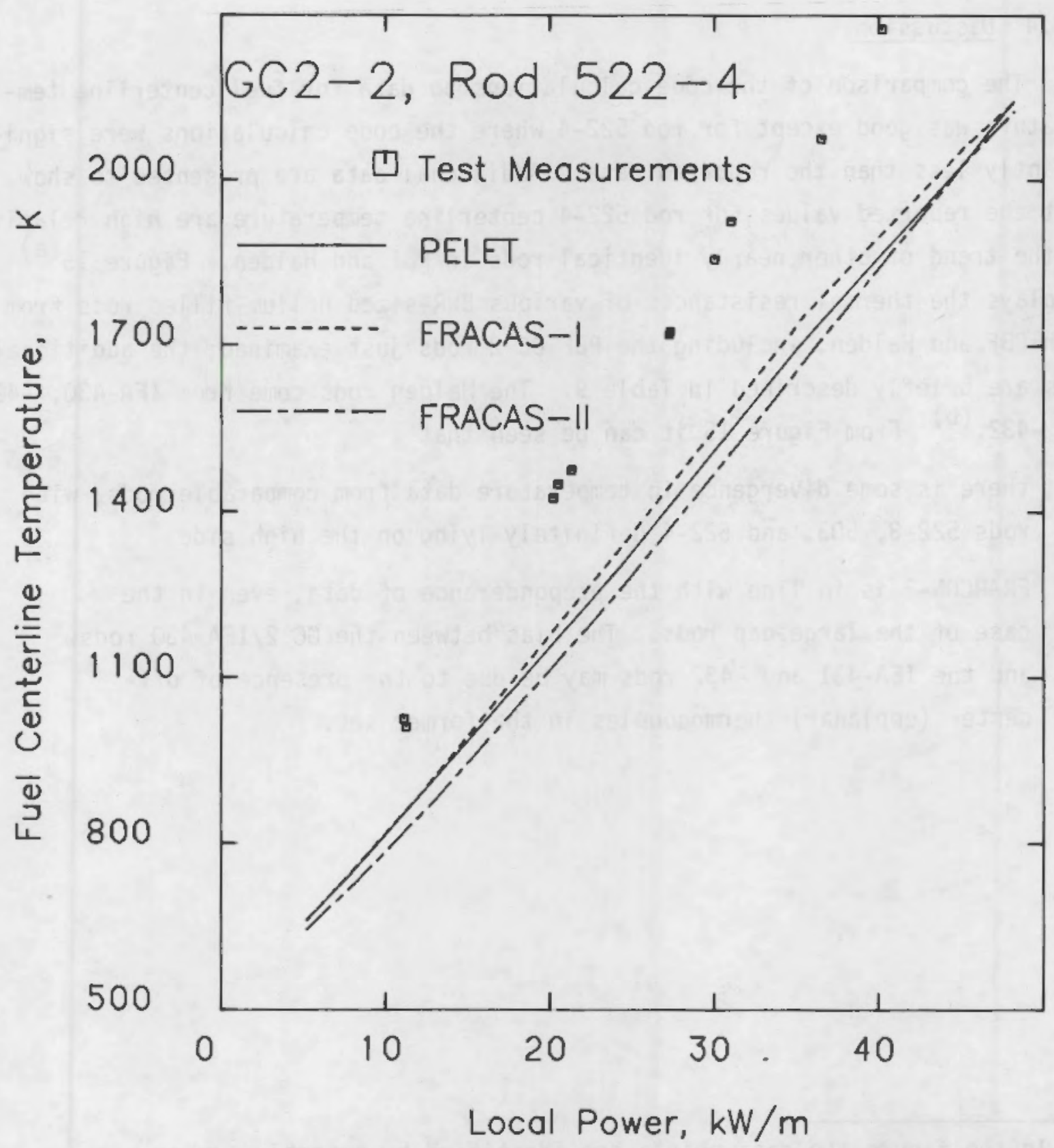

FIGURE 14. Comparison of PELET, FRACAS-I, and FRACAS-II Calculations and Rod 522-4 of GC 2-2 Centerline Temperature Data 


\subsubsection{Discussion}

The comparison of the code calculations to data for fuel centerline temperature was good except for rod 522-4 where the code calculations were significantly less than the reported data. Additional data are presented to show that the reported values for rod 522-4 centerline temperature are high relative to the trend of other nearly identical rods in PBF and Halden. Figure $15^{(\mathrm{a})}$ displays the thermal resistances of various BWR-sized helium-filled rods from both PBF and Halden, including the PBF GC 2 rods just examined; the additional rods are briefly described in Table 9. The Halden rods come from IFA-430, -431 and -432 . (b) From Figure 15 it can be seen that

- there is some divergence in temperature data from comparable rods, with rods 522-3, 503, and 522-4 definitely lying on the high side

- FRAPCON-2 is in line with the preponderance of data, even in the case of the large-gap rods. The bias between the GC 2/IFA-430 rods and the IFA-431 and -432 rods may be due to the presence of offcenter (coplanar) thermocouples in the former set.

(a) In the figure the data points are identified by assembly number followed by rod numbers; the shaded boxes indicate rods with centerline thermocouples only. Unshaded boxes represent rods that have both centerline and off-center thermocouples.

(b) IFA-431 and -432 are described in Sections 4.3 .3 and 4.4.2. IFA-430 was a specialized four-rod assembly containing gas flow rods (attached to an external system) and thermal performance rods with center and three off-center thermocouples; similar to the PBF GC 2 rods. The description of rod 3 from this assembly is included in Table 9. Further information on the test may be found in Reference 21 . 


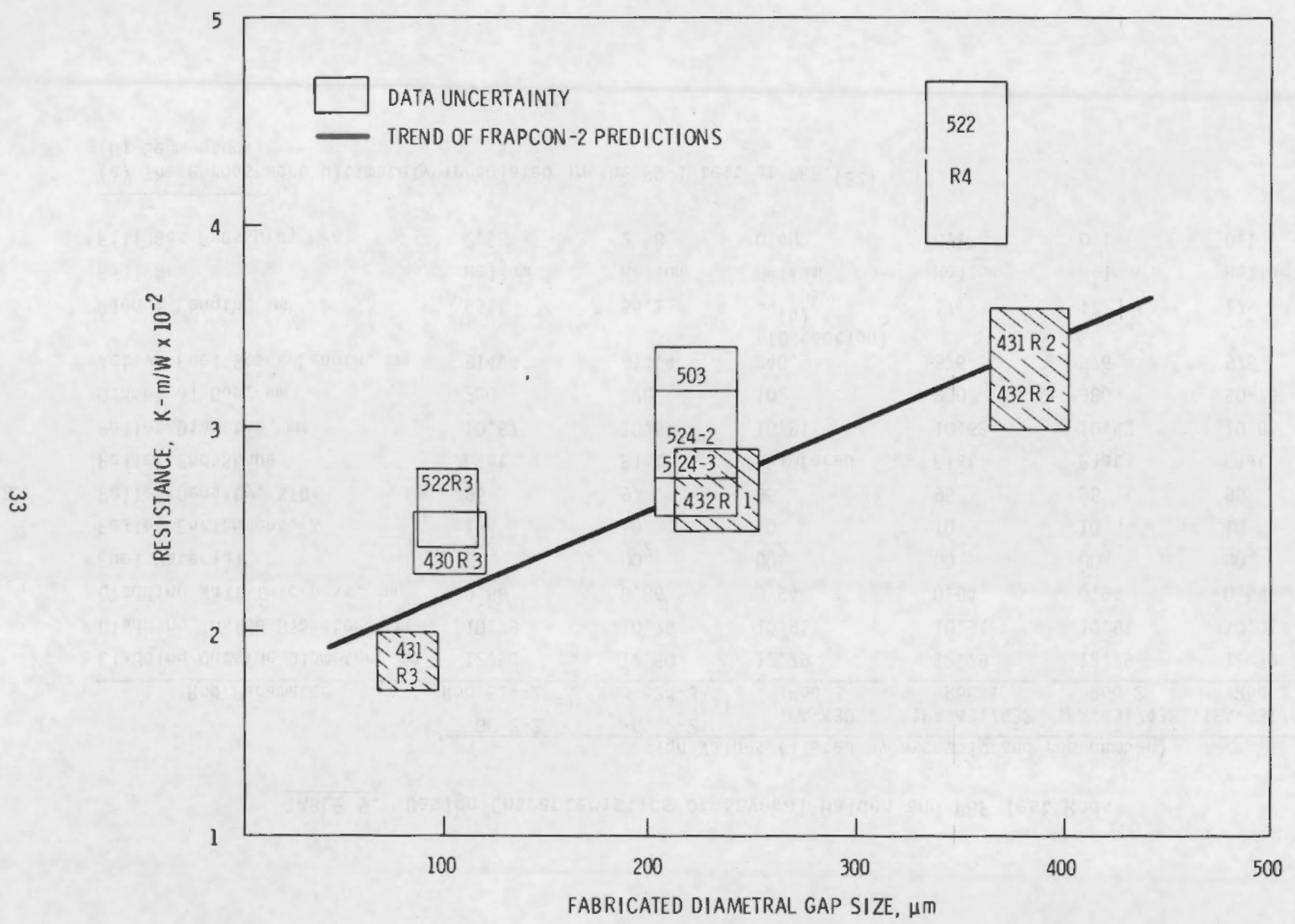

FIGURE 15. Comparison of FRAPCON-2 (PELET) Thermal Resistance Trends with Fabricated Gap Size 
TABLE 9. Design Characteristics of Several Halden and PBF Test Rods

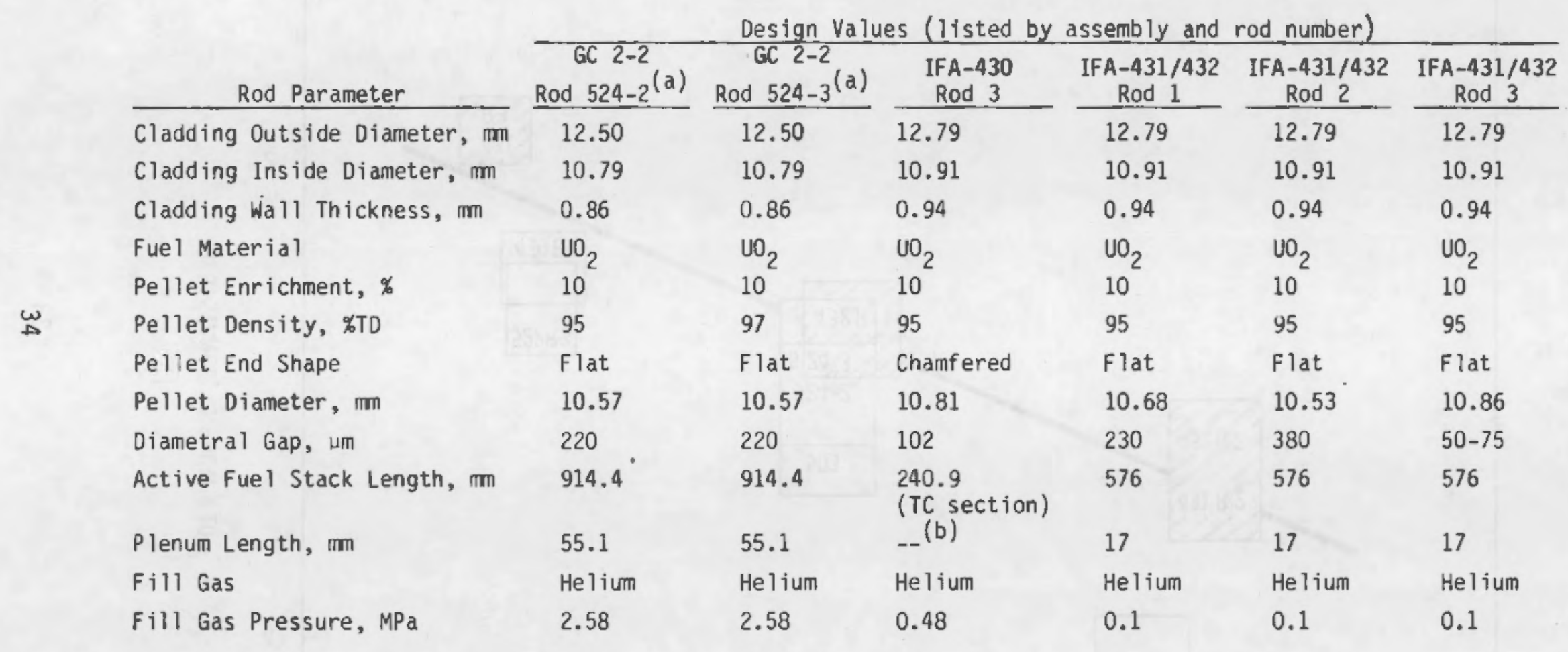

(a) These rods were ultimately irradiated in the PR-1 test at PBF. (32)

(b) Segmented. 


\subsection{EFFECT OF AS-FABRICATED FUEL DENSITY ON BEGINNING-OF-LIFE FUEL}

TEMPERATURE

The effect of fuel density on fuel temperatures comes through the effective fuel conductivity. As the fuel porosity increases, the fuel thermal conductivity decreases and (all other things being equal) the fuel temperature rises (see Figure 16). Centerline temperature versus local power data for the GC 2 rods 522-3 (already described) and 523-1 are presented. Rod 523-1 is identical to rod 522-3 except that the fuel density is nominally $92 \%$ theoretical density (TD) whereas that for rod $522-3$ is $95 \%$ TD.

\subsubsection{Comparison of FRAPCON-2 to GC 2 Test Data}

Each of the major code options has the correct trend with respect to the effect of initial fuel density upon fuel temperatures (see Figure 17). In each case, the calculated fuel temperatures are higher for the $92 \%$ TD rod than for the $95 \%$ TD rod. However, in both cases the code calculations are lower than the data. For example, in the code comparison to the 95\% TD 100- $\mu \mathrm{m}$ diametral gap 522-3 rod data (Figure 12) all three options fell below the measured data for centerline temperature by 50 to $75 \mathrm{~K}$. In Figure 18, a similar comparison for the 92\% TD 100-um gap rod 523-1 shows that the discrepancy between code and data is in the same direction and even worse. The code options undercalculate the data by $100 \mathrm{~K}$ at $30 \mathrm{~kW} / \mathrm{m}$ and by nearly $200 \mathrm{~K}$ at $40 \mathrm{~kW} / \mathrm{m}$. 


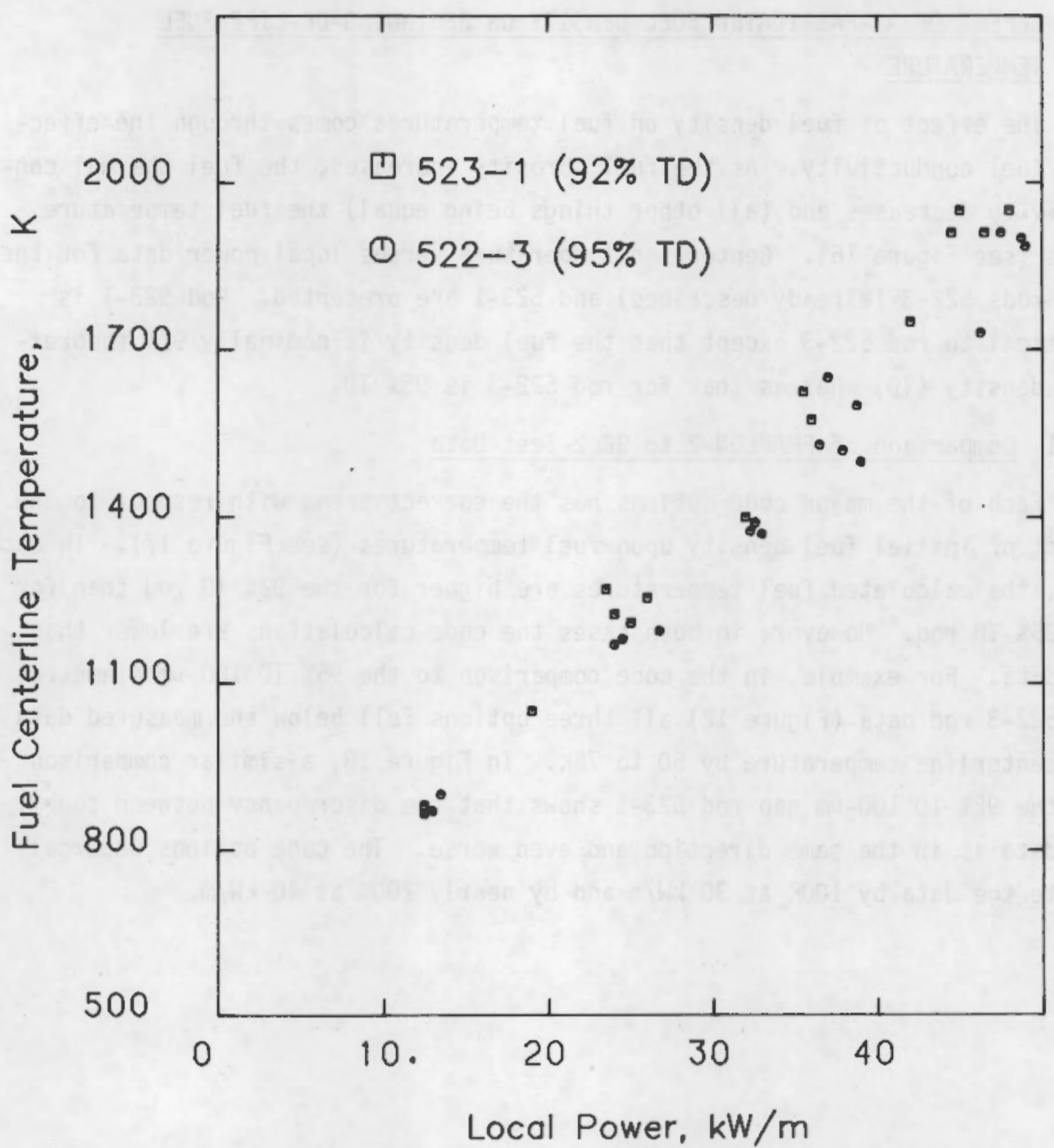

FIGURE 16. Demonstration of Fuel Density Effect Using Two GC 2 Test Rods with Helium Fill Gas and 100- $\mu$ m Diametral Fabricated Gaps (fuel densities: 95\% TD for rod 522-3 and 92\% TD for $\operatorname{rod} 523-1$ ) 

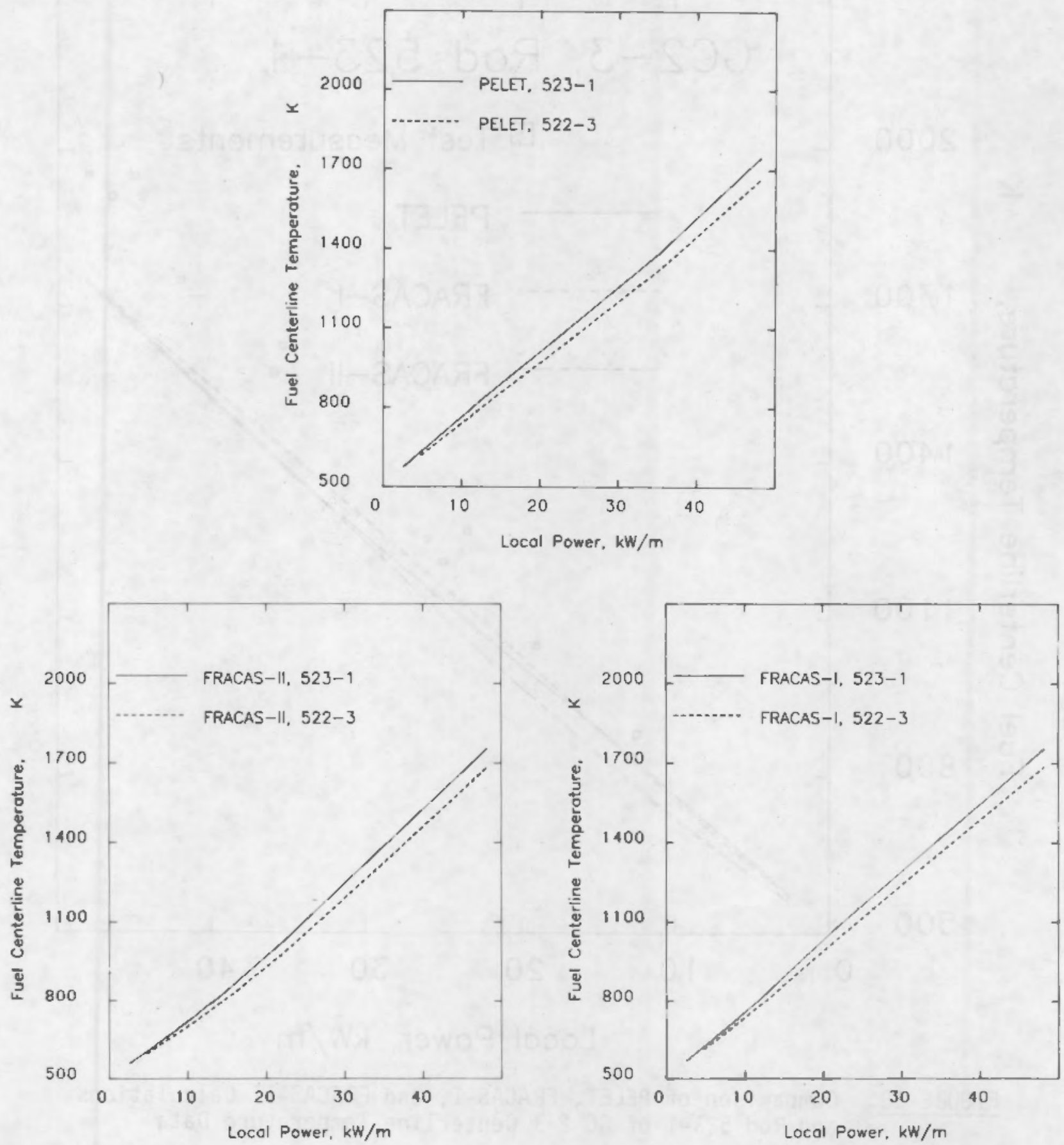

FIGURE 17. Predicted Fuel Density Effect Using the Major Code Options 


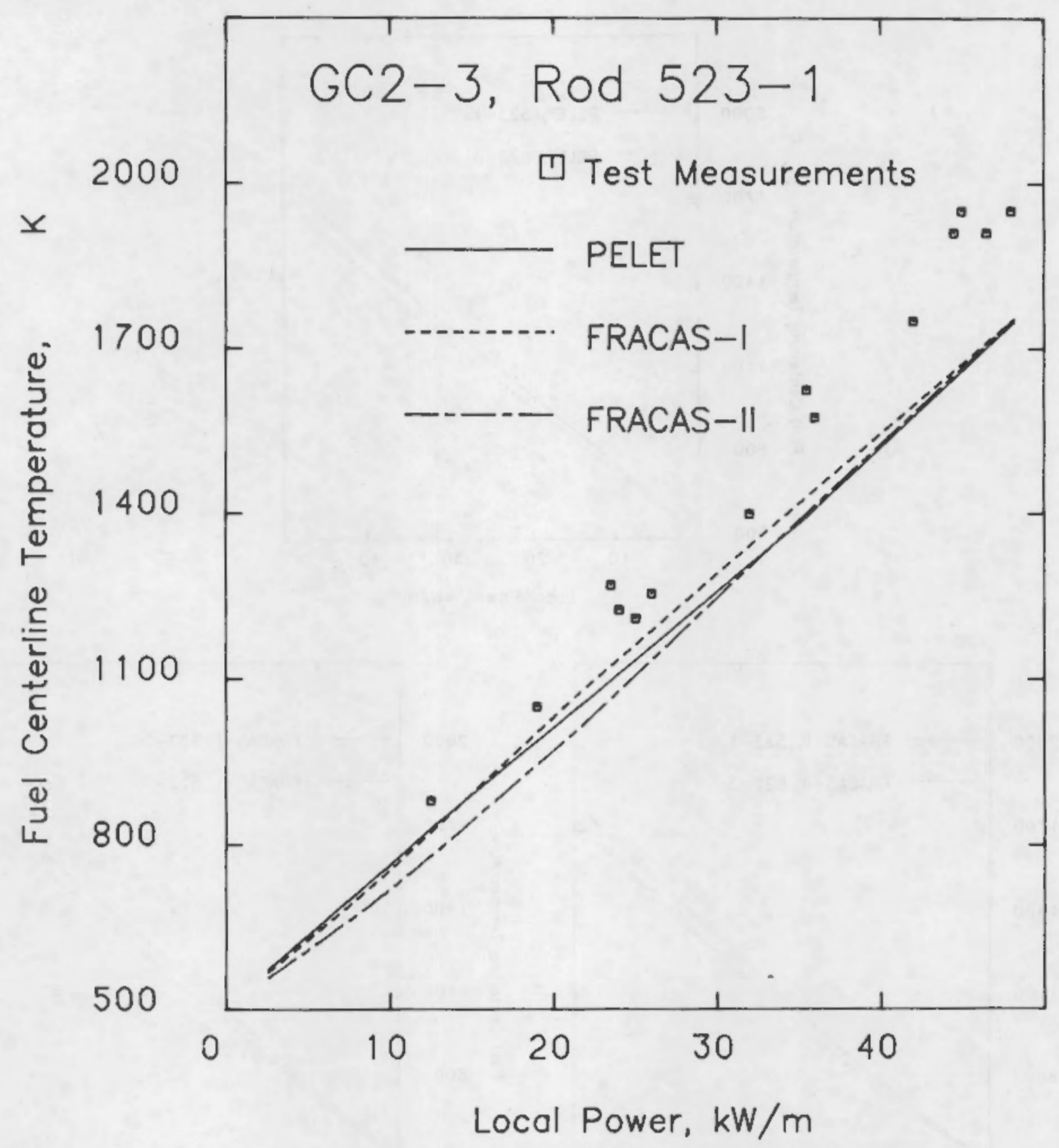

FIGURE 18. Comparison of PELET, FRACAS-I, and FRACAS-II Calculations and Rod 523-1 of GC 2-3 Centerline Temperature Data 


\subsubsection{Discussion}

The correct dependence of fuel temperatures upon fuel porosity is calculated by the code options; the absolute value of the dependence seems to be undercalculated at $92 \%$ TD. However, this does not automatically mean that the code calculations are incorrect. First of all, consider the apparent effect of off-center thermocouples (not modeled in FRAPCON-2) as deduced in Figure 15. The same resistance shift is necessary to bring FRAPCDN-2 in agreement with rod 522-3 as for rod 523-1. In other words, the relative resistance increase noted in the data between $92 \%$ and $95 \%$ TD fuel is calculated by FRAPCON-2.

Finally, consider Table 10, which presents BOL resistance data from

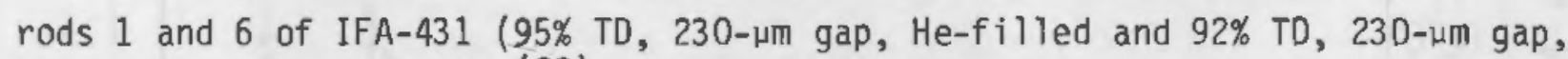
He-filled, respectively). (22) As shown, the FRAPCON-2 calculation of the relative density effect is correct.

\subsection{POWER AND GAP SIZE EFFECTS ON CLADDING DEFORMATION AT BEGINNING OF LIFE}

The cladding deformation measured in-reactor includes total rod elongation and (rarely) cladding ridge and wave formation. Both axial elongation and elastic ridge formation at $\mathrm{BOL}$ have been observed to decrease (relax) significantly over a constant power hold period of about $10 \mathrm{~h} .{ }^{(23)}$ The actual mechanism is not clear, but one FRAPCON option (the FRACAS-II model) seeks to model this behavior through enhanced fuel hot pressing.

The effect of fabricated gap size upon both axial elongation and ridging would be to diminish the observed values with increasing gap size. This is demonstrated in Figures 19 and 20, where the axial and diametral (ridge)

TABLE 10. Measured and Calculated Resistances for Rods 1 and 6 of IFA-431 Using PELET

\begin{tabular}{|c|c|c|c|}
\hline $\begin{array}{l}\text { Rod } \\
\text { Number }\end{array}$ & $\begin{array}{c}\text { Fuel } \\
\text { Density, } \\
\text { \%TD } \\
\end{array}$ & $\begin{array}{c}\text { Measured } \mathrm{BOL} \\
\text { Resistance, } \\
\mathrm{K}-\mathrm{m} / \mathrm{kW} \\
\end{array}$ & $\begin{array}{l}\text { Calculated } \\
\text { Resistance, } \\
\mathrm{K}-\mathrm{m} / \mathrm{kW}\end{array}$ \\
\hline $\begin{array}{l}1 \\
6\end{array}$ & $\begin{array}{l}95 \\
92\end{array}$ & $\begin{array}{l}26 \text { to } 27 \\
28 \text { to } 30\end{array}$ & $\begin{array}{l}27 \\
29\end{array}$ \\
\hline
\end{tabular}




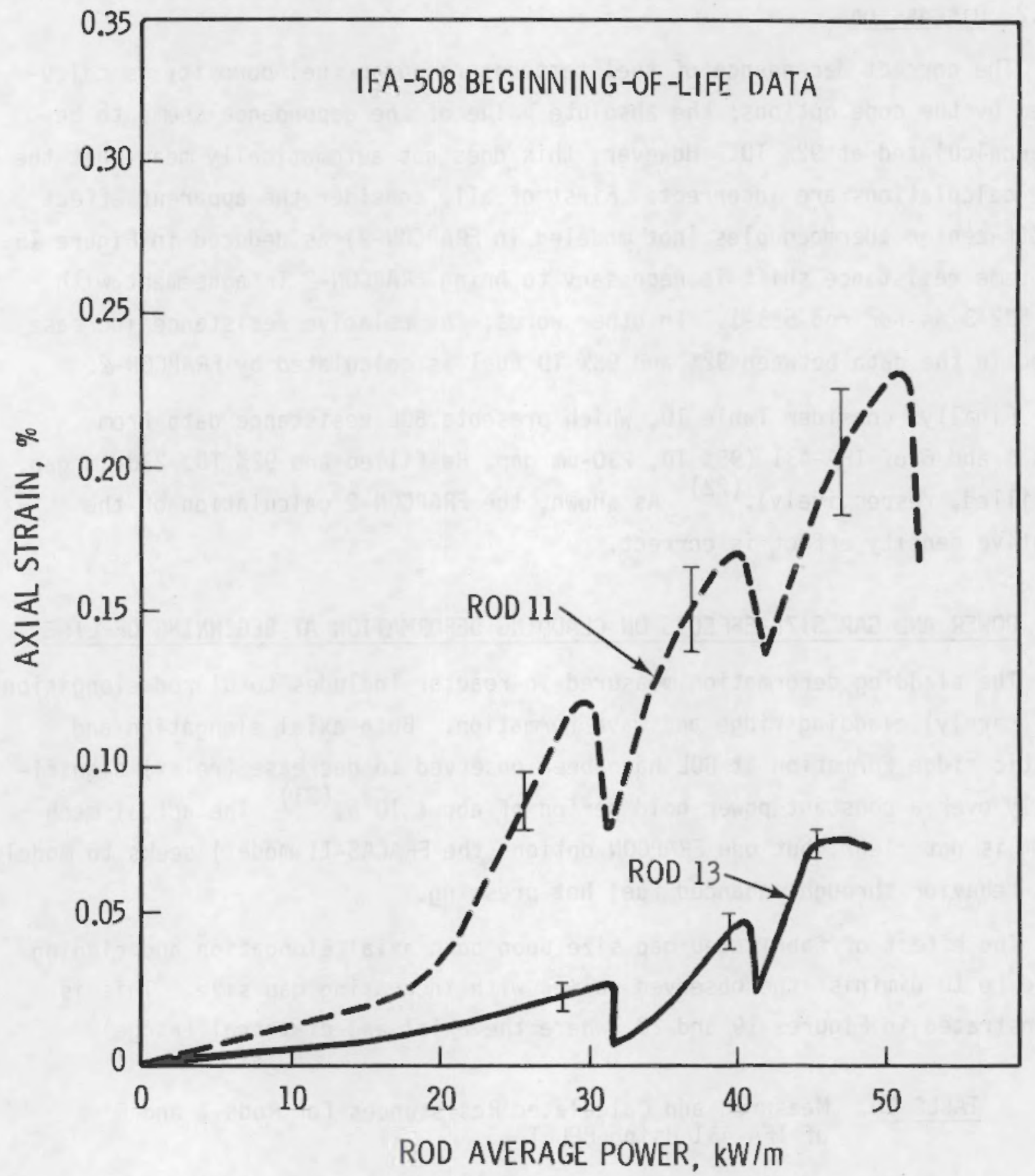

FIGURE 19. Demonstration of Gap Size Effect on Axial Elongation Using IFA-508 Data (gap sizes: $220 \mu \mathrm{m}$ for rod 13 and $100 \mu \mathrm{m}$ for $\operatorname{rod} 11$ ) 


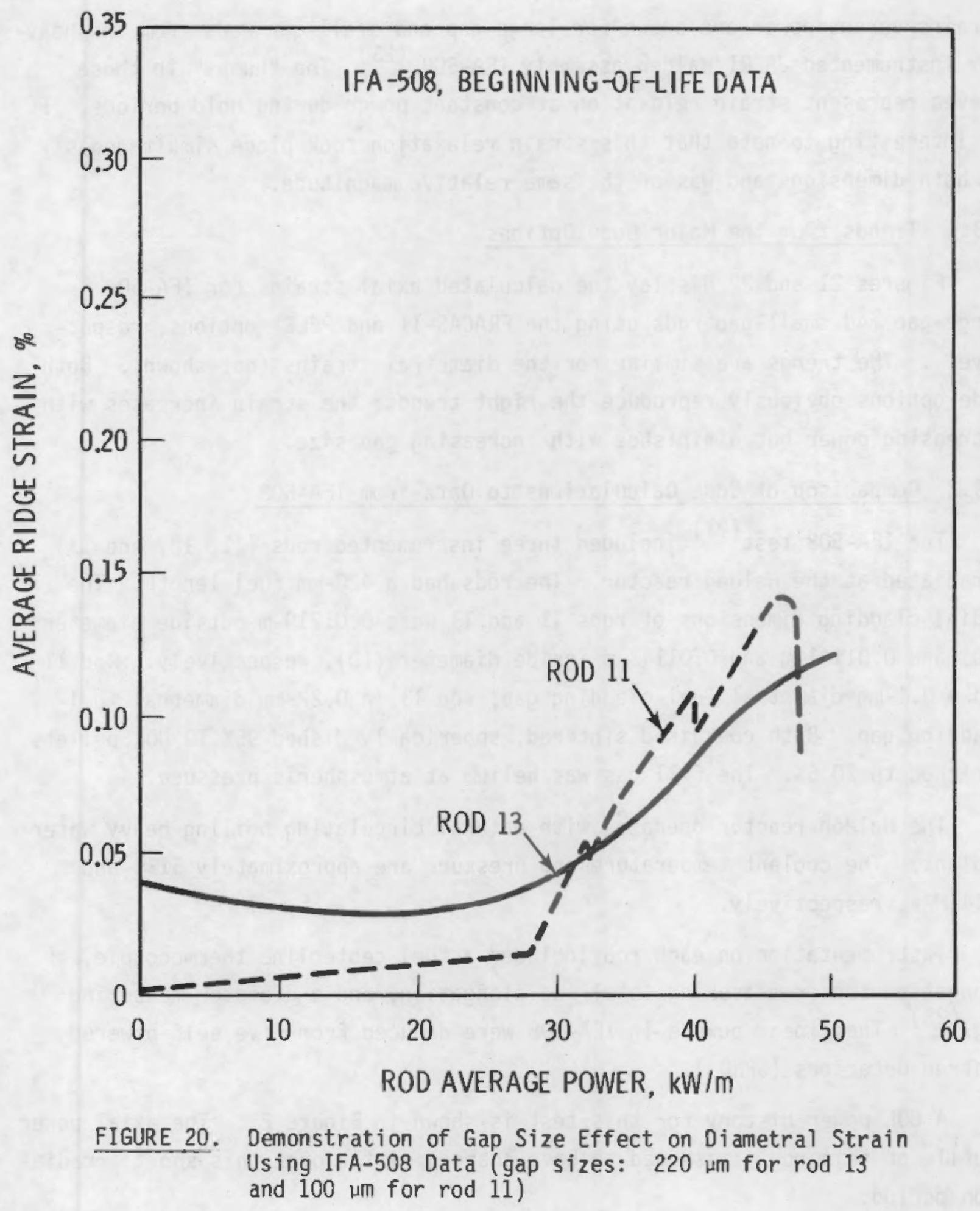


strains versus power are shown for large-gap and small-gap rods from the heavily instrumented JAERI/Halden assembly IFA-508. (23) The "humps" in these curves represent strain relaxation at constant power during hold periods. It is interesting to note that this strain relaxation took place simultaneously in both dimensions and was of the same relative magnitude.

\subsubsection{Trends from the Major Code Options}

Figures 21 and 22 display the calculated axial strains for IFA-508 large-gap and sma11-gap rods using the FRACAS-II and PELET options, respectively. The trends are similar for the diametral strains (not shown). Both code options obviously reproduce the right trends; the strain increases with increasing power but diminishes with increasing gap size.

\subsubsection{Comparison of Code Calculations to Data from IFA-508}

The IFA-508 test ${ }^{(23)}$ included three instrumented rods (11, 12, and 13) irradiated at the Halden reactor. The rods had a $420-\mathrm{mm}$ fuel length. The radial cladding dimensions of rods 11 and 13 were $0.01219-m$ outside diameter (OD) and 0.01141-m and 0.01143-m inside diameter (ID), respectively. Rod 11 had a 0.1-mm diametral fuel-cladding gap; rod 13, a 0.22-m diametral fuelcladding gap. Both contained sintered, spherically dished $95 \%$ TD UO 2 pellets enriched to $10.5 \%$. The fill gas was helium at atmospheric pressure.

The Halden reactor operates with natural circulating boiling heavy water coolant. The coolant temperature and pressure are approximately $513 \mathrm{~K}$ and $3.34 \mathrm{MPa}$, respectively.

Instrumentation on each rod included a fuel centerline thermocouple, an elongation sensor measuring total rod elongation, and a diameter-measuring rig. (28) The linear powers in IFA-508 were deduced from five self-powered neutron detectors (SPNDs).

A BOL power history for this test is shown in Figure 23. The axial power profile of this rod is assumed to have changed little over this short irradiation period. 


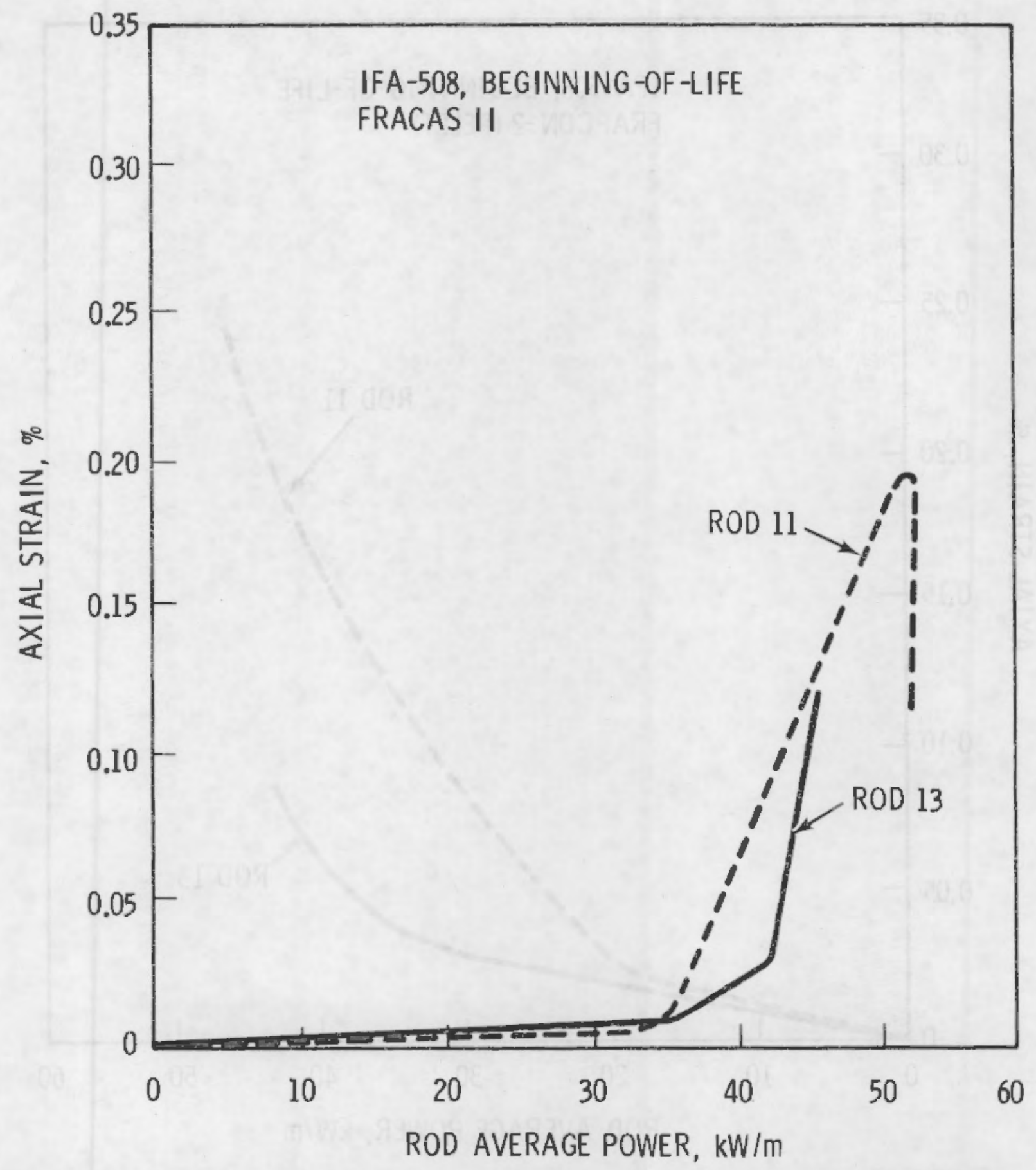

FIGURE 21. Predicted Gap Size Effect on Axial Elongation Using FRACAS-II 


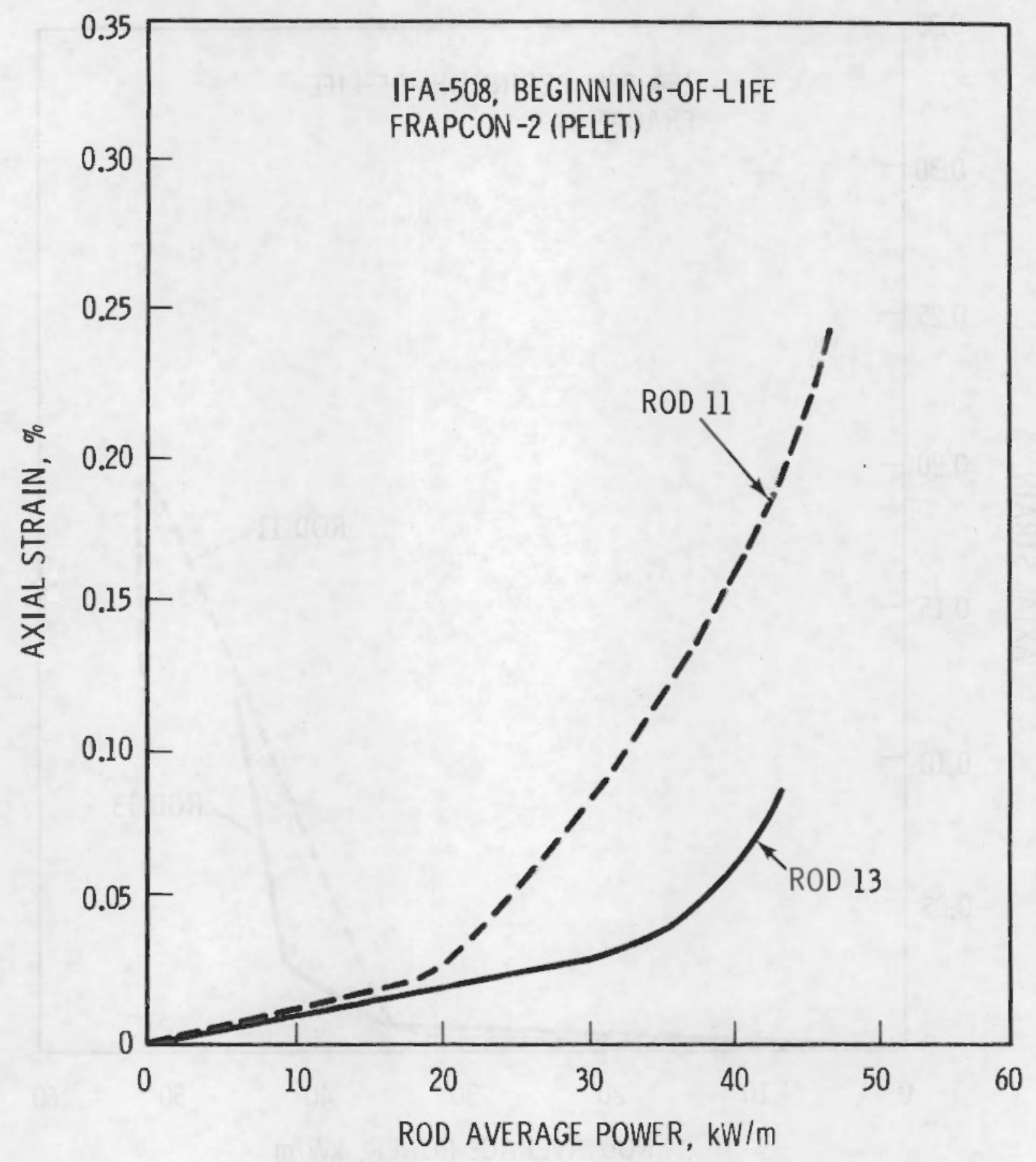

FIGURE 22. Predicted Gap Size Effect on Axial Elongation Using PELET 


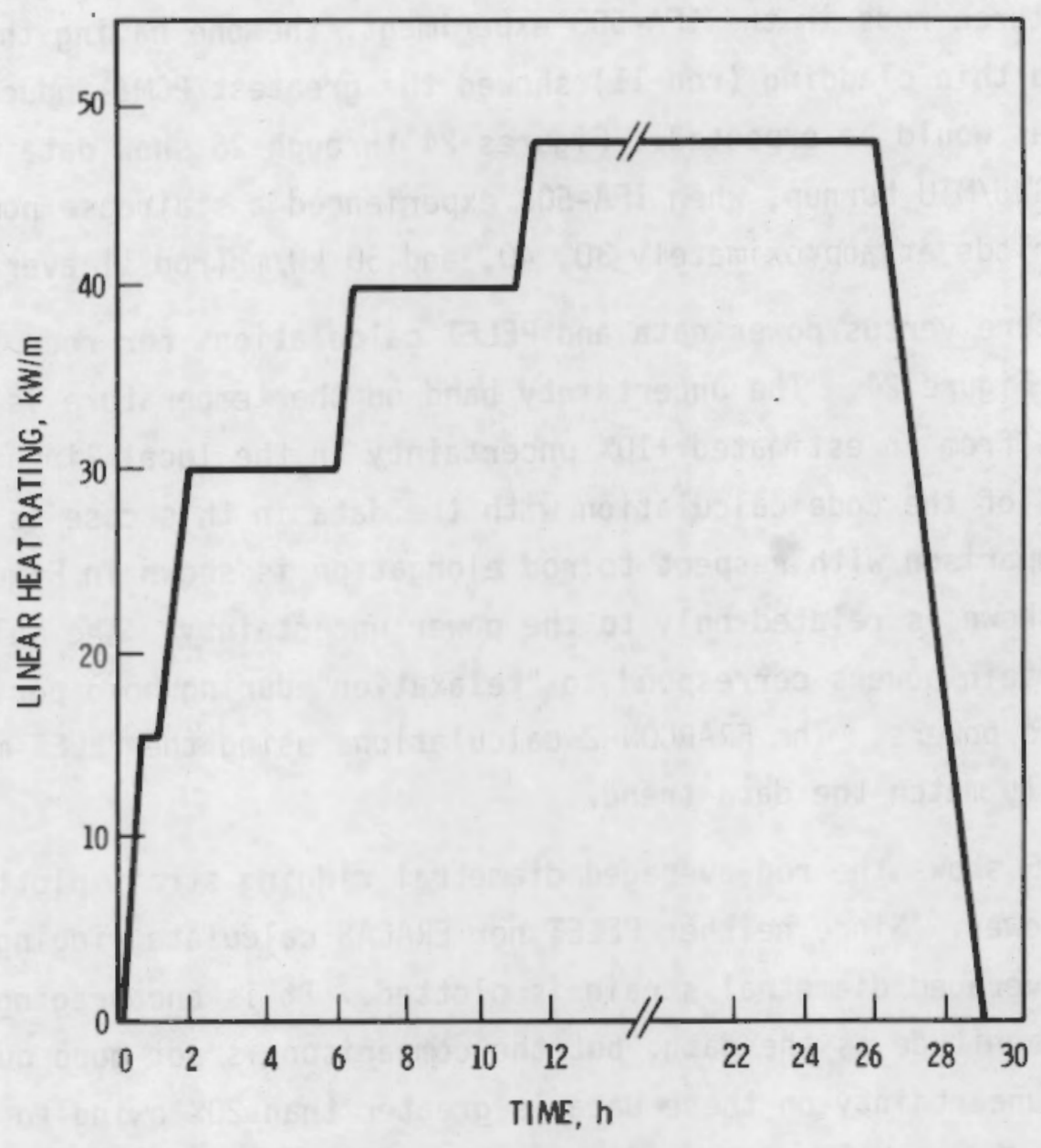

FIGURE 23. Step Power Ramp in the First Cycle for IFA-508 
Of the three rods in the IFA-508 experiment, the one having the relatively small gap and thin cladding (rod 11) showed the greatest PCMI-induced cladding deformation as would be expected. Figures 24 through 26 show data from this rod at 0.07 GWd/MTU burnup, when IFA-508 experienced a staircase power ramp with hold periods at approximately 30,40 , and $50 \mathrm{kw} / \mathrm{m}$ (rod 11 average power).

Temperature versus power data and PELET calculations for rods 11 and 13 are shown in Figure 24. The uncertainty band on the temperature is simply that which results from an estimated $\pm 10 \%$ uncertainty in the local linear power. The agreement of the code calculation with the data in this case is excellent. A similar comparison with respect to rod elongation is shown in Figure 25 . The uncertainty shown is related only to the power uncertainty. The multiple data values at certain powers correspond to "relaxation" during hold periods at those specific powers. The FRAPCON-2 calculations using the PELET mechanical model generally match the data trend.

Figure 26 shows the rod-averaged diametral ridging strain plotted against average rod power. Since neither PELET nor FRACAS calculate ridging strain, the axially averaged diametral strain is plotted. It is encouraging that this is the same magnitude as the data, but the comparison is not good quantitatively. The uncertainty on these data is greater than $20 \%$ owing to the small deflections that are being measured. An uncertainty analysis on these data is not available; therefore, no estimated experimental error is shown.

Figure 27 shows centerline temperature data from rods 13 and 11 compared to FRACAS-II calculations; agreement is good in both cases. Axial elongation calculations are compared to the staircase ramp data for both rods in Figure $28 \mathrm{a}$. Neither calculation registers the apparent relaxation; both attain good agreement with the data at full power but not at intermediate powers. A similar comparison for the diametral strain for both rods is shown in Figure 28b. In this case, FRACAS-II does begin to register relaxation at full power for rod 11; and its agreement with the magnitude of the data is much better than the PELET/RADIAL calculation. 


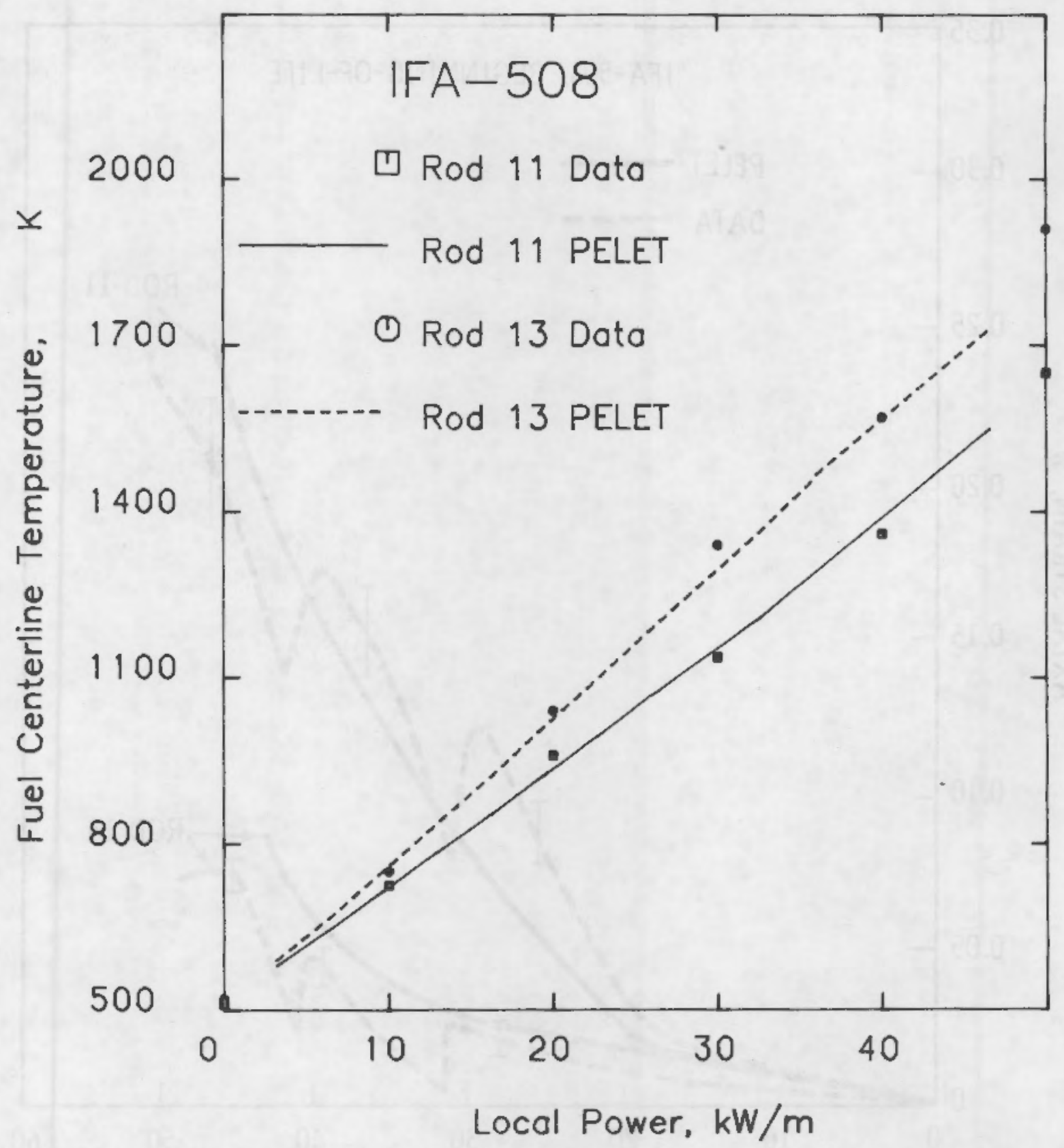

FIGURE 24. Beginning-of-Life Centerline Temperature Data for Rods 11 and 13 of IFA-508 Compared to PELET Calculations 


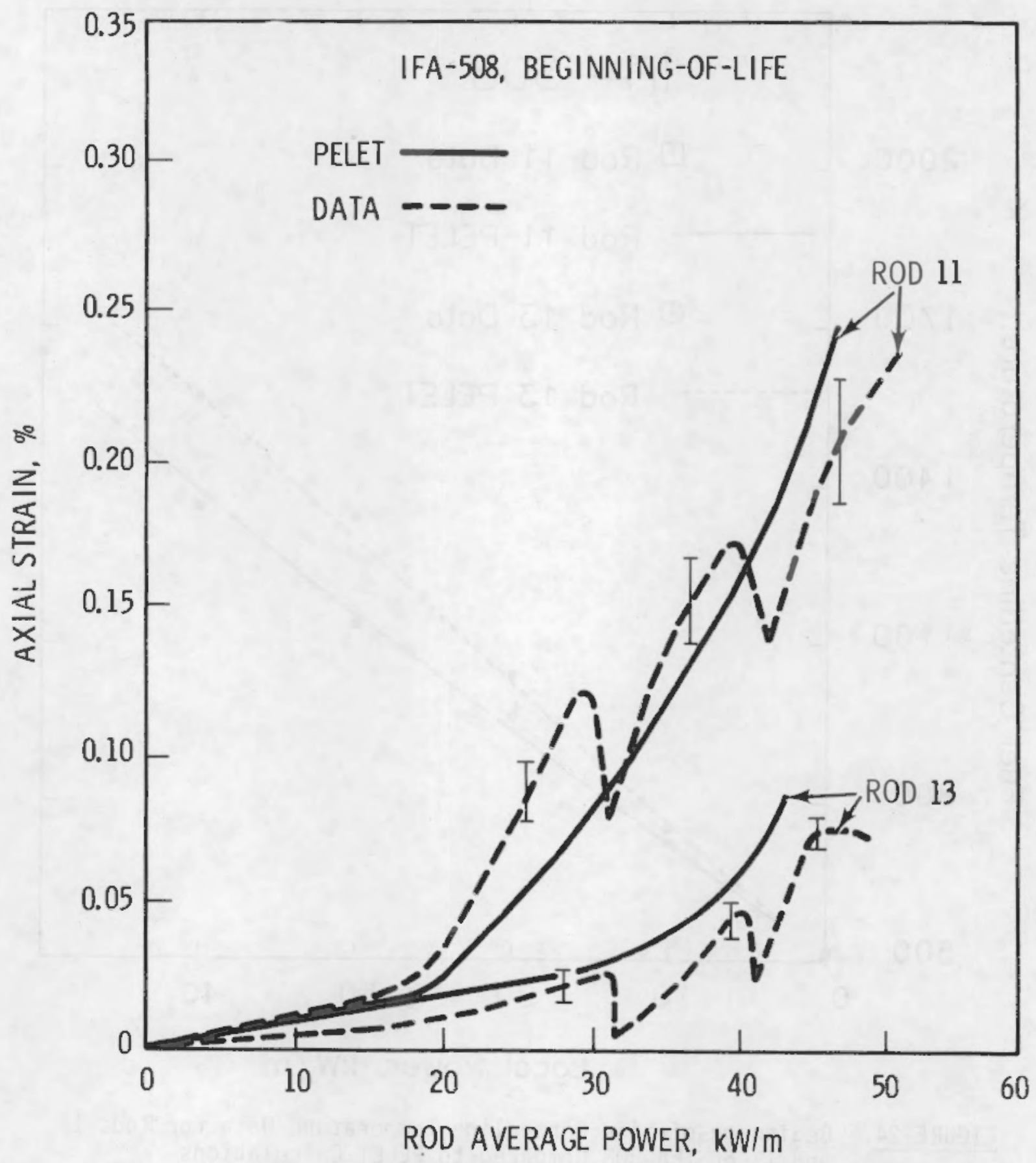

FIGURE 25. Beginning-of-Life Axial Elongation Data for Rods 11 and 13 of IFA-508 Compared to PELET Calculations 


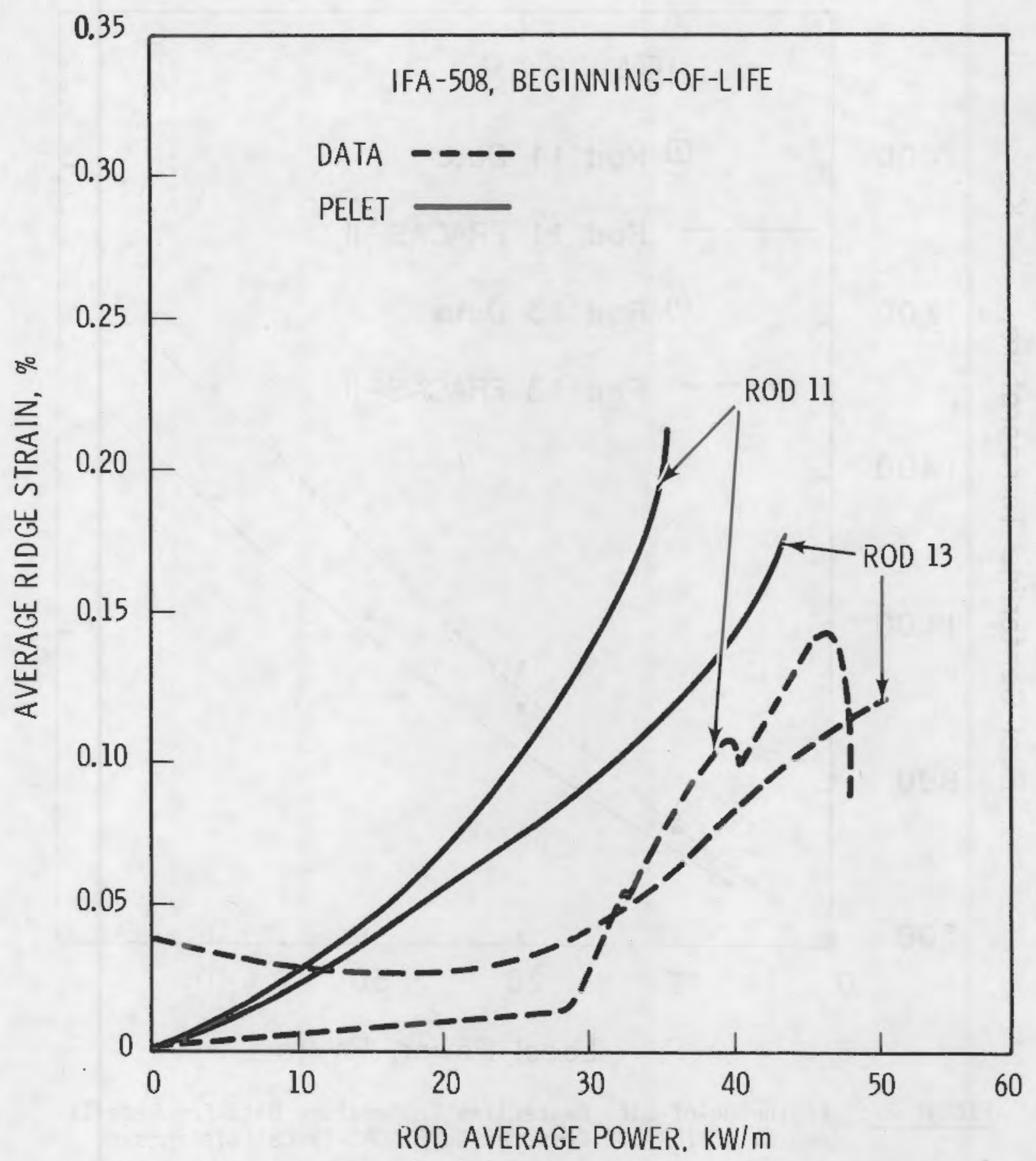

FIGURE 26. Beginning-of-Life Diametral Strain Data for Rods 11 and 13 of IFA-508 Compared to PELET Calculations 


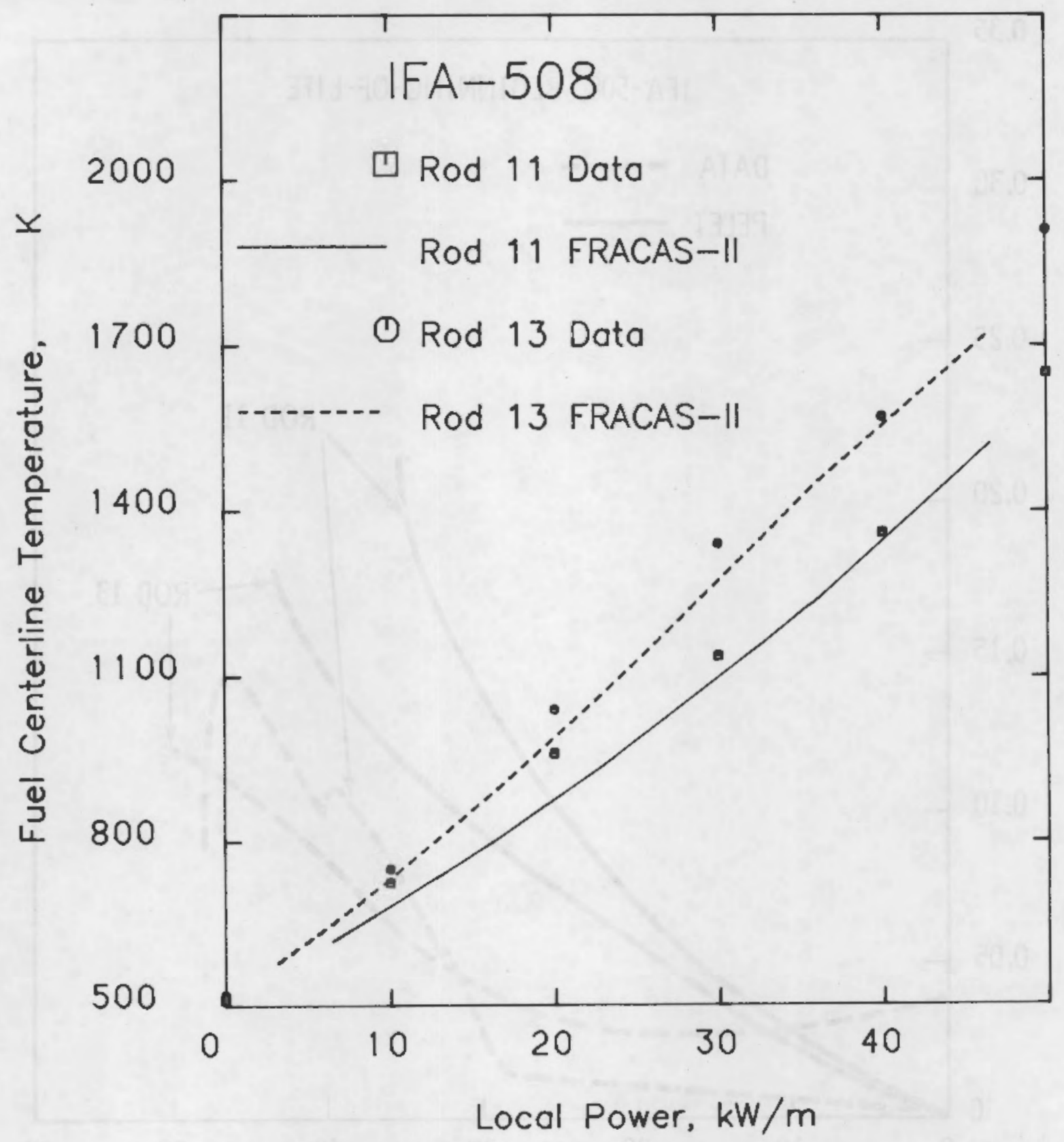

FIGURE 27. Beginning-of-Life Centerline Temperature Data for Rods 11 and 13 of IFA-508 Compared to FRACAS-II Calculations 


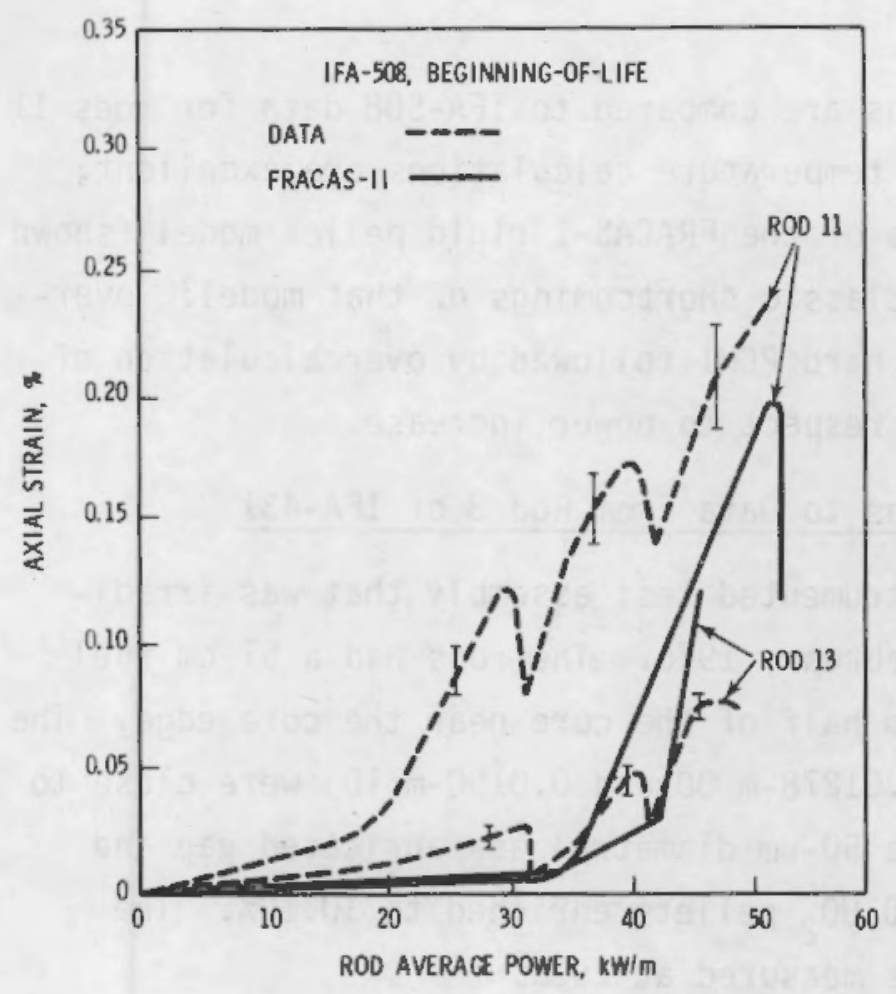

a) Axial Elongation

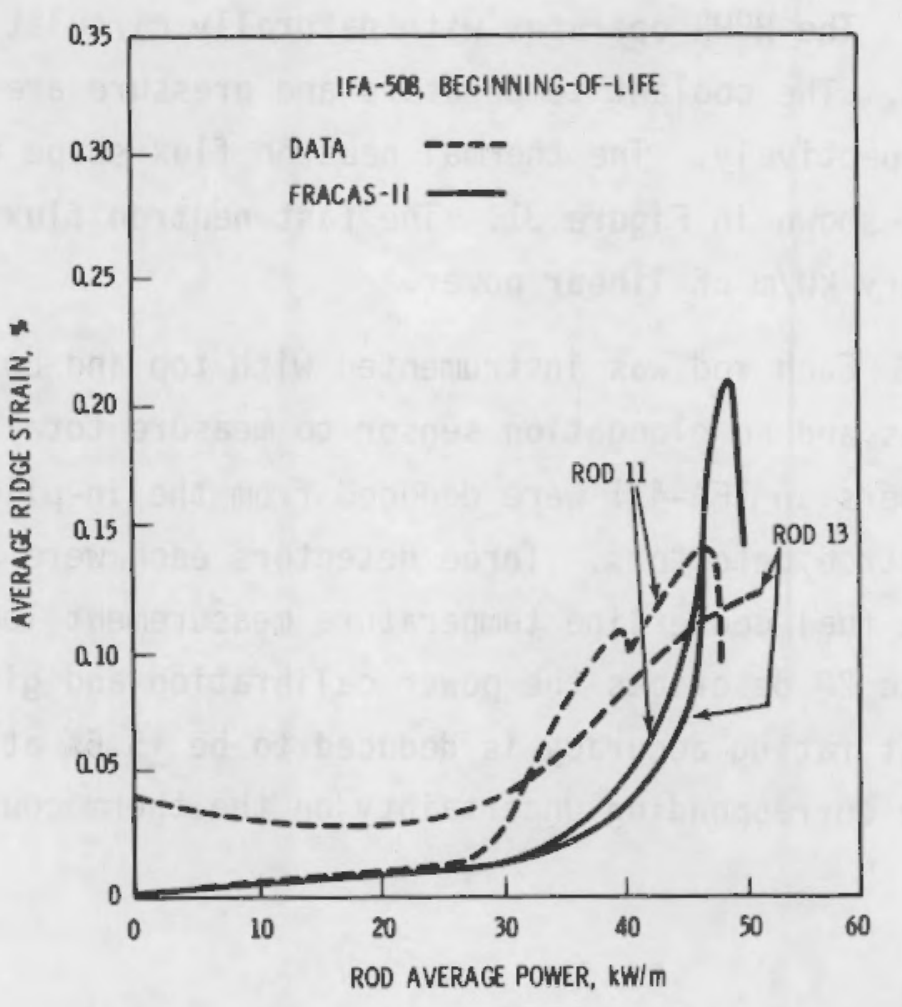

FIGURE 28. Beginning-of-Life Cladding Deformation Data for Rods 11 and 13 of IFA-508 Compared to FRACAS-II Calculations 
FRACAS-I temperature calculations are compared to IFA-508 data for rods 11 and 13 in Figure 29. Although these temperature calculations are excellent, the cladding deformation calculations of the FRACAS-I rigid pellet model (shown in Figures 30a and 30b) display the classic shortcomings of that model: overcalculation of the power to initiate hard PCMI followed by overcalculation of the severity of the interaction with respect to power increase.

\subsubsection{Comparison of Code Calculations to Data from Rod 3 of IFA-431}

IFA-431 $(22,24)$ is a six-rod instrumented test assembly that was irradiated in the HBWR from June 1975 to February 1976. The rods had a $57-\mathrm{cm}$ fuel length and were located in the bottom half of the core near the core edge. The radial dimensions of the cladding (0.01278-m OD and 0.0190-m ID) were close to BWR cladding dimensions. Rod 3 had a 50-um diametral as-fabricated gap and contained sintered, flat-ended $95 \%$ TD $\mathrm{UO}_{2}$ pellets enriched to $10.10 \%$. The fill gas was helium at 1 atm pressure measured at $293 \mathrm{~K}$.

The HBWR operates with naturally circulating, boiling heavy water coolant. The coolant temperature and pressure are approximately $513 \mathrm{~K}$ and $3.34 \mathrm{MPa}$, respectively. The thermal neutron flux shape and fuel and instrument locations are shown in Figure 31. The fast neutron flux is about $5 \times 10^{15} \mathrm{n} / \mathrm{m}^{2}-\mathrm{s}$ for every $\mathrm{kW} / \mathrm{m}$ of linear power.

Each rod was instrumented with top and bottom fuel centerline thermocouples and an elongation sensor to measure total rod elongation. The linear powers in IFA-431 were deduced from the in-pile BOL calibration of six vanadium neutron detectors. Three detectors each were at the lower and upper planes of the fuel centerline temperature measurement locations (see Figure 32). Reference 22 describes the power calibration and gives a calibration error. Linear heat rating accuracy is deduced to be $\pm 5.6 \%$ at the $2 \sigma$ confidence leve $\}$, and the corresponding uncertainty on the thermocouple readings is $\pm 3 \%$. 


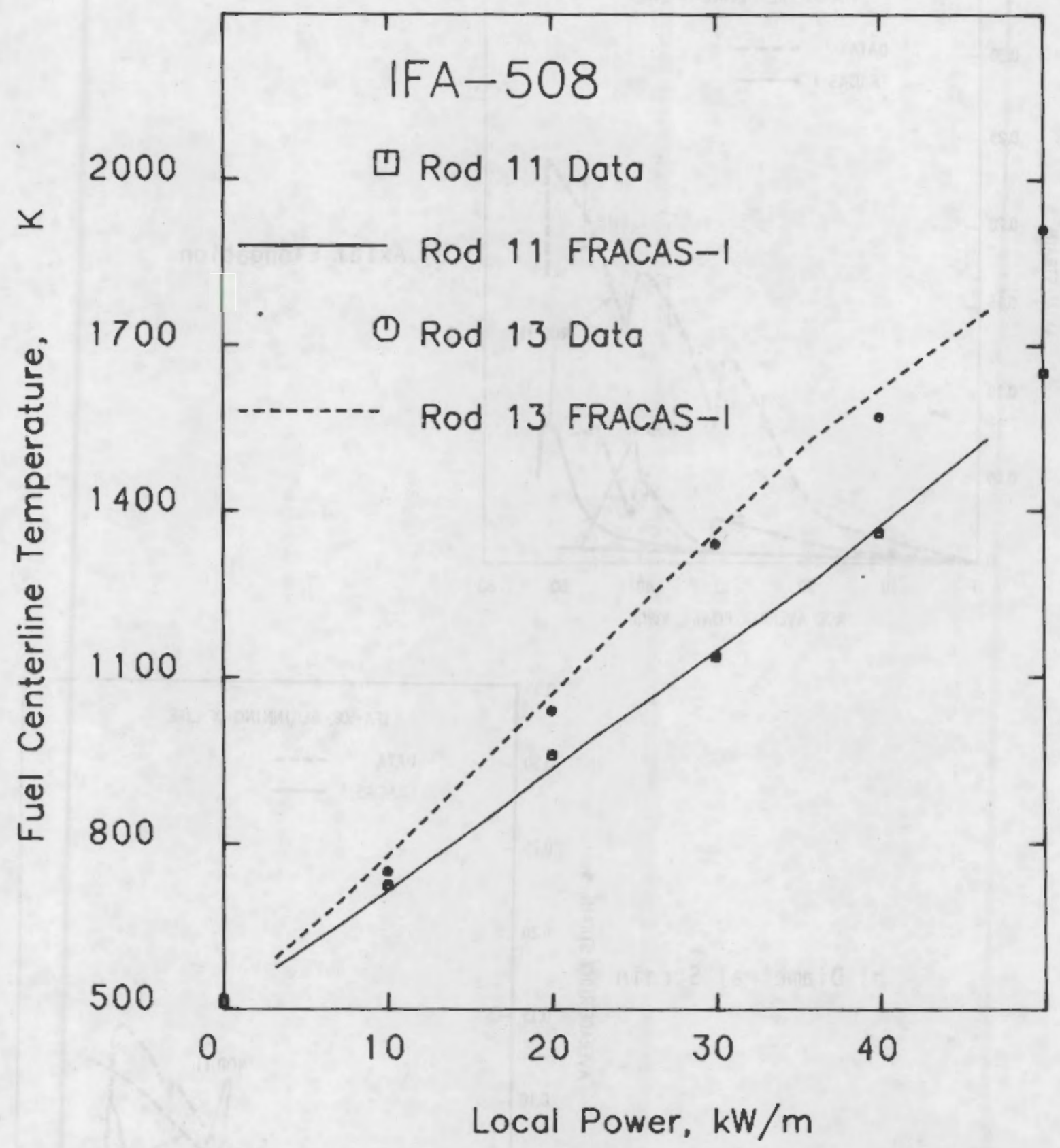

FIGURE 29. Beginning-of-Life Centerline Temperature Data for Rods 11 and 13 of IFA-508 Compared to FRACAS-I Calculations 


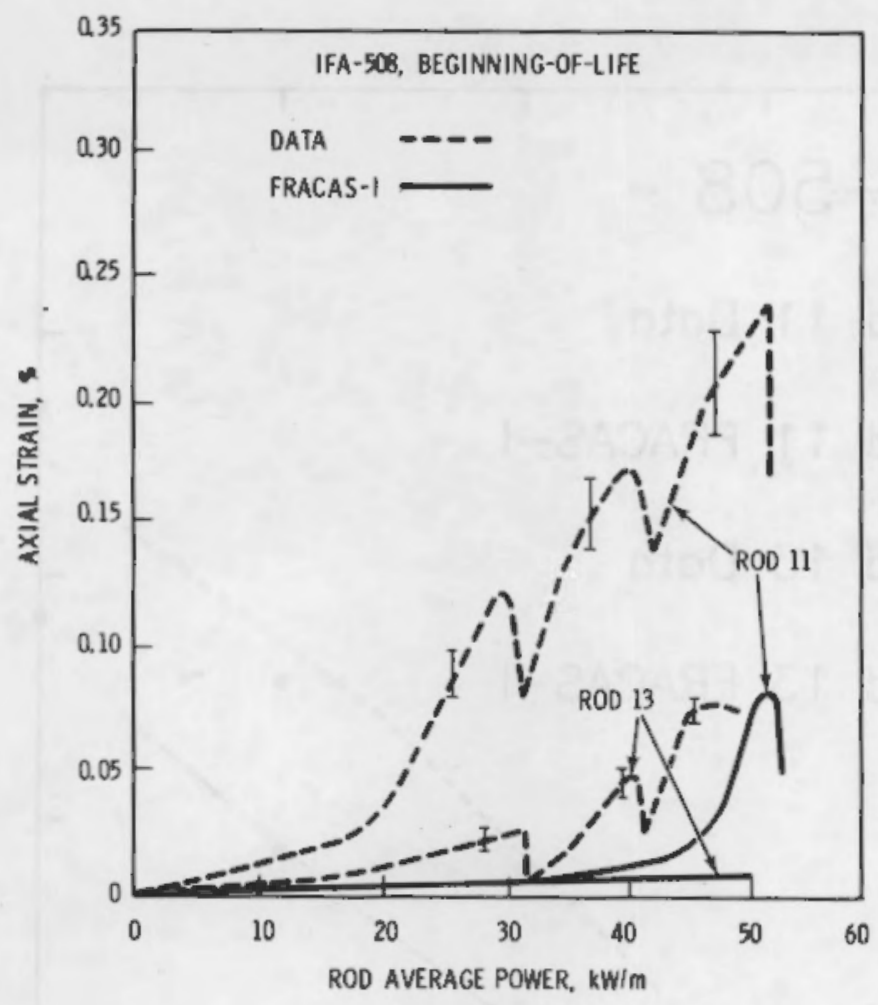

a) Axial Elongation

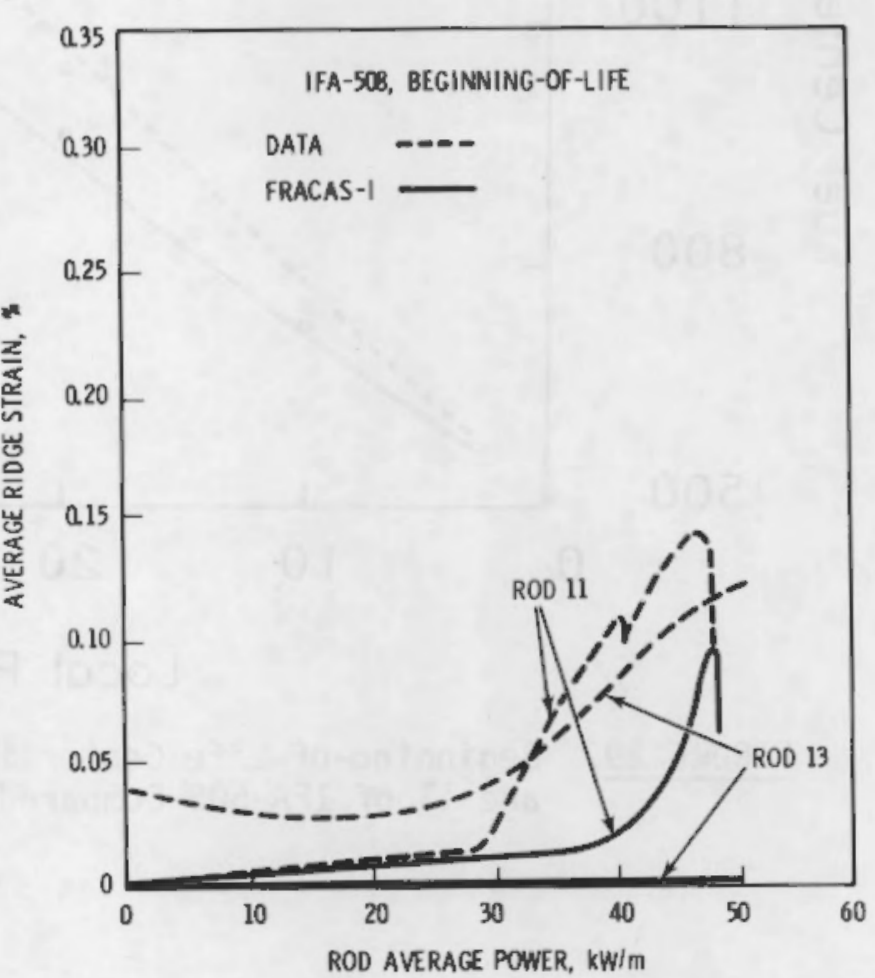

FIGURE 30. Beginning-of-Life Cladding Deformation Data for Rods 11 and 13 Compared to FRACAS-I Calculations 


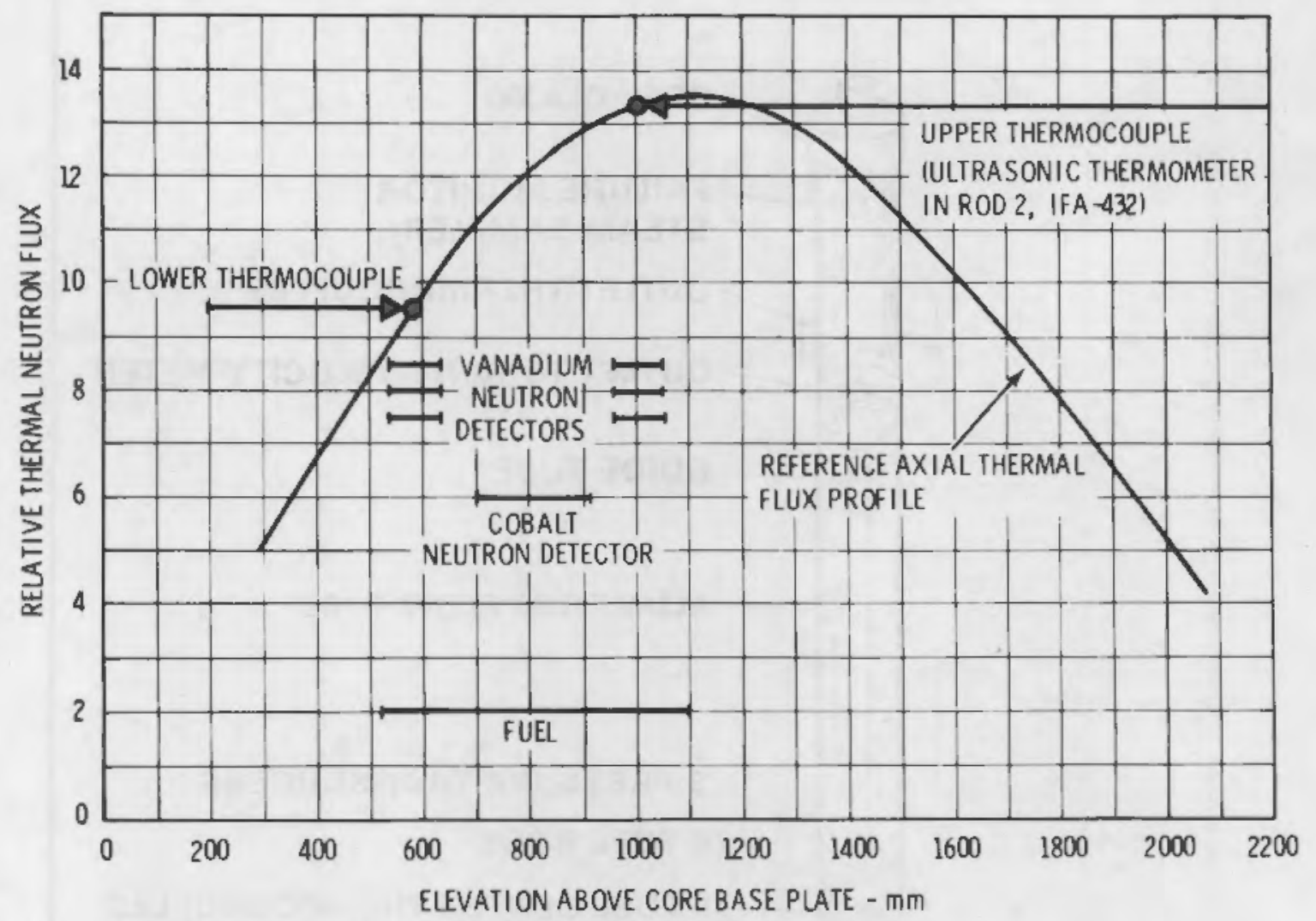

FIGURE 31. Arrangement of Temperature Sensors, Neutron Detectors, and Fuel Relative to Reference Axial Thermal Flux Profile for IFA-432 and IFA-431

The power history for rod 3 at upper and lower themocouple locations is shown in Figure 33. The axial power profile of this rod is assumed to have changed little over the short irradiation period. The peak burnup at the peak power location attained at EOL was 5.265 GWd/MTU. Minor variations between peak and measured power are not considered significant.

Rod 3 was selected as the test case primarily because it shows temperature and elongation in a small-gap rod where firm fuel-cladding contact is achieved and where, as a consequence, there is minimal uncertainty in the fuel-cladding gap resistance. Gas release was not an issue in this irradiation.

Both mechanics packages were tested against the data since significant rod elongation data were available. Resintering tests have shown the fuel used in 


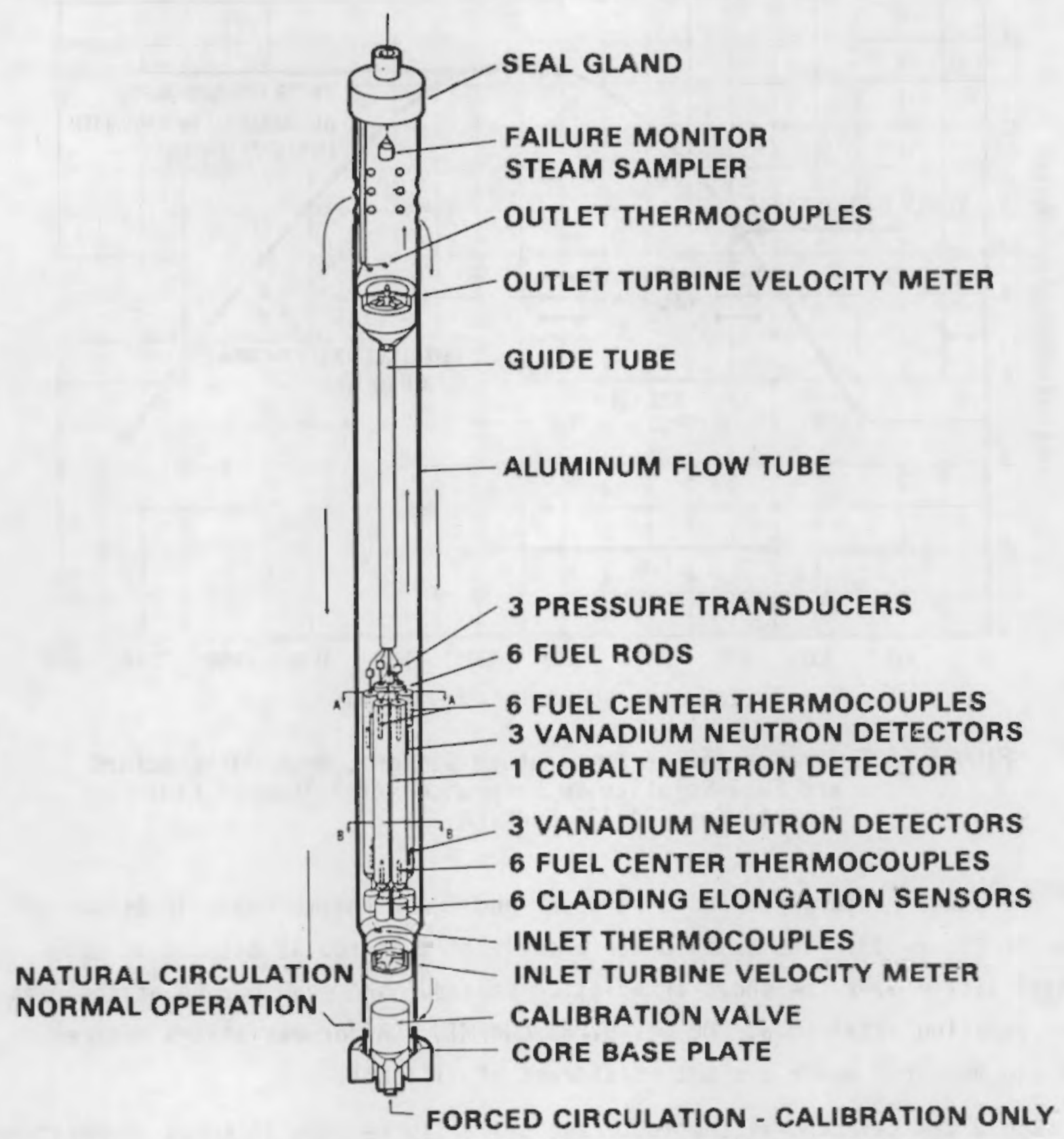

FIGURE 32. Schematic of IFA-431 and IFA-432 


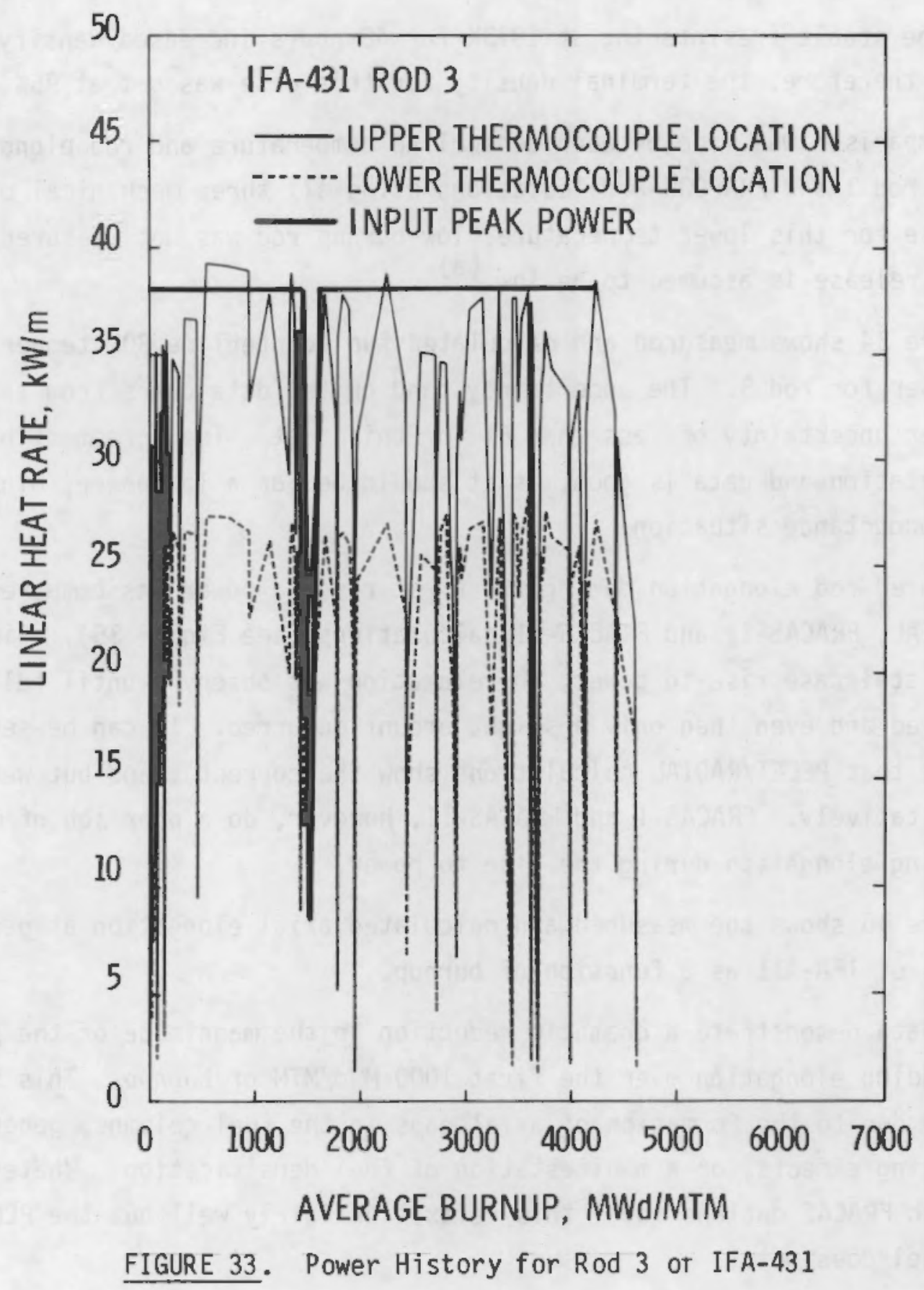


rod 3 to be stable (resintering at $1973 \mathrm{~K}$ for 48 hours increased density only $0.3 \%$ TD); therefore, the terminal density for this case was set at 95\% TD.

A comparison was made between centerline temperature and rod elongation data from rod 3 and FRAPCON-2 calculations using all three mechanical options. Gas release for this lower temperature, low-burnup rod was not measured; however, the release is assumed to be low. (a)

Figure 34 shows measured and calculated fuel centerline BOL temperature versus power for rod 3. The uncertainty band on the data comes from an estimated power uncertainty of less than $6 \%$ for this test. The agreement between code calculation and data is good, as it should be for a low-power, highcontact conductance situation.

Measured rod elongation during the first rise to power was compared with PELET/RADIAL, FRACAS-I, and FRACAS-II calculations (see Figure 35). Since this was not a staircase rise to power, no relaxation was observed until full power was achieved and even then only a slight amount occurred. It can be seen from the figure that PELET/RADIAL calculations show the correct trend but were only fair qualitatively. FRACAS-I and FRACAS-II, however, do a poor job of modeling the cladding elongation during the rise to power.

Figure 36 shows the measured and calculated axial elongation at peak power from rod 3 of IFA-431 as a function of burnup.

The data demonstrate a dramatic reduction in the magnitude of the peak power cladding elongation over the first 1000 MWd/MTM of burnup. This behavior may be due to the formation of axial gaps in the fuel columns, general fuel cracking effects, or a manifestation of fuel densification. Whatever the cause, both FRACAS options model this relaxation fairly well but the PELET/ RADIAL model does not.

(a) This assumotion is based on the fact that rod 6 of IFA-431 operated at higher temperatures and had a measured gas release fraction of only $0.25 \%$. (32) 


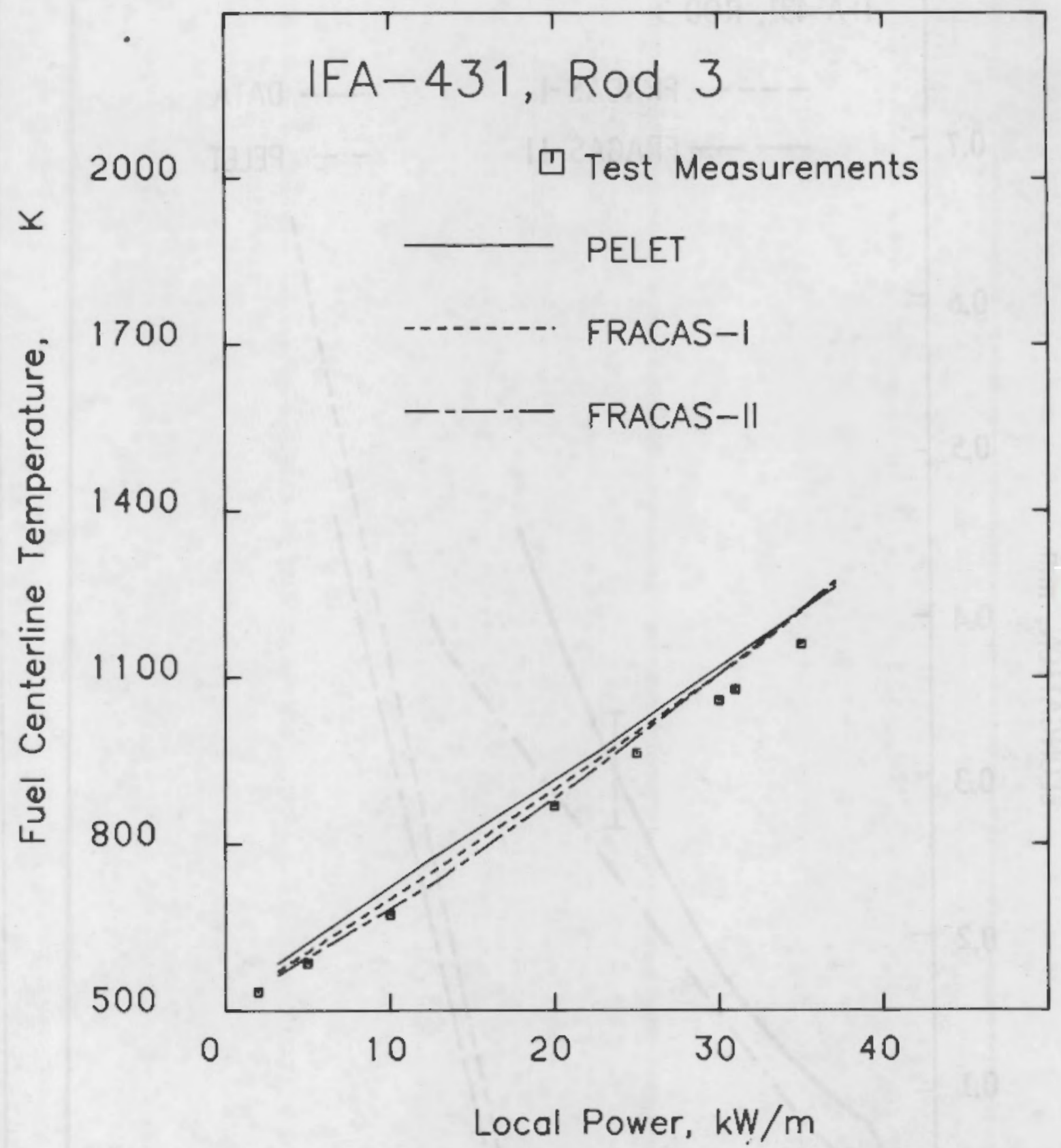

FIGURE 34. Measured and Calculated Beginning-of-Life Fuel Centerline Temperatures for Rod 3 of IFA-431 Using PELET, FRACAS-I, and FRACAS-II 


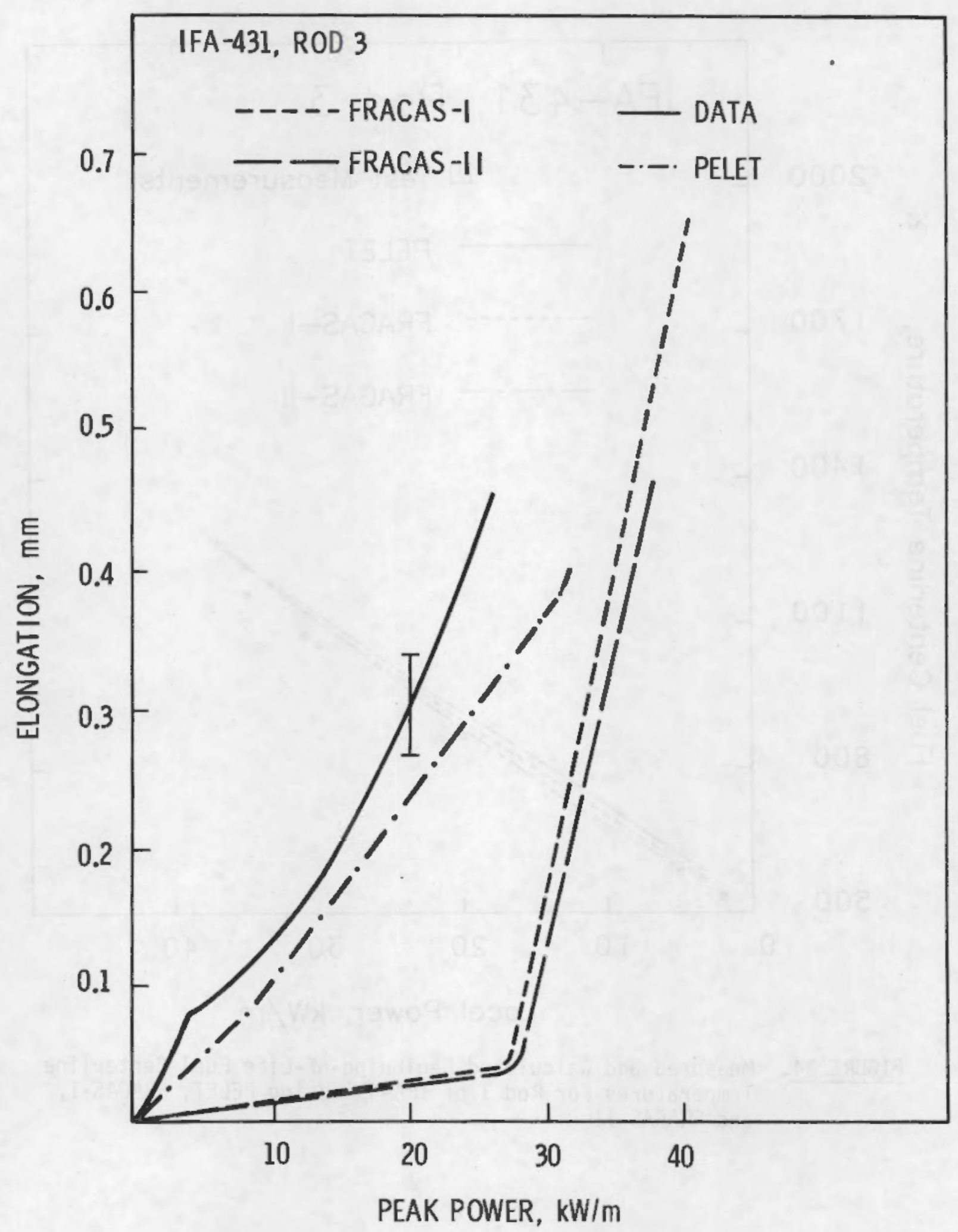

FIGURE 35. Measured and Calculated Fuel Rod Elongation on First Rise to Power for Rod 3 of IFA-431 Using PELET, FRACAS-I, and FRACAS-II 


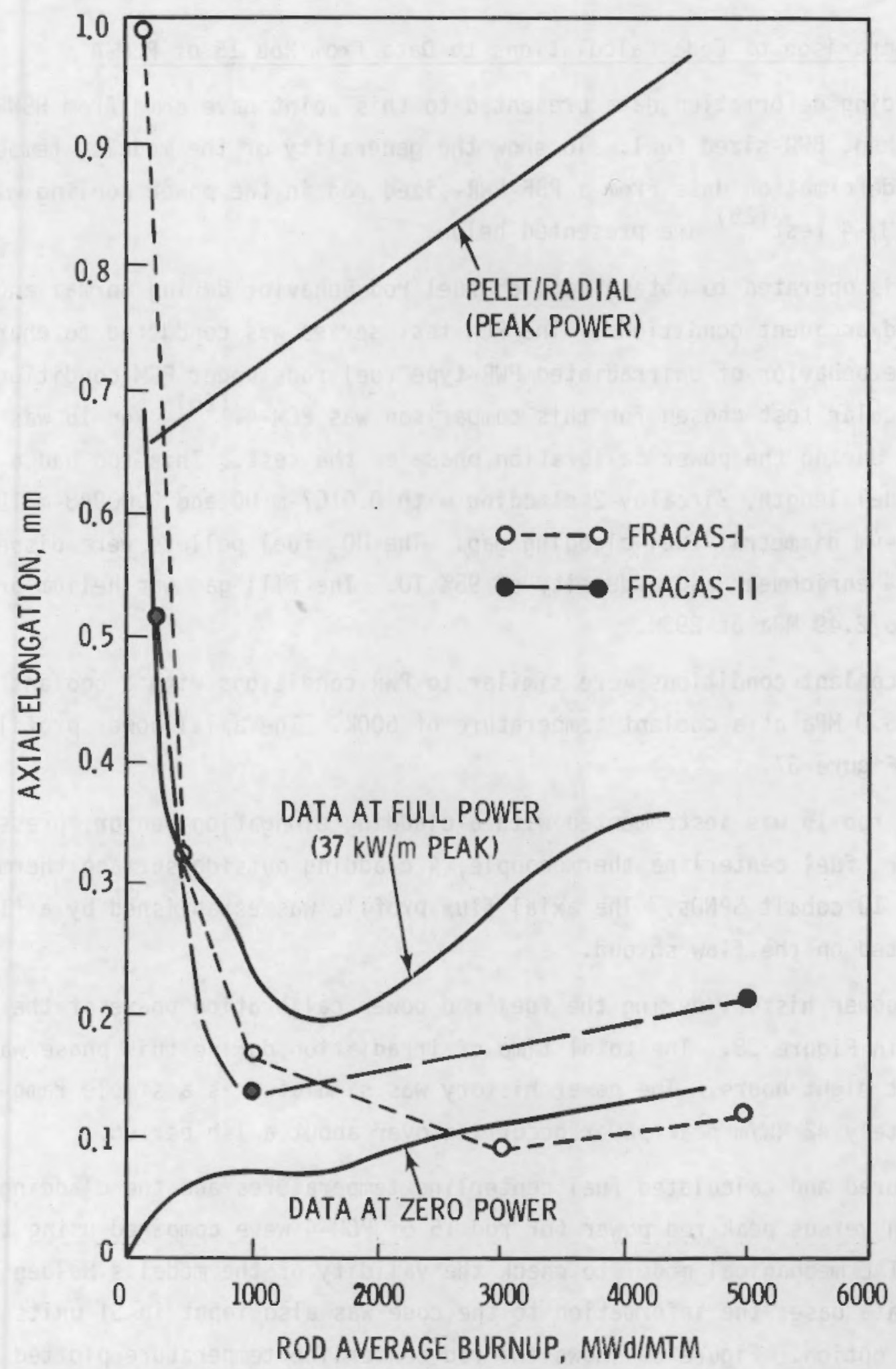

FIGURE 36. Measured and Calculated Rod Axial Elongation Versus Burnup for Rod 3 of IFA-431 


\subsubsection{Comparison of Code Calculations to Data from Rod 15 of PCM-4}

Cladding deformation data presented to this point have come from HBWR, $10 \%$ enriched, BWR-sized fuel. To show the generality of the models, temperature and deformation data from a PBF PWR-sized rod in the power cooling mismatch (PCM) -4 test $^{(25)}$ are presented below.

$\mathrm{PBF}$ is operated to obtain data on fuel rod behavior during normal and postulated accident conditions. The PCM test series was conducted to characterize the behavior of unirradiated PWR-type fuel rods under PCM conditions. The particular test chosen for this comparison was PCM-4. ${ }^{(26)}$ Rod 15 was simulated during the power calibration phase of the test. This rod had a $0.914-m$ fuel length, Zircaloy-2 cladding with $0.0107-m$ OD and 0.00948-m ID, and a $180-\mu m$ diametral fuel-cladding gap. The $\mathrm{UO}_{2}$ fuel pellets were dished with a $20 \%$ enrichment and a density of $95 \%$ TD. The fill gas was helium pressurized to $2.49 \mathrm{MPa}$ at $293 \mathrm{~K}$.

The coolant conditions were similar to PWR conditions with a coolant pressure of $15.0 \mathrm{MPa}$ at a coolant temperature of $600 \mathrm{~K}$. The axial power profile is shown in Figure 37.

Test rod 15 was instrumented with a cladding elongation sensor, pressure transducer, fuel centerline thermocouple, 4 cladding outside surface thermocouples, and 10 cobalt SPNDs. The axial flux profile was established by a flux wire mounted on the flow shroud.

The power history during the fuel rod power calibration phase of the test is shown in Figure 38. The total time of irradiation during this phase was only about eight hours. The power history was simulated as a simple ramp to approximately $42 \mathrm{~kW} / \mathrm{m}$ peak power occurring over about a $1-\mathrm{h}$ period.

Measured and calculated fuel centerline temperatures and the cladding elongation versus peak rod power for rod 15 of PCM-4 were compared using the PELET/RADIAL mechanical model to check the validity of the model's Halden reactor data base; the information to the code was also input in SI units to test that option. Figure 39 shows the rod centerline temperature plotted versus rod peak power. The data and the calculation agree well for the entire power ramp. 


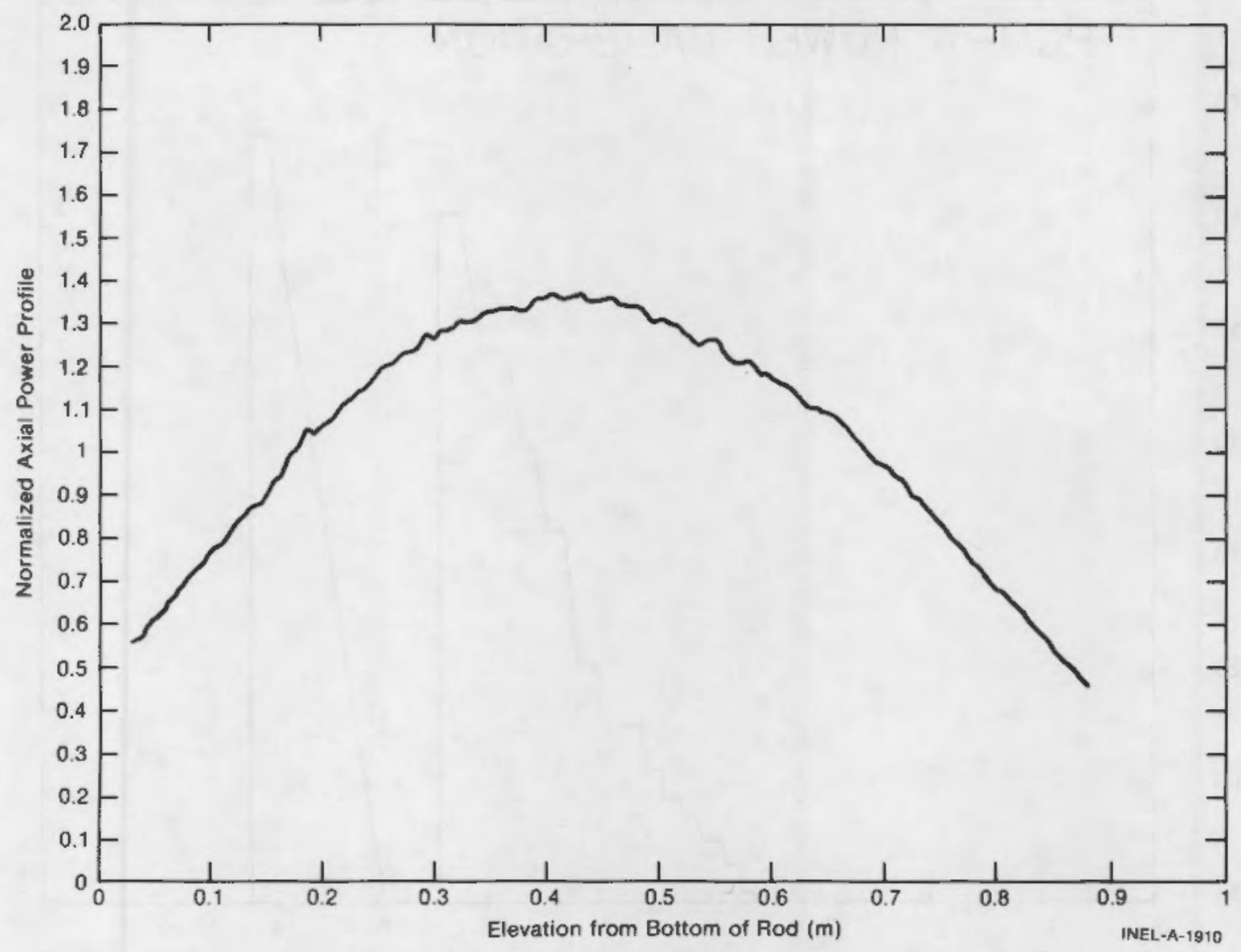

FIGURE 37. Axial Power Profile for Test PCM-4, Determined from Cobalt Wire Activation

Figure 39 also presents a comparison of the fuel centerline temperature as a function of local rod power calculated using the two FRACAS models. The calculated centerline temperatures are slightly lower than the experimental data. FRACAS-II calculated a temperature that was $50 \mathrm{~K}$ below the data at $30 \mathrm{~kW} / \mathrm{m}$ while FRACAS-I calculated the fuel centerline temperature at 10K below the data at $30 \mathrm{~kW} / \mathrm{m}$.

Cladding elongation is plotted versus power in Figure 40 . The point at which significant fuel-cladding interaction occurs (where the slope of elongation versus power changes suddenly) agrees well between the PELET calculation and data. The data show a slightly greater rod elongation at peak power than calculated by the code. Figure 40 also shows the FRACAS-II elongation calculation versus local power for rod 15 of PCM-4. 


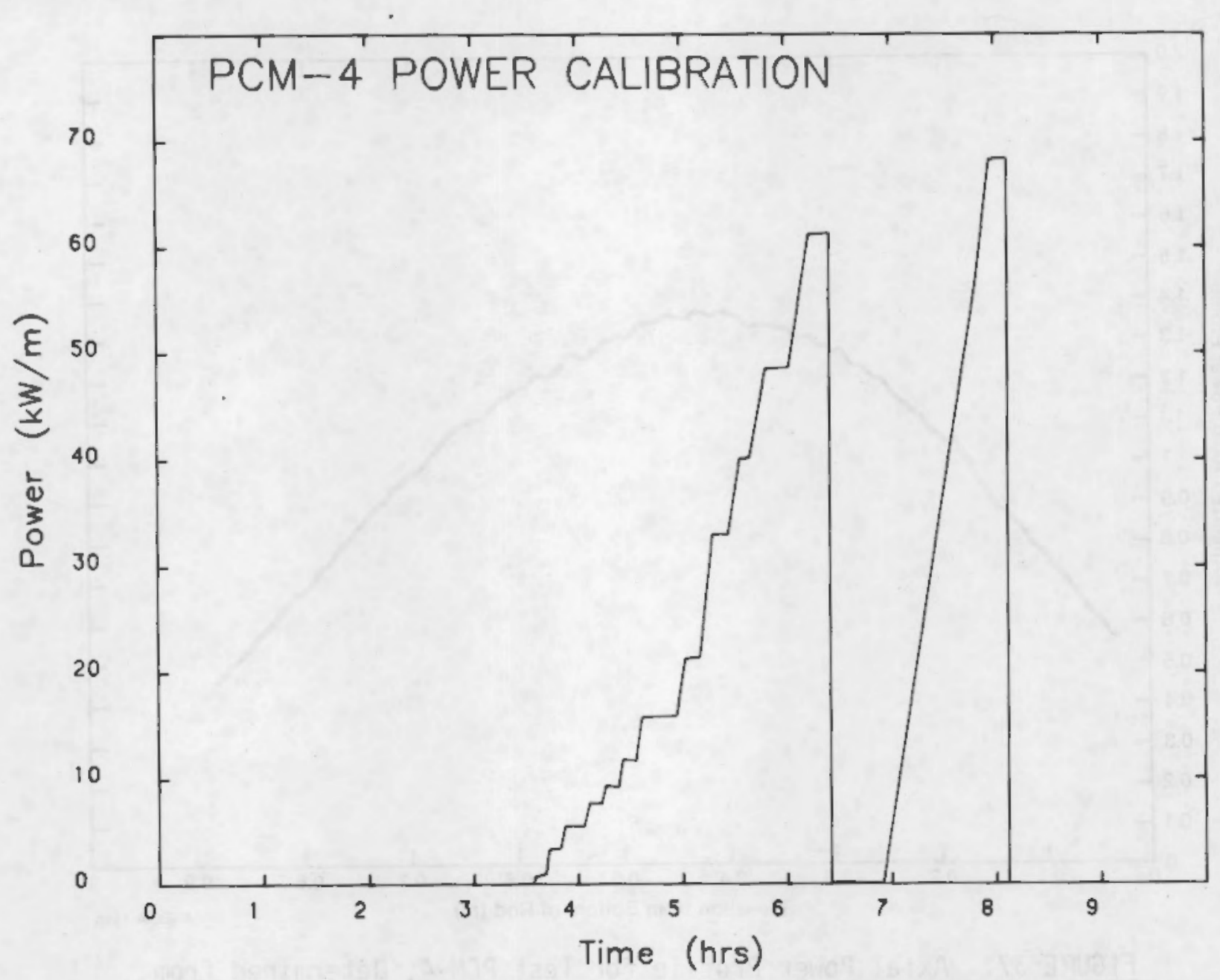

FIGURE 38. Typical Fuel Rod Peak Power During the Fuel Rod Power Calibration Phase 


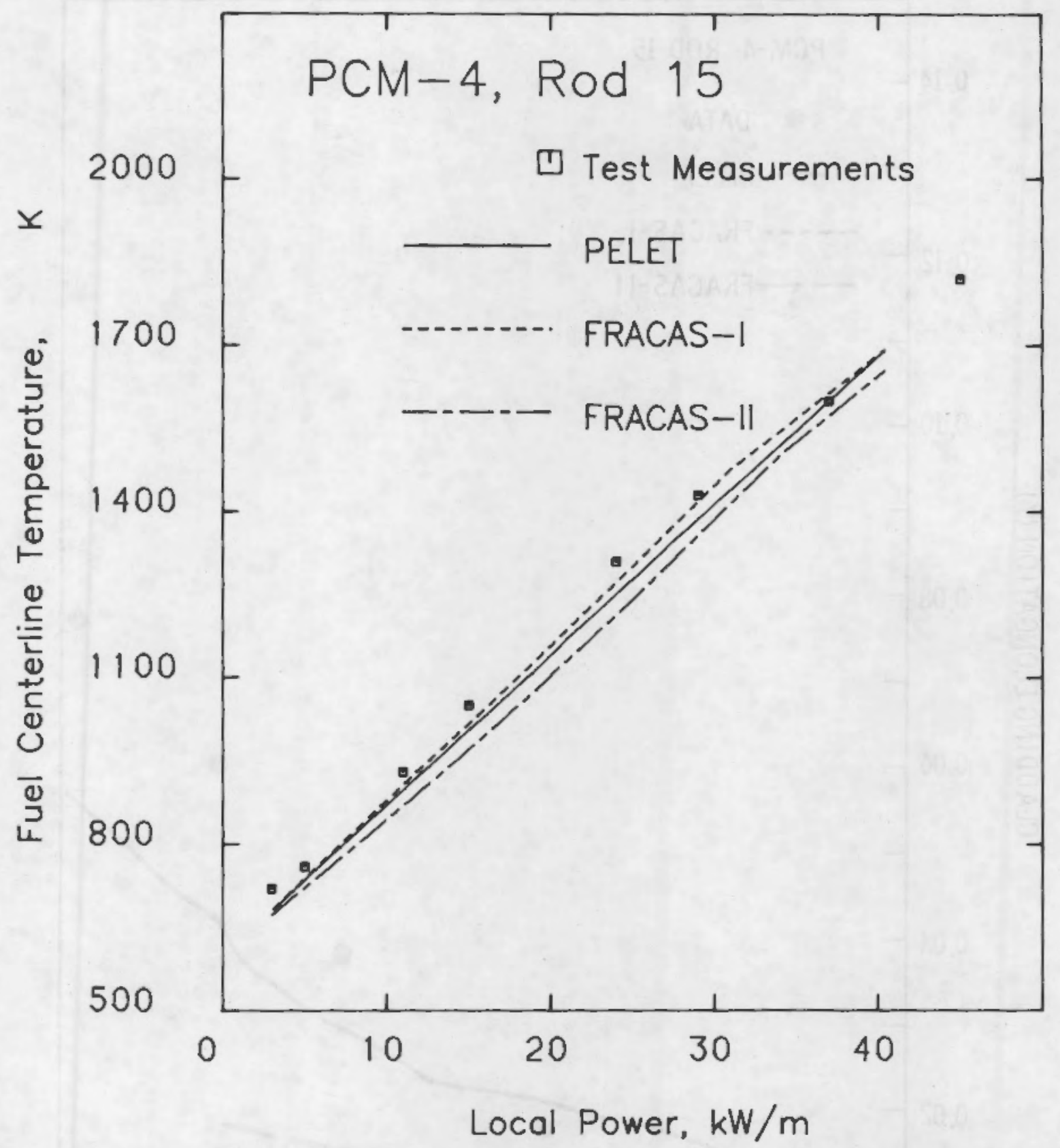

FIGURE 39. Comparison of PELET, FRACAS-I, and FRACAS-II Calculations and Rod 15 of PCM-4 Centerline Temperature Data 


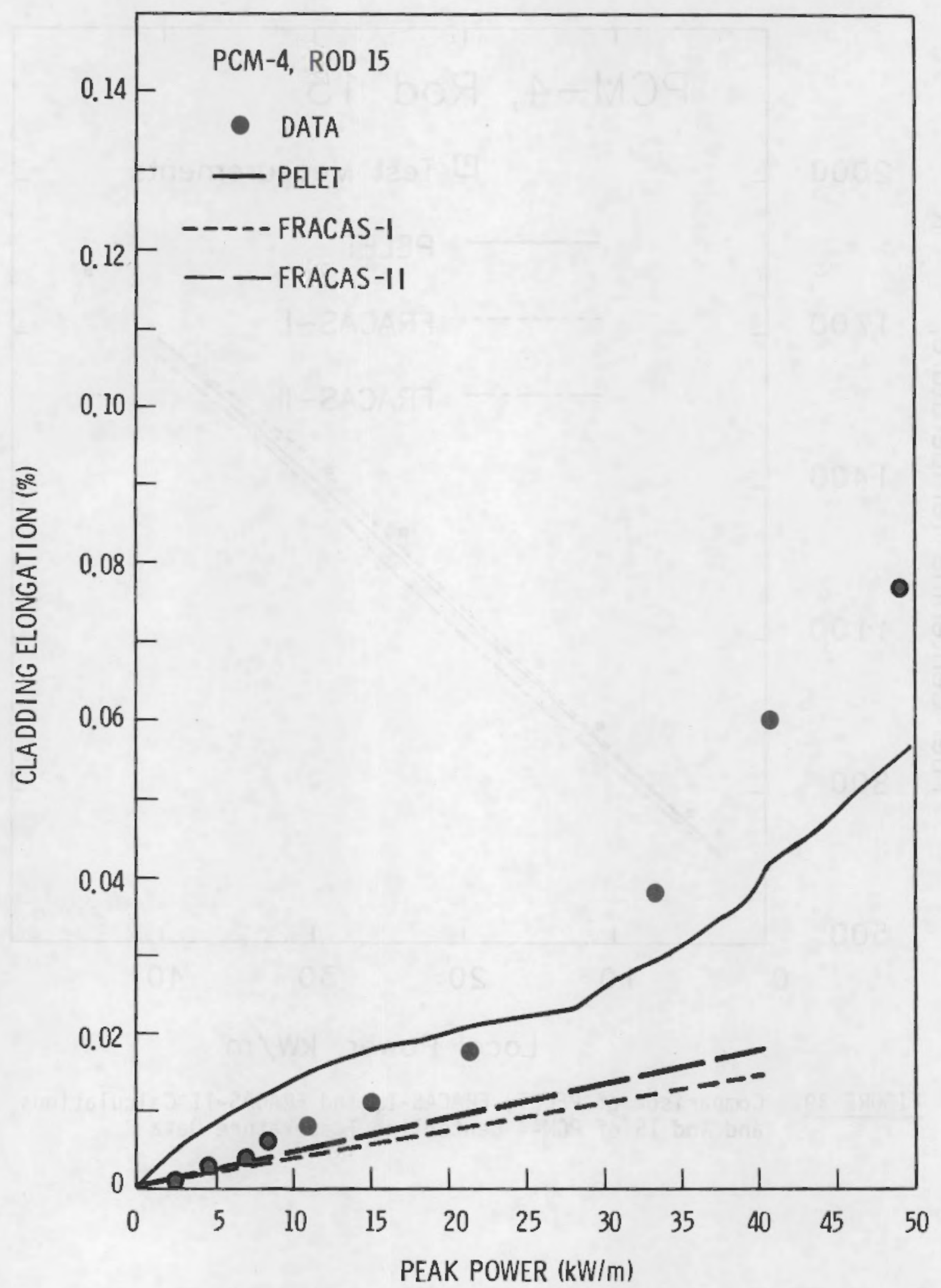

FIGURE 40. Calculated and Measured Cladding Elongation Versus Peak Rod Power for Rod 15 of PCM-4 Using FRAPCON-2 with PELET, FRACAS-I, and FRACAS-II 


\subsubsection{Discussion of Cladding Deformation Results}

With respect to the onset of fuel-cladding axial interaction at $\mathrm{BOL}$, the PELET option clearly evidenced the best agreement to data, followed by FRACAS-II, and then by FRACAS-I. The same ranking applies to the incremental severity of axial interaction (i.e., the slope of the BOL axial elongation versus power curve). These conments apply categorically to all four rods examined above.

With respect to the "rod-averaged diametral strain" reported at BOL for IFA-508 rods, the situation is not so clear. FRACAS-II does the best overall job for magnitude and incremental severity; FRACAS-I undercalculates the onset of radial interaction and overcalculates the severity of it. PELET is generally correct for the onset and severity of radial interaction but overcalculates the magnitude, quite possibly because it has no fuel relaxation built into its models.

Finally, with respect to the apparent relaxation of the interactions, FRACAS does an excellent job of calculating both the magnitude and speed of relaxation. This is not too clear in the IFA-508 cases, but it is shown dramatically in the rod 3, IFA-431 case (see Figure 36).

For these helium-filled, low-burnup, low-resistance rods, all three mechanical options fed back adequately to the thermal models as evidenced by the close match to centerline temperature data.

\subsection{FISSION GAS AND BURNUP EFFECTS}

The major thermal effect of burnup is of ten the production and release of fission gas, which degrades the thermal conductivity of the helium fill gas and consequently increases fuel thermal resistance. This effect is manifested more strongly in unpressurized BWR rods than in pressurized PWR rods because the initial helium inventory is at least 15 times greater (see Figures 41 and 42). At all burnups fuel temperatures increase with increasing power, but the thermal resistance varies from nominal values at low burnup ( 25 to $30 \mathrm{~K}-\mathrm{m} / \mathrm{kW}$ ) to very high values at high burnup $(40$ to $60 \mathrm{~K}-\mathrm{m} / \mathrm{kW}$ ) in a fission gas-saturated BWR rod. 


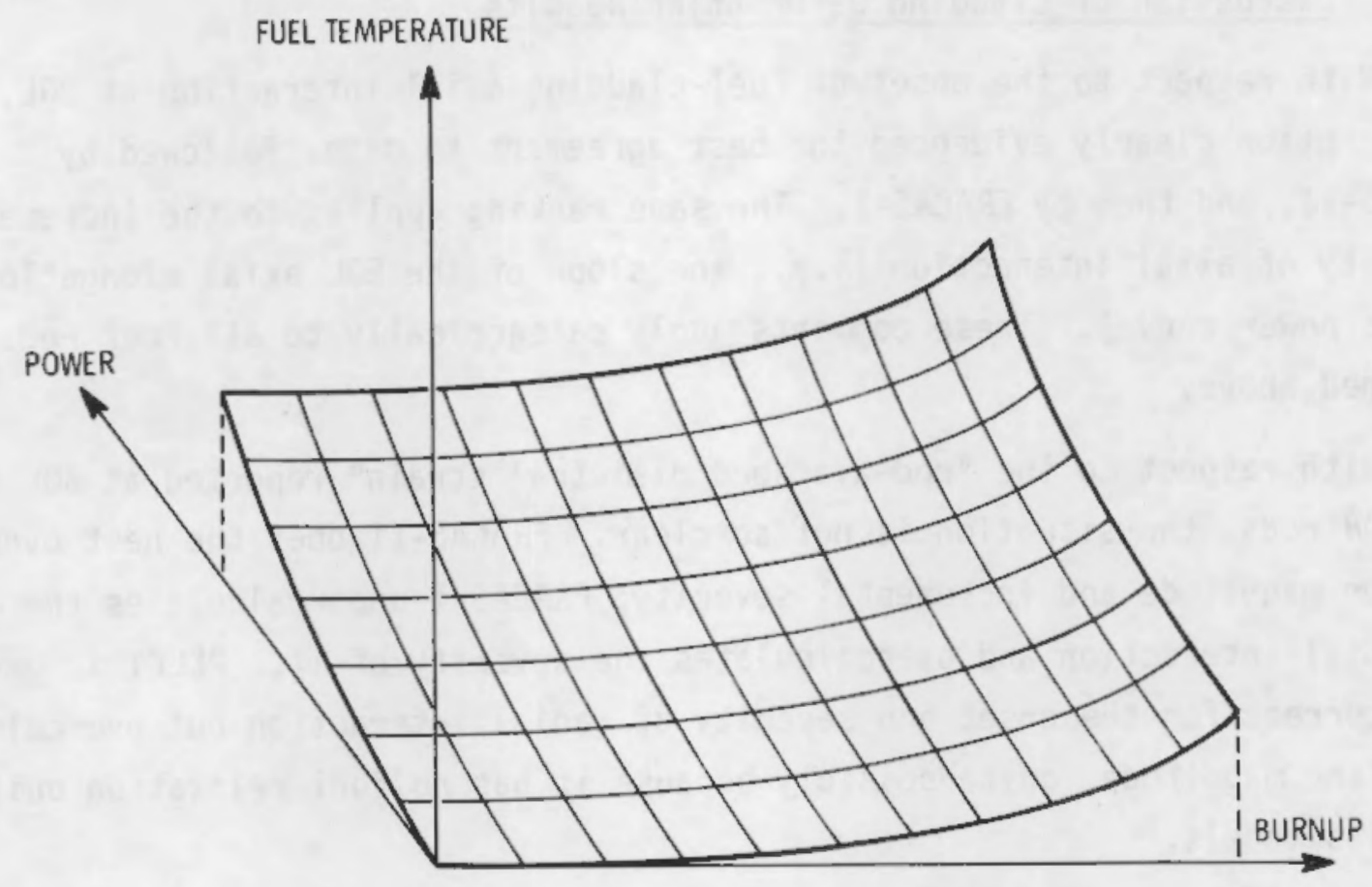

BWR DESIGN FUEL ROD

FIGURE 41. Representation of Burnup Effects Upon Fuel Temperatures for an Unpressurized BWR Rod

FUEL TEMPERATURE

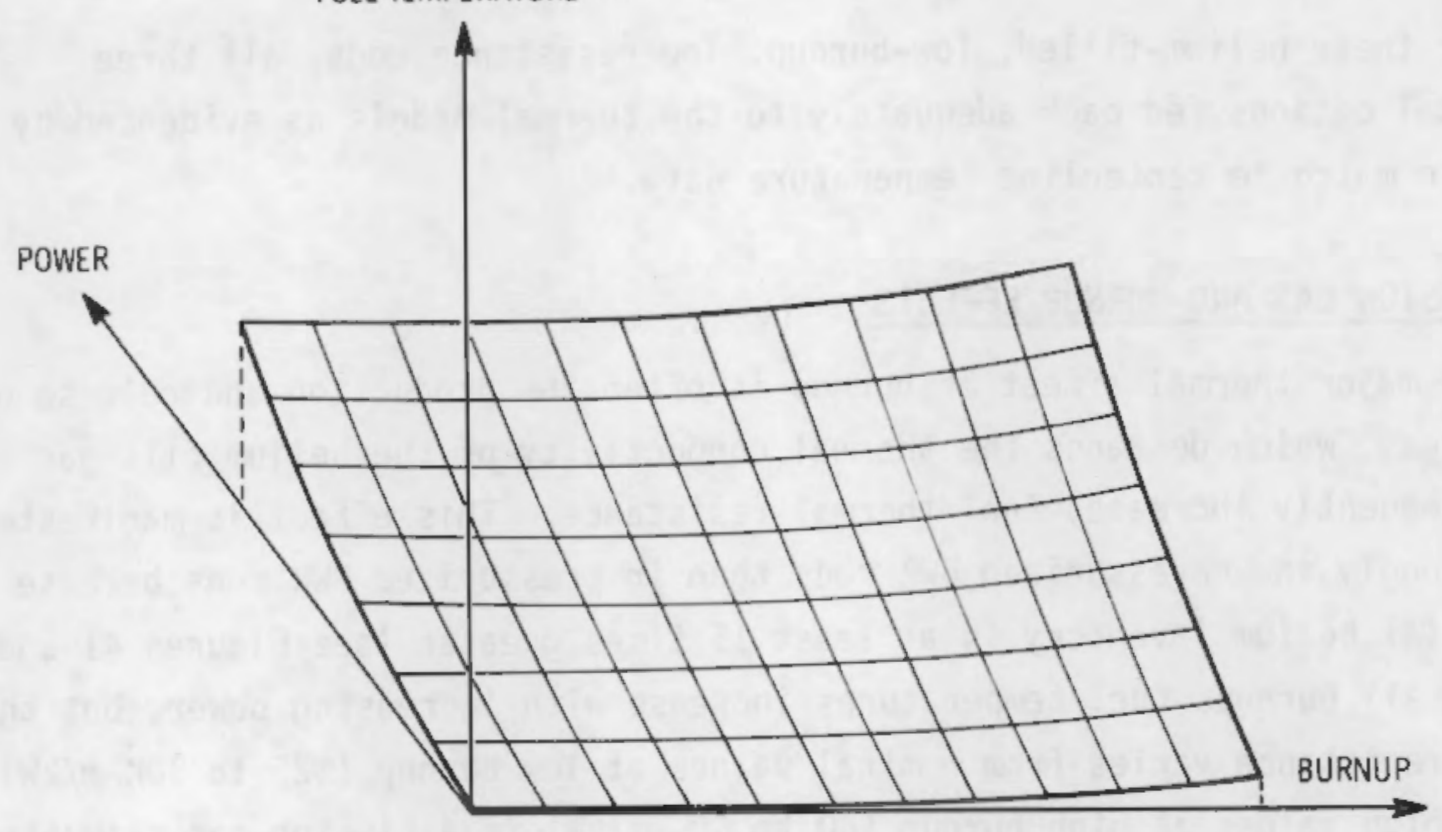

PWR DESIGN FUEL ROD

FIGURE 42. Representation of Burnup Effects Upon Fuel Temperatures for a Pressurized PWR Rod 
The field of burnup and power thus may be divided into at least four subregions each for both pressurized and unpressurized rods: 1ow burnup/low power; low burnup/high power; high burnup/low power; and high burnup/high power. The cases examined in this section apply to the three most interesting of these eight subregions: low burnup/high power (unpressurized); high burnup/ high power (unpressurized); and high burnup/low power (pressurized). In all cases, variables of interest will be fission gas release and fuel temperatures; and where possible, the cladding creepdown (because of its feedback to fuel temperatures and potential significance to fuel failure in overpower) will also be examined.

Fuel cracking, fuel densification, and fuel swelling are other burnupdependent effects that are implicitly present in the fuel temperature data (and are explicitly accounted for in the code options). However, because explicit comparison of code calculations to data is not possible for the cases examined, these effects will not be discussed.

\subsubsection{Comparison of Code Calculations to Data from the Studsvik S150 Experiment (a)}

The Studsvik 5150 experiment ${ }^{(27)}$ was conducted at high power and provided high-temperature gas release data for a short time period. A four-rod cluster of instrumented BWR-sized rods were irradiated in the $R 2$ reactor at Studsvik, Sweden. The peak linear power was about $66 \mathrm{~kW} / \mathrm{m}$ at the final burnup of approximately $4.4 \mathrm{GWd} / \mathrm{MTU}$. Rod 11 was a nominal-gap rod with a fuel centerline thermocouple in the top of the fuel (first $0.0508 \mathrm{~m}$ ). The cladding had a 0.01226-m OD and a 0.01068-m ID with a diametral fuel-cladding gap of $200 \mu \mathrm{m}$. The fuel consisted of dished $94.4 \% \mathrm{TD} \mathrm{UO}_{2}$ pellets, and the total fuel length was $0.523 \mathrm{~m}$. The fill gas was helium at a pressure of $0.1 \mathrm{MPa}$ at $293 \mathrm{~K}$.

The Studsvik reactor provides typical BWR conditions of $8-\mathrm{MPa}$ coolant pressure and $529 \mathrm{~K}$ coolant temperature. The axial flux shape was skewed and

(a) Low-burnup/high-power BWR rod. 
essentially maintained throughout the irradiation (see Figure 43). Unfortunately, the centerline thermocouple was located in the high flux gradient end of the rod, and the ratio of local power to average power at the thermocouple tip was sensitive to control rod movements throughout the irradiation. Fast flux is quoted as $1.4 \times 10^{15} \mathrm{n} / \mathrm{m}-\mathrm{s}$ per $\mathrm{kW} / \mathrm{m}$.

Quoted uncertainty for the thermocouple reading was $\pm 5 \%$. The method of power determination and its uncertainty are not discussed in Reference 27.

The detailed power history is shown in Figure 44 . The reader should note the variability of the local power at the thermocouple relative to the rod average power as compared with the fairly constant ratio of peak-to-average power.

Rather than defining eight axial profiles to describe the power history, one representative profile has been defined that represents the peak-to-average power ratio. Specific comparison with measured fuel centerline temperatures may be made by interpolation and extrapolation of the calculated axial dependent temperature profile, given the current local value of power that should be associated with a particular thermocouple reading. Input peak power closely matches the curve in Figure 44.

Profilometry of this rod has shown positive permanent (hoop) strains, indicating PCMI. Therefore, both the FRACAS-II and PELET mechanical options as well as both the MacDonald-Weisman and Beyer-Hann gas release models were compared with experimental data.

Figure 45 shows measured and calculated fuel centerline temperature versus burnup from the thermocouple located at the top of the rod. The error bars correspond to an estimated power uncertainty of $\pm 10 \%$. Measured and calculated gas release fractions and the inferred and calculated lifetime peak fuel centerline temperatures are also shown. These temperatures were inferred from the microstructure observed in the postirradiation examination (PIE) metallographic section taken near the rod center. 


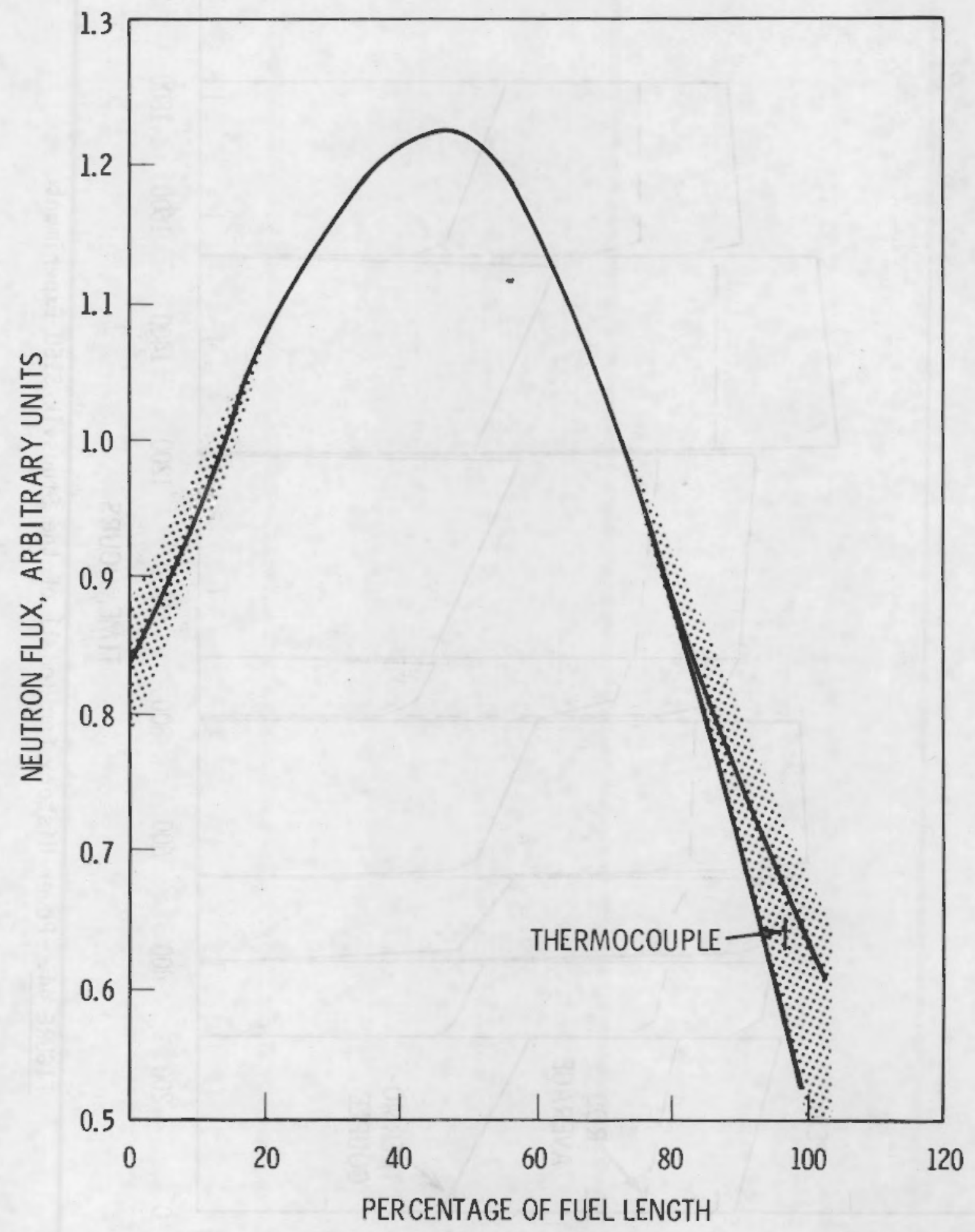

FIGURE 43. Axial Flux Variation for the Studsvik S150 Experiment 


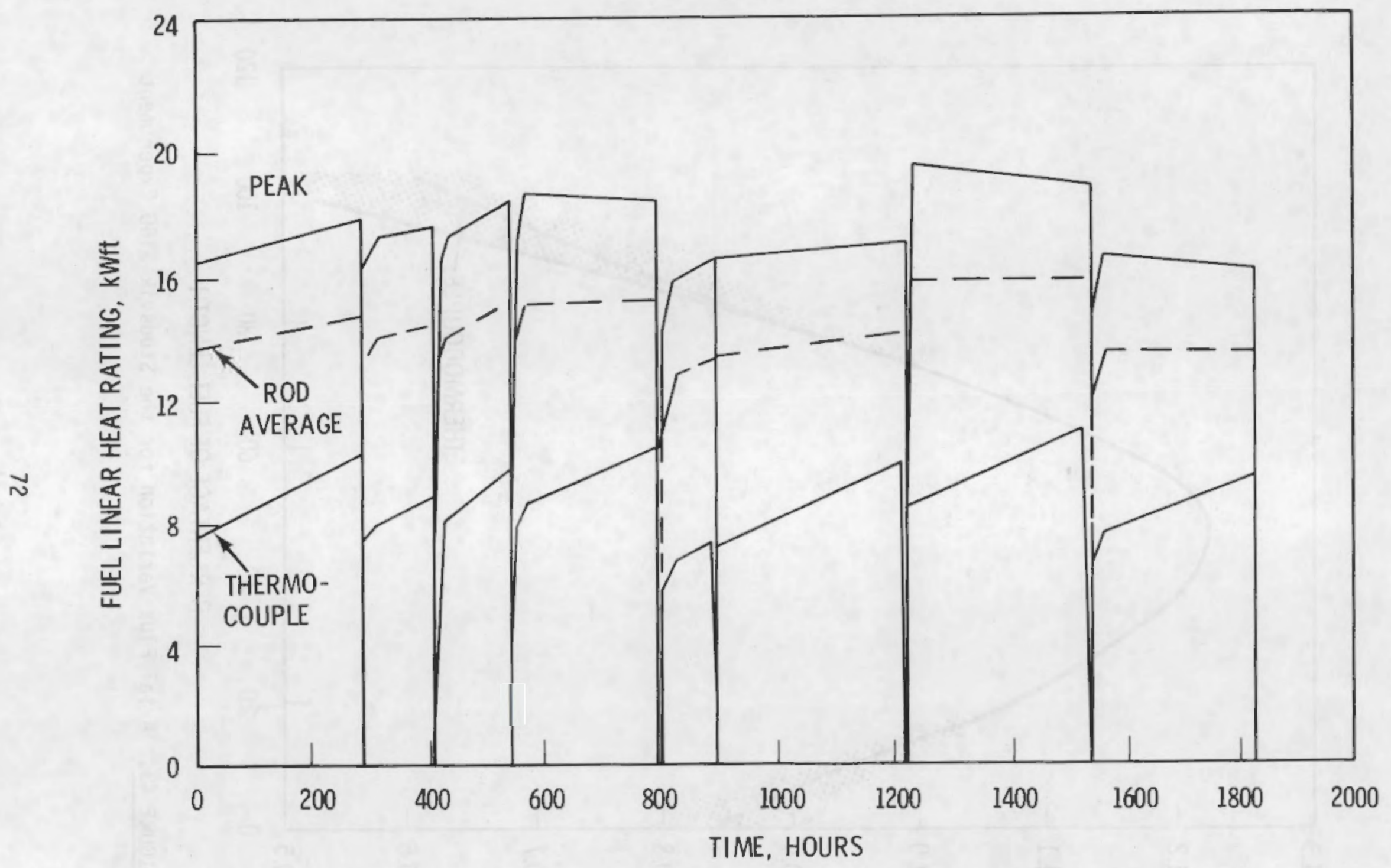

FIGURE 44. Power History for Rod 11 of the Studsvik S150 Experiment 


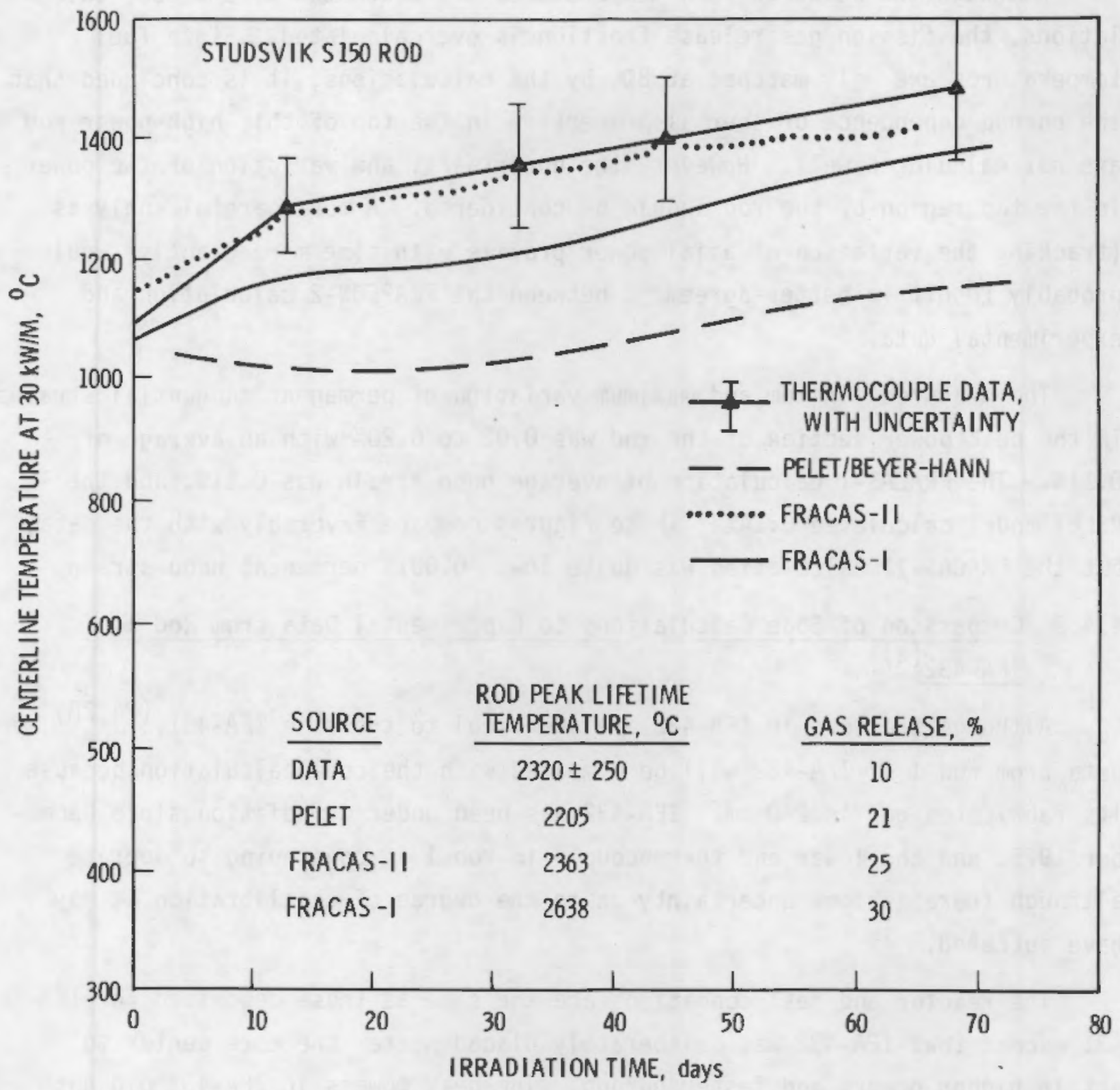

FIGURE 45. Measured and Calculated Fuel Centerline Temperature and Gas Release for Rod 11 of the S150 Experiment Using PELET, FRACAS-1, and FRACAS-II 
Although the measured fuel temperatures are bracketed by the code calculations, the fission gas release fraction is overcalculated. Since fuel temperatures are well matched at BOL by the calculations, it is concluded that the burnup dependence of thermal properties in the top of this high-power rod are not calculated well. However, the uncertainty and variation of the power in the top region of the rod should be considered. A more careful analys is (tracking the variation of axial power profile with time more exactly) would probably result in better agreement between the FRAPCON-2 calculation and experimenta 1 data.

The measured minimum and maximum variation of permanent tangential strains in the peak power section of the rod was 0.02 to $0.20 \%$ with an average of $0.11 \%$. The FRACAS-I calculation of average hoop strain was $0.11 \%$, and the PELET model calculated $0.14 \%$. These figures compare favorably with the data, but the FRACAS-II calculation was quite low: $0.001 \%$ permanent hoop strain.

\subsubsection{Comparison of Code Calculations to Experimental Data from Rod 1 of IFA-432 $^{(a)}$}

Although the rods in IFA-432 are identical to those in IFA-431, $(24,28)$ data from rod 1 of IFA-432 will be compared with the code calculation because its fabricated gap is $230 \mathrm{~mm}$. IFA-432 has been under irradiation since December 1975, and the lower end thermocouple in rod 1 is continuing to operate although there is some uncertainty as to the degree of decalibration it may have suffered.

The reactor and test conditions are the same as those described for IFA431 except that IFA-432 was deliberately placed nearer the core center to attain higher powers and faster burnup. The peak powers in IFA-431 did not exceed $39 \mathrm{~kW} / \mathrm{m}$; in IFA-432, peak powers slightly exceeded $50 \mathrm{~kW} / \mathrm{m}$.

(a) High-burnup/high-power BWR rod. 
The instrumentation for rod 1 of IFA-432 is the same as that described for rod 3 of IFA-431. In addition, rod 1 had a null balance pressure gauge so that measurements of internal gas pressure could be made during shutdowns and correlated to fission gas release. An analysis of the errors and uncertainties in this correlation is discussed in Reference 16.

The power history for rod 1 is shown in Figure 46. Peak and local (lower thermocouple site) powers are plotted versus rod-averaged burnup. The peak burnup attained at the end of the recorded history is estimated to be $28.3 \mathrm{GWd} /$ MTU. The input power history is shown relative to the actual power history in Figure 46. Deviations below the average power are not explicitly

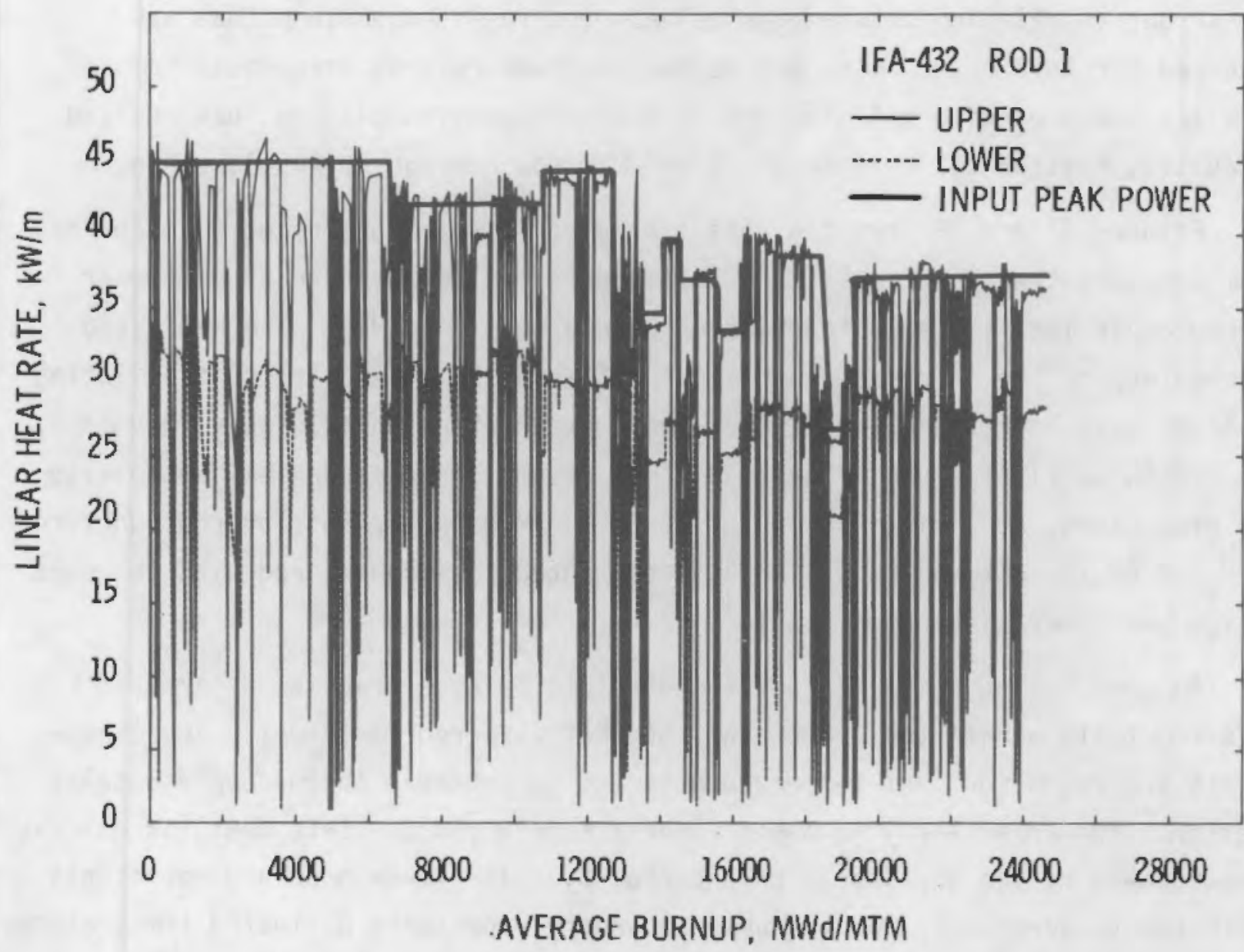

FIGURE 46. Power History for Rod 1 of IFA-432 Using PELET, FRACAS-I, and FRACAS-II 
modeled, but significant deviations above the average (even of short duration) are explicitly modeled since these affect fission gas release.

Axial elongation for this rod was most significant early in life, and the majority of the irradiation yields significant data on fission gas release correlated with fuel centerline temperature. Therefore, a variety of gas release models, including MacDonald-Weisman, Beyer-Hann, and ANS 5.4, were used. Since the fuel was the same type as in $\operatorname{rod} 3$ of IFA-431, terminal density was again set at $95 \%$ TD.

Measured centerline temperatures and gas release data from rod 1 of IFA432 are shown in Figures 47 and 48 . The data are presented first to emphasize the strong correlation between gas release and fuel temperature that was observed for this rod. Then, the centerline temperatures throughout the rod life are compared with calculations, and the comparison between inferred and calculated fission gas release at $23 \mathrm{GWd} / M T U$ rod average burnup is shown.

Figures 47 and 48 show the data trends for fission gas release (inferred from pressure transducer data) and fuel centerline temperature at the lower thermocouple location as a function of burnup to 23 GWd/MTU. The indicated uncertainty of the inferred gas release reflects the difficulty of translating pressure data to release rate, given the uncertainties in initial void volume, gas pressure, fission gas production, fuel volume changes, and helium leakage and production, etc. The data point at $23 \mathrm{GWd} / \mathrm{MTU}$ is a result of rod puncture on rod 8 of IFA-432, which was an uninstrumented replacement rod with the same design and power history as rod 1.

An encouraging point is that the absolute release fraction determined for this rod falls within the uncertainty of that inferred for rod 1 . The uncertainty indicated for fuel temperature is due to possible themocouple decalibration. The uncertainty in power (approximately $\pm 5 \%$ for this test) is quickly overshadowed by the decalibration uncertainty. The lower boundary represents indicated temperatures, and the upper boundary represents estimated temperatures assuming a burnup-dependent decalibration of $1 \%$ per GWd/MTU (the magnitude of the estimated transmutation-induced decalibration of the tungsten-rhenium thermocouples). 


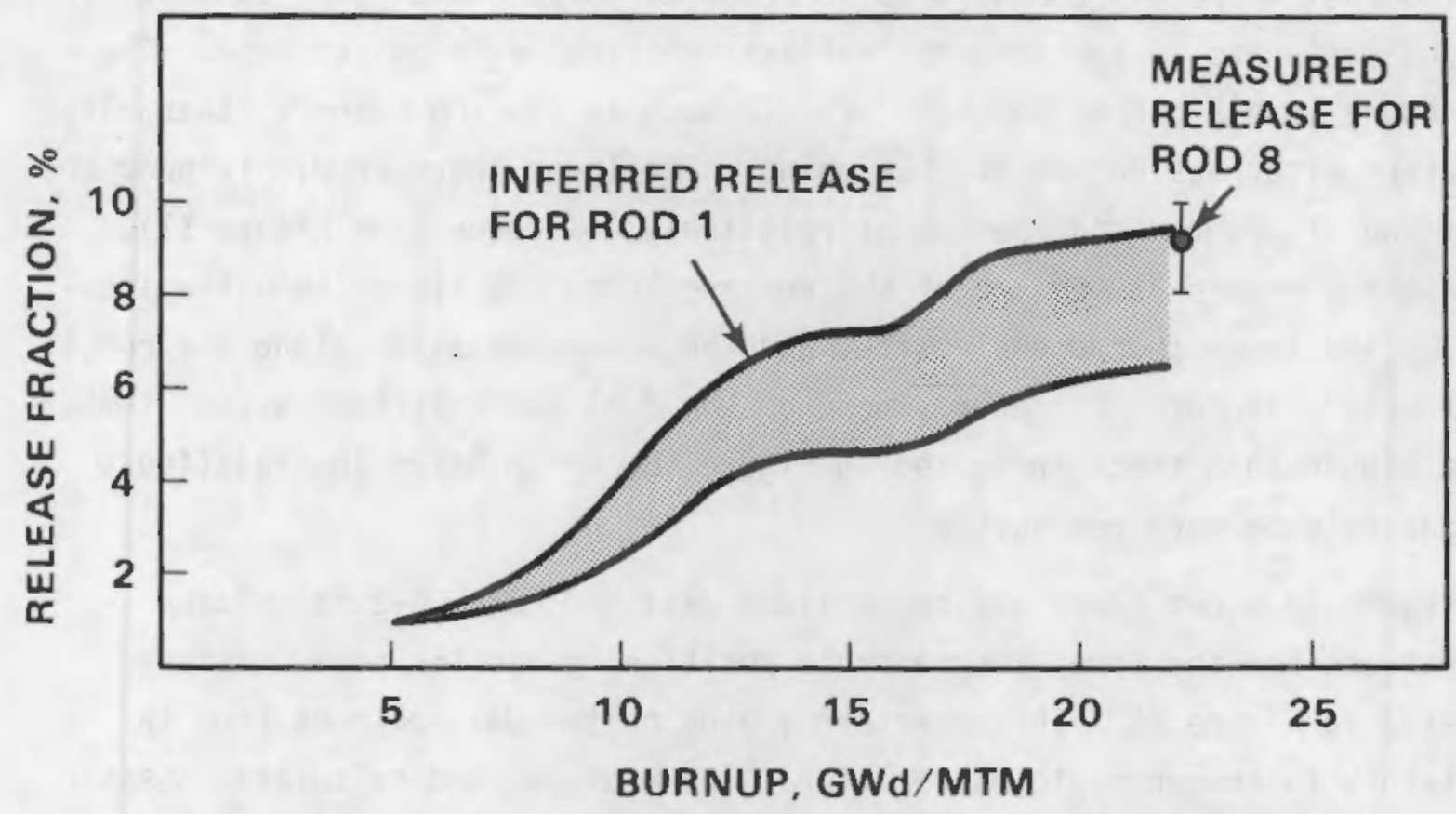

FIGURE 47. Inferred Gas Release for Rod 1 of IFA-432

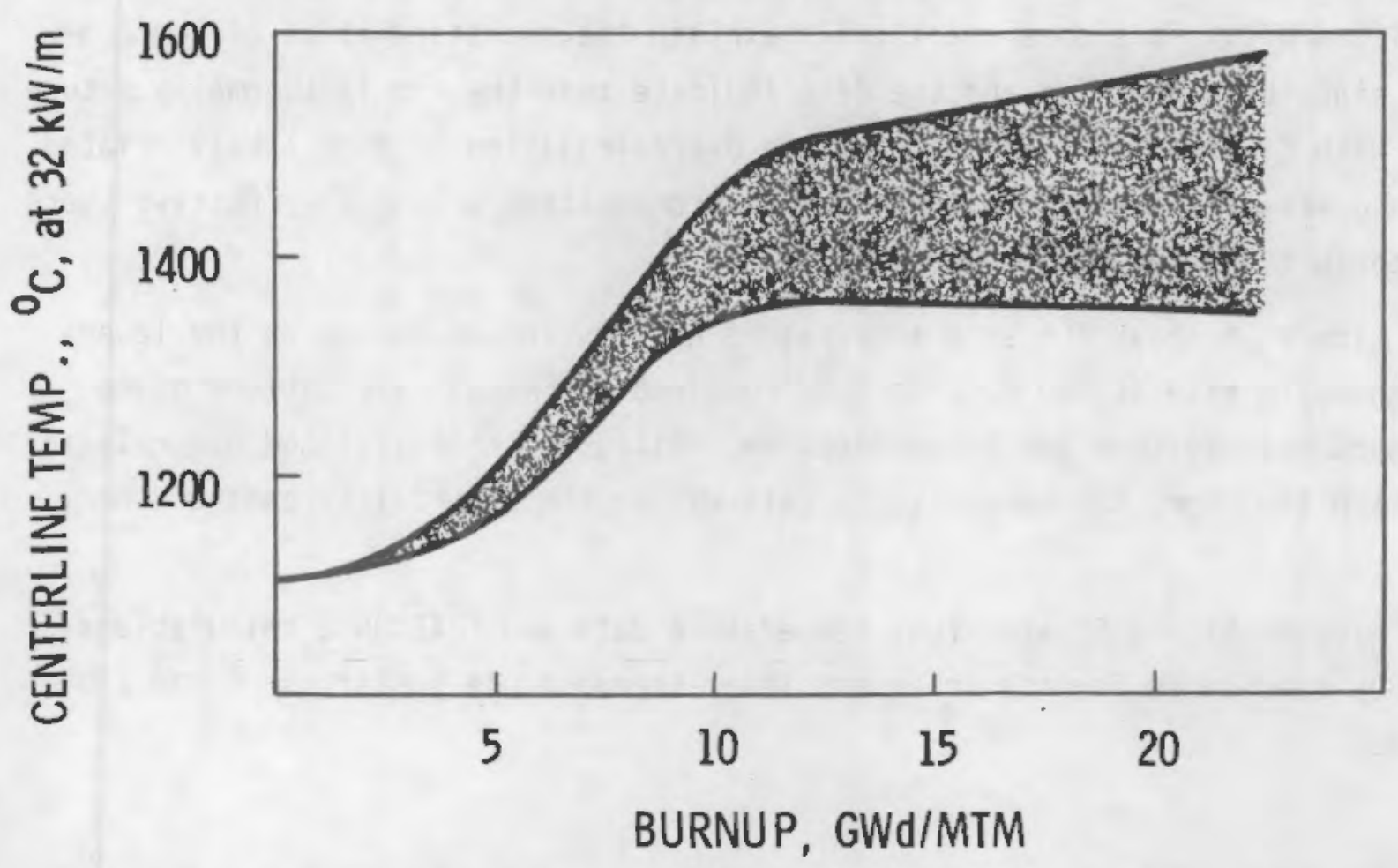

FIGURE 48. Measured Fuel Centerline Temperature at Constant Power for the Lower Thermocouple Location of Rod 1 of IFA-432 
The fuel temperature begins to increase at approximately the same burnup that the gas pressure and inferred release fraction begin to increase. The temperature levels off at about $10 \mathrm{GWd} / \mathrm{MTU}$ because the rod becomes "thermally saturated" with fission gas at that point. The lower thermocouple is near the bottom end of the rod and, hence, at relatively low power (see figure 31). The peak rod powers at the top of the rod are 30 to $50 \%$ higher than the local power at the lower thermocouple site, and the power variation along the rod is approximately linear. Therefore, most of the fuel rod experiences fuel temperatures higher than those indicated in Figure 48, which makes the relatively high gas release more reasonable.

Figure 49 shows power and temperature data and FRAPCON-2 calculated temperatures for the lower thermocouple position, given the power history indicated in Figure 46. The uncertainty band on the data accrues from the uncertainty in thermocouple calibration. The measured and calculated fission gas release fractions are indicated in figure 49. As shown, PELET/RADIAL, using the Beyer-Hann gas release model, somewhat overcalculates the gas release at $23 \mathrm{GWd} / \mathrm{MTU}$. This does not totally explain the overcalculation of temperature since both the code and the data indicate that the rod is thermally saturated with fission gas. The temperature overcalculation is more likely related to an overestimation of the effect of gas composition upon fuel-effective thermal conductivity at high burnup.

Figure 50 shows the same temperature history versus burnup at the lower thermocouple site of rod 1 , this time compared to FRACAS calculations using the MacDonald-Weisman gas release option. Although the calculated gas release was also too high, the temperatures fall within the uncertainty band of the data.

Figures 51 and 52 show fuel temperature data and FRAPCON-2 calculations for BOL conditions for the upper and lower thenmocouple positions of rod 1 of IFA-432. 


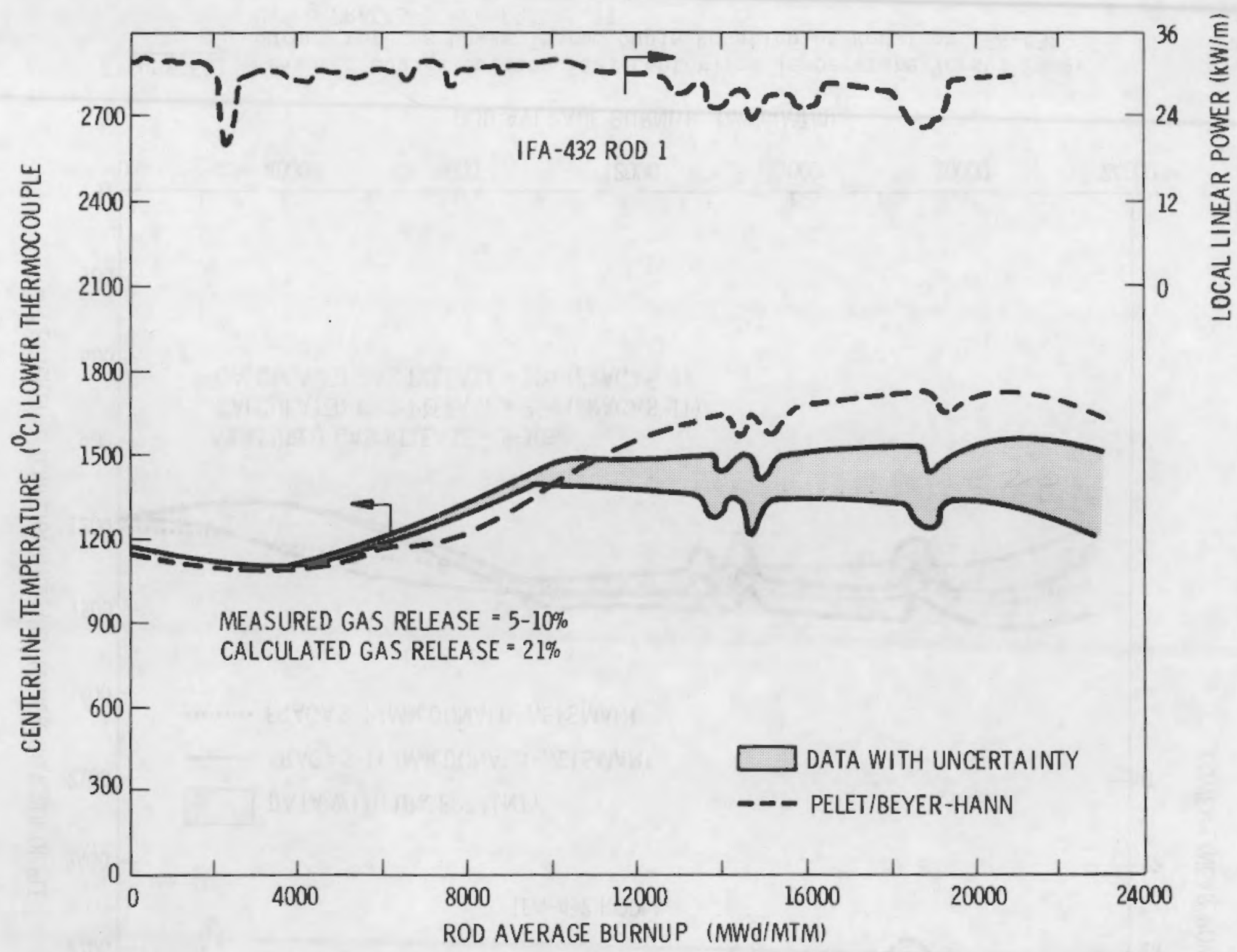

FIGURE 49. Measured and Calculated Fuel Centerline Temperature Versus Burnup for the Lower Thermocouple Location of Rod 1 of IFA-432 Using PELET 


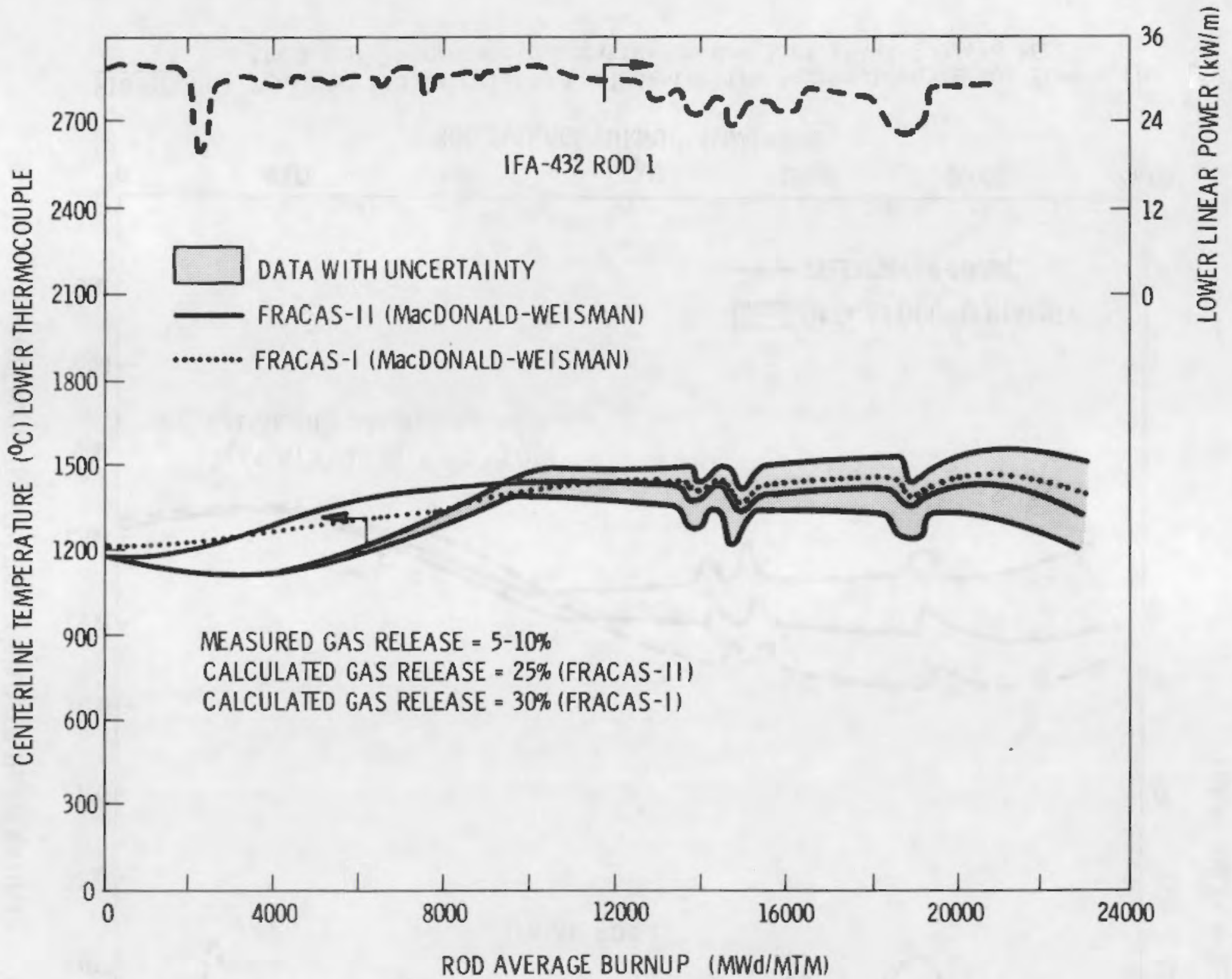

FIGURE 50. Measured and Calculated Fuel Centerline Temperature Versus Power Burnup for the Lower Thermocouple Location of Rod 1 of IFA-432 Using FRACAS-I and FRACAS-II 


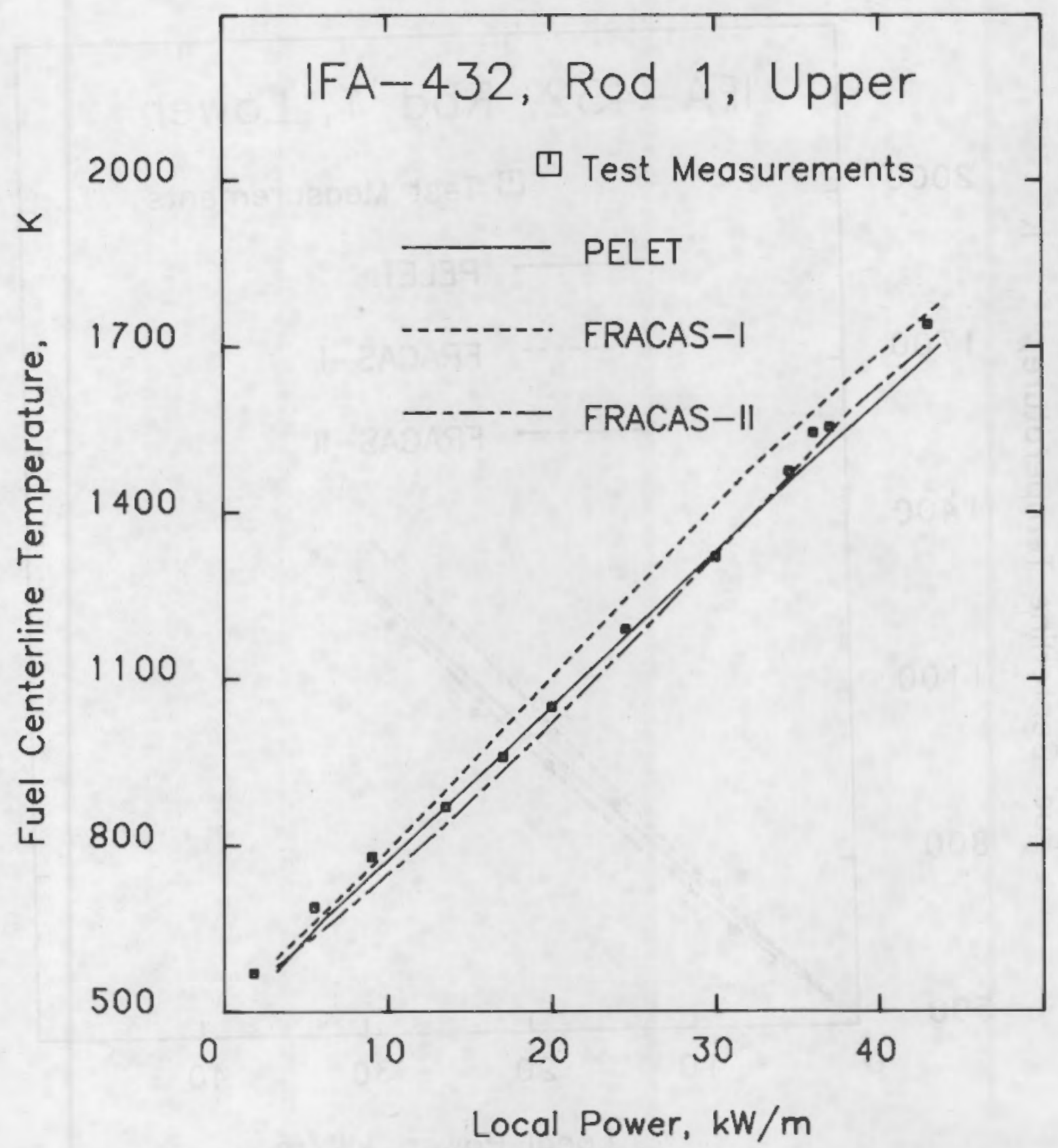

FIGURE 51. Comparison of PELET, FRACAS-I, and FRACAS-II Calculations with Rod 1 of IFA-432 Centerline Temperature Data (upper thermocouple) 


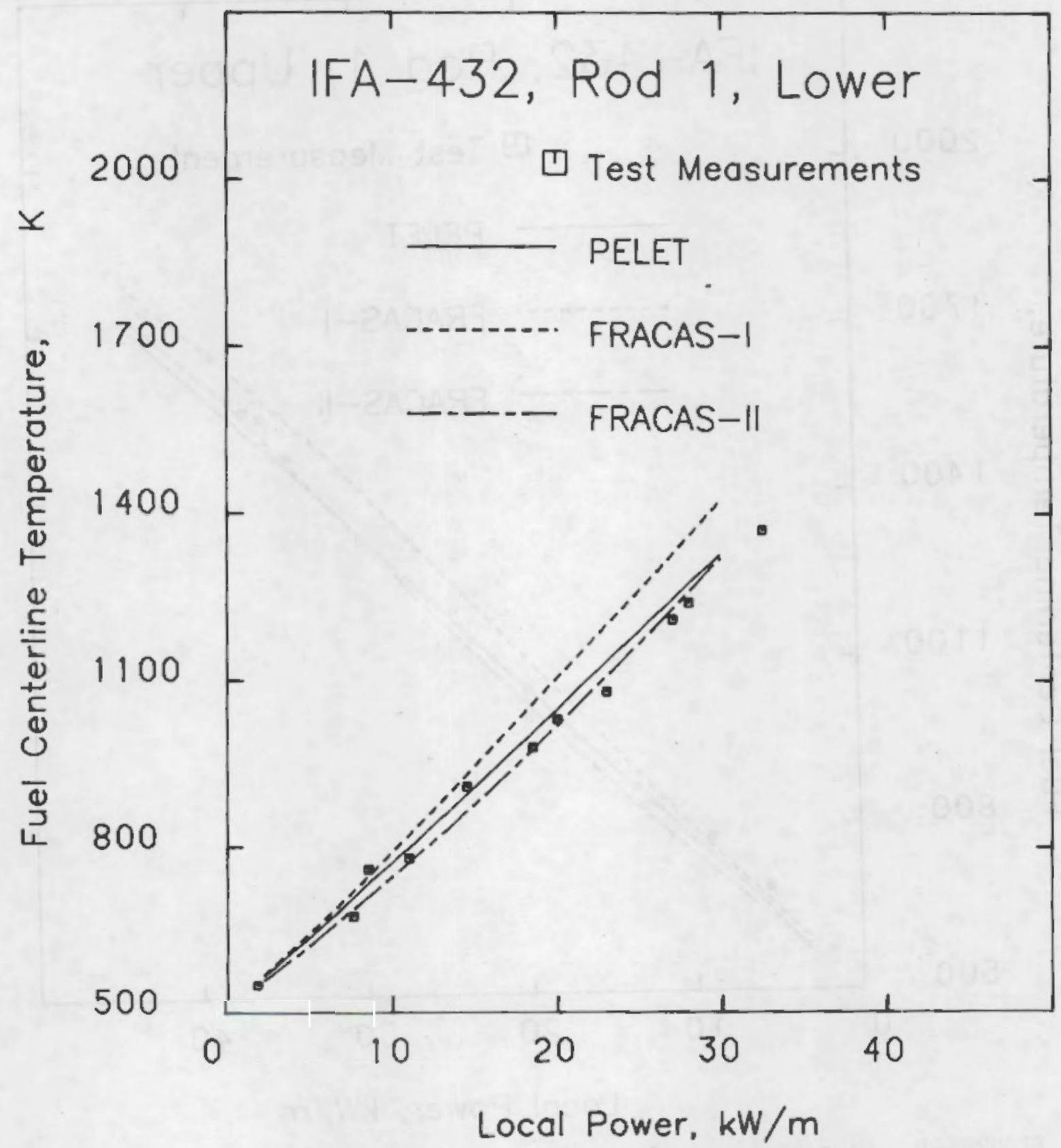

FIGURE 52. Comparison of PELET, FRACAS-I, and FRACAS-II Calculations with Rod 1 of IFA-432 Centerline Temperature Data (lower thermocouple) 
At the upper thermocouple (Figure 51), all three code options calculated temperature versus power acceptably well. At the lower thermocouple, however, the FRACAS-I calculation was $100 \mathrm{~K}$ conservative at $30 \mathrm{~kW} / \mathrm{m}$ while FRACAS-II and PELET calculations agreed well with the data.

\subsubsection{Comparison of Code Calculations to Experimental Data from Rod K-4 of H. B. Robinson Assembly $\mathrm{BOS}^{\text {(a) }}$}

Certain rods from the H. B. Robinson (Unit 2) PWR were selected for axial gas flow experiments. (29) Gas release profilometry, burnup, and power data are available for these rods, which attained 28 GWd/MTU average burnup from 1971 to 1974. Rod K-4, which was selected for simulation, represents a commercial PWR rod in both design and operation and has typical PWR dimensions: 2.86-m fuel length, Zircaloy-4 cladding with a $0.0107-\mathrm{m} 00$ and a $0.00946-\mathrm{m}$ ID, and a $165-\mu \mathrm{m}$ diametral gap. The pellets were dished $92 \% \mathrm{TO}_{2} \mathrm{UO}_{2}$ with an enrichment of $3.1 \%$. The fill gas was helium at a pressure of $1.5 \mathrm{MPa}$ at $293 \mathrm{~K}$.

Standard PWR coolant conditions are assumed (15 MPa pressure and 561K inlet temperature). The BOL axial flux shape is shown in Figure 53 . The fast flux is about $2 \times 10^{15} \mathrm{n} / \mathrm{m}$-s per $\mathrm{kW} / \mathrm{m}$, as derived from activation of cladding samples.

The assembly power history is given in Table 11 on a month-by-month basis. Note that the axial profile at EOL is much flatter than at BOL (compare Figures 53 and 54 ). The $\mathrm{BOL}$ axial profile is applied throughout the first 200 days of irradiation, and an average power profile $e^{(29)}$ is used thereafter. Figure 55 shows actial and input peak power histories.

EOL profilometry did not indicate strong PCMI in the H. B. Robinson rods. The cladding had ovalized slightly and the average diameter had reduced 50 to 100 microns; both the Beyer-Hann and MacDonald-Weisman models were run for this case.

(a) High-burnup/low-power PWR rod. 
TABLE 11. H. B. Robinson Assembly B05 Power History

\begin{tabular}{|c|c|c|c|}
\hline Date & Average & Peak & EFPD (a) \\
\hline $\begin{array}{l}\text { Oct. } 1971 \\
\text { Nov. } 1971 \\
\text { Dec. } 1971 \\
\text { Jan. } 1972 \\
\text { Feb. } 1972 \\
\text { Mar. } 1972 \\
\text { Apr. } 1972 \\
\text { May } 1972 \\
\text { June } 1972 \\
\text { July } 1972 \\
\text { Aug. } 1972 \\
\text { Sep. } 1972 \\
\text { Oct. } 1972 \\
\text { Nov. } 1972 \\
\text { Dec. } 1972 \\
\text { Jan. } 1973 \\
\text { Feb. } 1973 \\
\text { Mar. } 1973\end{array}$ & $\begin{array}{l}229.15 \\
228.62 \\
233.05 \\
237.58 \\
239.32 \\
228.85 \\
229.15 \\
224.75 \\
224.75 \\
226.62 \\
215.89 \\
212.97 \\
214.71 \\
207.65 \\
204.41 \\
213.72 \\
218.48 \\
200.50\end{array}$ & $\begin{array}{l}312.55 \\
316.91 \\
326.52 \\
313.20 \\
311.27 \\
285.54 \\
292.40 \\
285.81 \\
285.81 \\
283.02 \\
271.24 \\
256.48 \\
275.08 \\
273.31 \\
269.96 \\
268.68 \\
278.98 \\
263.66\end{array}$ & $\begin{array}{r}95.7 \\
120.0 \\
149.7 \\
177.2 \\
205.2 \\
235.5 \\
265.2 \\
270.7 \\
289.5 \\
312.6 \\
341.2 \\
369.0 \\
398.6 \\
423.6 \\
443.9 \\
460.4 \\
475.7 \\
487.2\end{array}$ \\
\hline Date & \multicolumn{3}{|c|}{ Cycle 2 Power, W/cm } \\
\hline $\begin{array}{ll}\text { May } & 1973 \\
\text { June } & 1973 \\
\text { July } & 1973 \\
\text { Aug. } 1973 \\
\text { Sep. } 1973 \\
\text { Oct. } 1973 \\
\text { Nov. } 1973 \\
\text { Dec. } 1973 \\
\text { Jan. } 1974 \\
\text { Feb. } 1974 \\
\text { Mar. } 1974 \\
\text { Apr. } 1974 \\
\text { May } & 1974\end{array}$ & $\begin{array}{l}177.57 \\
168.51 \\
182.85 \\
184.36 \\
178.75 \\
172.68 \\
174.61 \\
175.73 \\
176.65 \\
176.03 \\
175.50 \\
175.50 \\
175.07\end{array}$ & $\begin{array}{l}228.88 \\
215.40 \\
240.56 \\
244.34 \\
231.38 \\
227.11 \\
219.11 \\
222.25 \\
222.55 \\
221.01 \\
219.20 \\
219.17 \\
211.72\end{array}$ & $\begin{array}{r}6.5 \\
25.4 \\
58.8 \\
87.6 \\
116.6 \\
145.2 \\
166.2 \\
192.6 \\
221.2 \\
247.8 \\
278.1 \\
307.2 \\
311.8\end{array}$ \\
\hline
\end{tabular}

(a) Effective full-power days. 


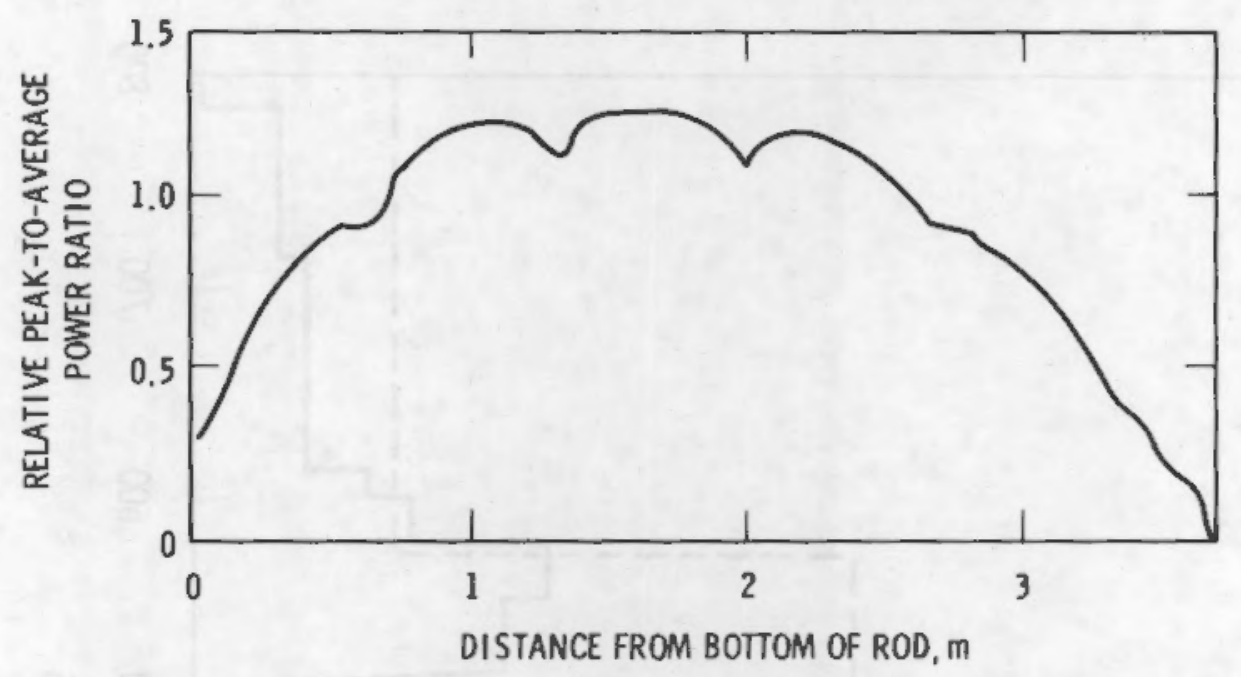

FIGURE 53. Beginning-of-Life Axial Power Profile for Assembly B05 from the H. B. Robinson Reactor

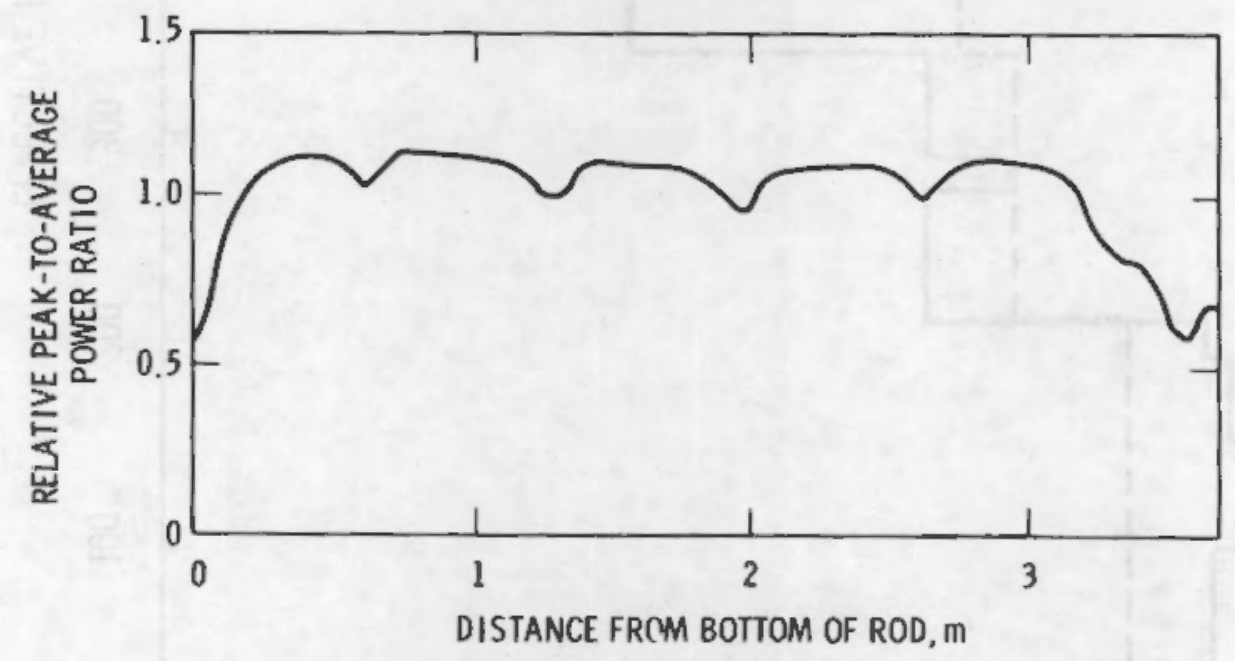

FIGURE 54. End-of-Life Axial Power Profile for Assembly B05 from the H. B. Robinson Reactor 


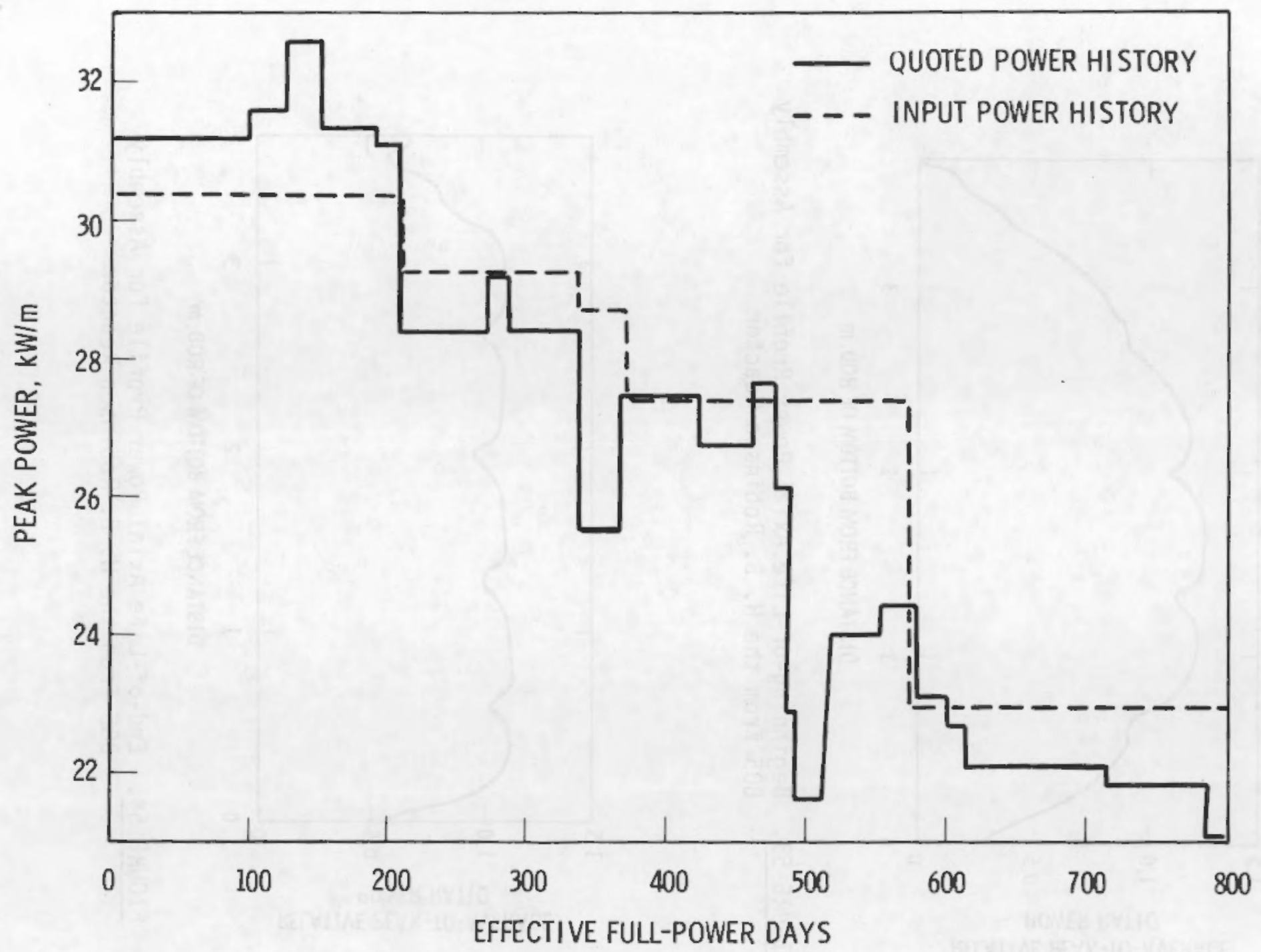

FIGURE 55. Input and Actual Power Histories for H. B. Robinson PWR Rod 
Since rod K-4 was uninstrumented, there is no measured temperature history. The calculated centerline and fuel surface temperatures are shown in Figure 56 for reference. Metallography for this rod showed no significant grain growth even in the peak power region--an observation that supports the calculation that the centerline temperature did not exceed 1573 to $1673 \mathrm{~K}$.

The observed fission gas release for this rod was $0.2 \%$. The PELET/BeyerHann combination calculated a $1 \%$ release; FRACAS-I/MacDonald-Weisman, a $4.9 \%$ release; and FRACAS-II/MacDonald-Weisman, a $2.9 \%$ gas release.

Cladding creep was observed to be a 50 - to 100 -micron reduction in diameter. FRACAS-I results were within the data with a negative creep strain of about 60 microns while FRACAS-II and PELET both calculated very simall negative strains (on the order of 1 micron).

\subsubsection{Discussion of Burnup Effects}

All code options tended to overcalculate the measured gas release for the cases studied. This occurred even for those cases where measured centerline temperatures were not overcalculated. This does not necessarily point to basic conservatism in the gas release models however, for in neither of the high gas release cases (Studsvik rod and rod 1 of IFA-432) was the measured fuel temperature representative of the peak fuel temperatures in the rod, which tend to dominate in gas release.

of the options presented, the FRACAS options tracked the through-life measured fuel temperatures more reasonably, whereas the Beyer-Hann gas release results were closer to the data. The ANS 5.4 option was also run in conjunction with the PELET option for rod 1 of IFA-432 with the following results:

Gas Release

End-of-Life Fuel Temperature in Thermocouple Region at $27 \mathrm{~kW} / \mathrm{m}$

$\begin{array}{ll}\frac{\text { ANS } 5.4}{31 \%} & \frac{\text { Data }}{10 \%} \\ 1450^{\circ} \mathrm{C} & 1350^{\circ} \mathrm{C}\end{array}$

Again the measured gas release was overcalculated even though the measured centerline temperature in the themocouple region was not badly overcalculated. 


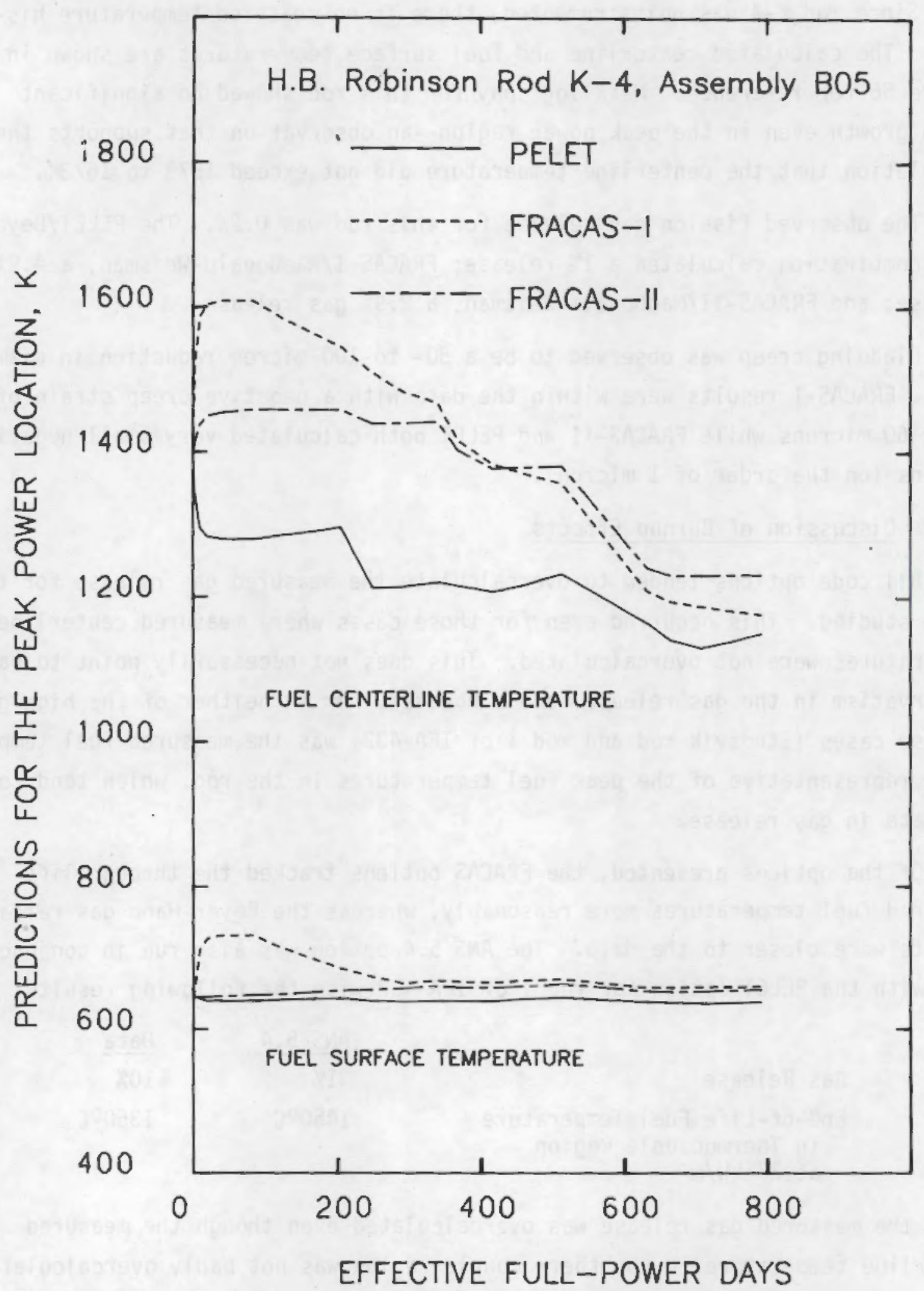

FIGURE 56. Calculated Pellet Surface and Center Temperatures Versus Irradiation Time for H. B. Robinson PWR Rod Using PELET, FRACAS-I, and FRACAS-II 
With respect to EOL radial cladding deformation, the PELET and FRACAS I mechanics options calculated positive diametral strain of the correct magnitude for the high-interaction Studsvik rod; however, only the FRACAS-1 option correctly calculated the significant creepdown.

In sumary, BOL measured temperatures and cladding deformation are matched well by both new code options (FRACAS-II and PELET); however, both options contain enpiricisms and require further refinement for calculating through-life trends. 



\subsection{SUMMARY OF EFFECTS}

\subsection{EFFECTS OF AS-FABRICATEO FUEL-CLAODING GAP}

The effect observed in experimental data is that at BOL (all other parameters being the same) fuel centerline temperature increases with increasing fuel-cladding gap size. This trend was observed in References 19 and 22 . This effect was, in fact, reproduced by all code options. It should be emphasized that the quantity compared to data was the fuel centerline temperature. The partition of thermal resistance between fuel and fuel-cladding gap calculated by the three code options is almost never the same, even though the total resistances (from fuel centerline out to the coolant) generally are the same. In particular, the PELET option assumes fuel-cladding contact at all times and produces relatively high gap conductance values at all times; whereas at medium to low powers, the FRACAS options generally modeled an "open" gap, relatively lower gap conductance, and relatively higher effective fuel thermal conductivity. These differences lead to variations in estimated stored energy within the fuel, even when the calculated centerline temperature in a given situation is neariy identical among the various options. Only tests of these options against transient fuel temperature data will ultimately isolate the more correct approach.

\subsection{EFFECTS OF AS-FABRICATED FUEL OENSITY}

The trend due to as-fabricated fuel density observed in experimental data is that with increasing fuel density there is an accompanying decrease in fuel centerline temperature. All of the thermal-mechanical options in FRAPCoN-2 exhibited this trend as can be seen from the comparisons of rod $523-1$ (92\% TO) and $\operatorname{rod} 522-3(95 \%$ To $)$.

\subsection{EFFECTS OF POWER ANO AS-FABRICATED GAP SIZE UPON BEGINNING OF LIFE CLADDING OEFOPMATION}

The following observed effects of power and gap size upon cladding deformation have mainly been deduced from BOL in-reactor cladding elongation measurements: 
- As power increases, incremental cladding deformation usually undergoes a marked change in character-mrom a small increnental change at low power that is generally assoclated with simpla cladding expansion to large incremental change with incremental power increase that is generally associated with PCMI.

- The onset of PCMI is not sharp: it is diffused over a finite power range.

- The onset of PCMI generally shifts to higher power with increasing fuel-ciadding as-fabricated gap size.

- At a high-power hold period following significant pCMl, dramatic and rapid relaxation of strain is of ten observed.

Both new code options (FRACAS-II and PELET) agreed well with medium-tohigh power cladding elongation data. The PELET option was most successful in modeling the onset of PCMI; and the FaACAS options, in response to hot pressing and/or fuel densification, did far better at modeling strain relaxation and attenuation with increasing burnup.

With respect to diametral deformation measured in IFA-508, FRACAS-11 was more successful with the small-gap rod data (100-um dametral). The FRACAS-I option seriously undercalculated the data from both rods.

\subsection{EFFECTS OF FUEL BURNUP}

The effects of fuel burnup include fuel irradiation sweliting, fuel densiflcation, fission product release, and cladding irradiation growth. Although fuel swelling and densffication effects were not measured directly in the experiments, their influence on the overall rod behavior warrants discussion. Fuel irradiation swelling occurs due to the existence of fission products trapped in the fuel matrix and therefore has an effect only after significant burnup. Because of the change in the effective as-fabricated pellet radus: this phenomena has a significant influence on fuel temperatures at medium-tohigh burnup. Densification is a BOL phenomena in which the fuel resinters resulting in a decrease in the effectuve as-fabricated pellet radus. This effect is not observed beyond 10 GWdMTU but has a significant influence on 
fuel temperatures at low burnup. Cladding irradiation growth is credited with catsing cladding elongation at extended burnup. All of the above phenonena are tinodeled in FRAPCON-z.

The effect of fisston product release is qualitatively well known. As rod irradiation progresses, some fission products are trapped in the fuel matrix while others are released to the free voids within the cladding. The Internal gas pressure increases as a direct result of the increased number of moles of gas in the rod. These fission products also degrade the gas themal conductivity and, hence, the transport of energy to the coolant.

The trends exhibited by all themal-mechanical options are consistent with the trends observed in the experinental data. However, FRAPCon-2 gererally overcalculated the inferred experimental data for fission gas release as was seen in the Studsvik and IFA-432 comparisons. 



\subsection{CONCLUSIONS}

The following conclusions are based on the results of the developmental assessment of FRAPCON-2:

- FRAPCON-2 capabilities exceed those of FRAPCON-1. These additional capabilities include a mechanistic gas release model along with four other gas release models, a local deformation mode?, an evaluation model option, an autonated uncertainty estimation option, and three thermal-mechanical analysis models.

- FRAPCon-2 is a viable tool for analyzing L.WR fuel rod behavior. Proper qualitative trends were calculated for generic PWR and BWR fuel rods. The centerline temperature rose initially due to fuel densification, then dec?ined as fuel swelling and cladding creep became important, and finally leveled off as fission products accumulated.

- FRAPCON-2 compares favorably with the experimental fuel centerline temperature data presented in this report. Calculations using all three thermal-mechanical options (FRACAS-I, FRACAS-II, and PELET) were consistent1y within $10 \%$, and of ten within $5 \%$, of the centerline temperature data from a variety of experimental facilities including Halden, PBF, and Studsvik. The one exception to good agreement is that for rod 522-4 of GC 2-2; FRAPCON-2 calculated center? ine fuel temperatures that were 14 to $28 \%$ below the experimental data at $25 \mathrm{~kW} / \mathrm{m}$. The experimental centerline temperature of this rod was shown to be high relative to other comparable Halden and PBF test rods.

- FRAPCON-2 models fuel rod defornation behavior with mixed success. The code calculated cladding axial elongation within $25 \%$ of the experimental data for rod 3 of IFA-431 and rods 11 and 13 of IFA-508 at $30 \mathrm{~kW} / \mathrm{m}$ at $\mathrm{BOL}$. However, calcutations varied as much as $400 \%$ from the experimental data after 2000 MWd/MTd. 
- FRAPCON-2 calculates gas release that is often greater than the experimental data. The code calculation of gas release fraction for rod $\mathrm{K}-4$ in the $H, B$. Robinson reactor varied from 1 to $4.9 \%$, whereas the inferred experimental data was $0.2 \%$. The calculated gas release fraction for the Studsvik $\$ 150$ rod 11 was 24 to $33 \%$ while the measured gas release fraction was $10 \%$. 


\subsection{REFERENCES}

1. Befna, G, A. , et al. December 1980. FRAPCON-2: A Computer Code for the Calculation of Steady-State Thernal-Mechanical Behavior of Oxide Fue? Rods. NUREG/CR-1845, EG\&G Idaho, Inc*, Idaho FaTls, Idaho.*

2. Latss, E. T., et a). January 1981. Independent Assessment of the SteadyState Fuel Rod Analys is Code FRAPCON-2, EGG-CAAP-5335, EGQG Idaho, Inc.; Idaho Falls, Idaho.

3. Dearien, J. A., et a1. July 1977. FRAF-53: A Computer Code for the Steady-State Analysis of Oxide Fuel Rads, TREE-NUREG-1107, EGQG Idaho, Inc * Idaho Falls, Idaho:

4. Beyer, C. E., et al. November 1975. GAPCON-THERMAL-2: A Computer Prouram for Calculating the Thernal Behavior of an oxide Fuel Rod. BNWL-1898, Pacific Northwest Laboratory, Richland, Washington.

5. Bohn, M. P. April 1977. FRACAS; A Subcode for the Analys is of Fuel Pellet Cladding Mechanical Interaction. TREE-NDREG-1028, EGaG Idaho, Inc., Idaho Falls, Idaho.

6. Berna, G. A., and M. P. Bohn. February 1981. FRAPCON-1: A Conputer Code for the Steady-State Analysis of Oxide Fue 1 Rods. NUREG/CR-1A63, EGG-2039, EGQG Idaho, Inc." thaho Falls, Idaho.*

7. Beyer, C. E, and C. R. Hann. Novenber 1974. Calculation of Fission Gas Release fron $\mathrm{HO}_{2}$ Fuel. BNWL-1875, Pacific Northwest Laboratory. Ríchland, Washingtor.

8. Gooth: A. H. 1957. A Method of Calculating Fission Gas Diffusion from U0, Fuel and Its Application to the $X-2$ Loop Test. AECL-496, CROC-721, Chalk River Nuclear Laboratories, Ghatk River, Ontario, Canada.

9. Weisman, J., et al. November 1969. Fission Gas Release from $\mathrm{NO}_{2}$ Fuel Rod with Time Varying Bower Histories." ANS Trans. 12:2.

10. Rausch, W. N, and F. E. Panisko. August 1979. ANS 5.4: A Computer Subroutine for Calculating Fission Gas Release. NUREG/CR-1213, PNL-3077, Pacific Northwest Laboratory, Richland, Washington.*

11. Argonne National Laboratory. Ottober 1980. Light Water Reactor Safety Research Program: Quarterly Progress Report, April-June 1980. NUREG/CR-1801, ANL-80-107, Argonne, Ill ino is, *

12. Rest, d. June 1978. GRASS-SST: A Comprehensive, wechanics Model for the Calculation of Fission Gas Behavior in 00 gased Fuels During SteadyState and Transient Conditions. NUREG TR -0202, ANL-78,53, Argonne National Laboratory, Argonne, Illinois, * 
13. EG\&G Idaho, Inc, April 1980. Quarterly Jechnical Progress feport on Water Reactor Safety Programs Sponsored by the Nuclear Regulatory Comission's Oivision of Reactor Safety Research, January-March 1980. MUREG/CR-1400, EGQC-2631, pp. 19m20, Idaho Fahs, Idano*

14. EGeG Idaho, InC. January 1979. Quarterly Technical Progress Report on Water Reactor Safety Programs Sponsored by the Nuclear Regulatory Comnission's Division of Reactor Safety Research, Dctober-December 1978. NIREG/CR-05I2, TREE-1298, p, 43, Idaho FalTs, Idaho,

15. Lanning, 0. 0. January 1978. GAPCON-THERMAL-3 Code Description. PAL-2434, Pacific Northwest Laboratory, Richland, washington.

16. Williford, R. E., et a1. April 1980. The Analysis of Fuel Relocation for NRC/PNL Halden Assemo Thes IFA-431, IFA-432 and IFA-513. NUREG/CR-D583, PNo-2709, Pacific Northwest Laboratory, Richland, Washington.*

17. Mikic, B. B. "Thermal Contact Conductance: Theoretical Considerations." International Journal of Heat and Mass Trans. 14:205-214.

18. Laats, E. T, et a. May 1980. Independent Assessment of the SteadyState fuel Rod Analys is Code FRAPCON-1. NLREG/CR-1339, EGG-2020, EGQG Idaho, Inc., Idaho Falis, Idaho,*

19. Garner, R. W., et al. Hovember 1978. Gap Conductance Test Series-2 Test Results Report for Tests Go $2-1$, GC $2-2$ and GR $2-3$. NUREG/CR-0300, TREE -1268 , EG\&G Idano, Inc, Idaho Fals, Idaho. $x$

20. Cole, J. T., and R. E. Wood. "Power Burst Faciitity Fuel Studies." Nuclear Tech. 28(1):9-22.

21. Appelhans, T. D., et al, June 1979, Startup Test Results Report for Hateen IFA-430. TRFBP-TR-318, EG\&G Idaho, Inc. Idaho FaTls, Idaho.

22. Hant, C. R., et al. 1978. Data Report for NRC/PNL Halden Assembly IFA-431. NUREG/CR-0560, PNL-2673, PaC ffic Northwest Laboratory, Richland, Washington,*

23. Jehida, M., and $M_{*}$ Ichikawd. November 1980. "In-plle bianeter Measurement of Light Water Reactor Test Fuel Rods for Assessment of Pellet Cladding Mechanical Interaction." Nuclear Tech. $51: 33-44$.

24. Hann, C. R., et a1. 1977. Test Design, Precharacterization and Fue Asserto ly Fabrication for Instrumented Fue Assemalies IFA-43I and IFA-432. NUREG/CR-0332, BNWL-1988, Pacific Northwest Laboratory, Richland, Washington.* 
25. Broughton, J. M* May 1976. Light Water Reactor Fuel Behavior Brogram Description: PCM Flel Behavior Experiment Requirements. SRD-106-76, EGEG Idaho, Inc., Idaho Falls, Idaho.

26. Peeler, G. B., et al. June 1977. Power Cooling Mismatch Test Series. Test PCM-4, Test Results Report. TFBP-TR-190, EGEG Idaho, Ine, Idaho FalTs, Jaho.

27. Freeburn, H. R., et a1. 1977. Light Water Reactor Fuel Rod Modeling Code Evaluation. EPRI-NP-369, Electric Power Research Inst tute, Palo Alto, Californita.

2B. Bradley, E. R., et a1. 1979. An Evaluation of the In-Pile Pressure Data fron Instrumented Fuel Assembles IfM-43I and IFA-43?. NUREG CR-1139, PNL-3206, Pacific Northwest Laboratory, Richland, Washington.*

29. Dagbjartsson, S. 3., et al. 1977. Axial Gas Flow in Irradiated PwR Fuel Rods. TREE/NuREG-1158, EGeg Idaho, Inc., Idaho FalTs, Idaho.

30. Hagrian, C. L., et al. February 1900. MATPRo-Version 2 (Revision 1): A Handbook of Materials Properties for Use in the Analysis of Light Water Reactor Fuel Rod Behavior. HUTEG/CR-0697, TREE-1280, EG\&G Idaho, Inc.; Idaho Falis, Itaho.*

31. Sparks, D. T., et a1. 1980. Power cooling Mismatch Test Series Test PR-1, Quick-Look Report. EGG-TFBP-5I22, EGkb Idaho, Inc., Jdaho Falls, Taho.

32. Nealley, C., et a1. Dctober 1979. Postirradiation Data Analysis for NRC/PNL Halden Assembly IFA-431. NUREGICR-0797, PNL-2975, Pacific Northwest laboratory, Richland, Washington.*

*Avallable for purchase from the NRc/GPo sales Program, U.S. Nuclear Regulatory Compisston, Washington, DC 20555, and/or the Natonal Technical Information Service, Springfield, VA 22161. 

APPENDIX

DEVELOPMENTAL ASSESSHENT CASES DUTPUT 
APPENDIX

\section{DEVELOPMENTAL ASSESSMENT CASES OUTPUT}

The output from each of the developmental assesment computer runs was recorded on microfiche. Copies of specific case cutput may be obtained from the authors at minimal charge.

Tables A.1. A.2, and A.3 present a listing of the developmental cases available. Listings of the input data decks used to make the FRAPCoN-2 developmental assessment computer runs are also provided.

TABLE A.1. Developmental Assessment Microfiche Using FRACAS-I

\begin{tabular}{|c|c|c|}
\hline Case & & Microf iche Heading \\
\hline IFA-430, $\operatorname{Rod} 3$ & & IFA 430 ROO 3 MECHAN=2, NGASR=0 \\
\hline $1 F A-432$, Rod 1 & & IFA 432 ROD I MECHAN=2, NGASR $=0$ \\
\hline GC $2-1, \operatorname{Rod} 503$ & & GC $2-1$ ROO 503 MECHAN $=2$, NGASR $=0$ \\
\hline IFA 508, Rod 13 & & IFA 508 ROO 13 MECHAN=? NGASR=0 \\
\hline GC $2-3, \operatorname{Rod} 523-1$ & , & GC 203 ROD $523-1$ MECHAN=2, MGASR=0 \\
\hline $\operatorname{IFA}-431, \operatorname{Rod} 3$ & & IFA 431 ROD 3 MECHAN $=2, \mathrm{NGASR}=0$ \\
\hline H. B. Robinson, god $\mathrm{K}-4$ & & HB RORINSON ROO $\mathrm{K}-4$ MECHAN=2,NGASR $=0$ \\
\hline $\mathrm{PCH}-4, \operatorname{Rod} 15$ & & PCM4 ROD 15 MECHAN =2, NGASR=0 \\
\hline IfA 508, Rod 11 & & IFA $50 Q$ ROD 11 MECHAN $=2, N G A S R=0$ \\
\hline GC $2-2, \operatorname{Rod} 522-3$ & & GC $2-3$ MECHAN $=2$, NGASR $=0$ \\
\hline GC $2-2, \operatorname{Rod} 522-4$ & & GC 2-2 ROD $522-4$ NECHAN $=2$, NGASR $=0$ \\
\hline Studsurk, Rod 11 & & STUDSVIK ROD 11 MECHAN=2, NGASR=0 \\
\hline Generic PIR & & STANDARD PAR MECHAN=2, NGASR $=0$ \\
\hline Generic BWR & & STANOARD BWR MECHAN =2, NGASR $=0$ \\
\hline
\end{tabular}


TABLE A.2. Developmental Assessment Microfiche Using FRACAS-II

Case
IFA-430, Rod 3
GC 2-1, Rod 503
IFA-508, Rod 13
GC 2-2, Rod $522-3$
GC 2-2, Rod 522-4
PCM-4, Rod 15
H. B. Robinson, Rod K-4
Stud5vik, Rod 11
GC 2-3, Rod $523-1$
IFA-431, Rod 3
IFA-432, Rod 1
IFA-508, Rod 11
Generic BWR
Generic PWR
Generic PWR

Microfiche Heading

IFA 430 ROD 3 MECHAN $=3$, NGASR $=0$

GC 2-1 ROO 503 MECHAN $=3$, NGASR $=0$

IFA 508 ROD 13 MECHAN $=3$, NGASR $=0$

GC $2-2$ ROO $522-3$ MECHAN $=3$, NGASR $=0$

GC 2-2 ROD 522-4 $\mathrm{MECHAN}=3$, NGASR $=0$

PCM4 ROO 15 MECHAN $=3$, NGASR $=0$

HE ROBINSON ROD $K-4$ MECHAN $=3$, NGASR $=0$

STUDSUIK ROO 11 MECHAN $=3$, NGASR $=0$

GC 2-3 ROO 523-1 MECHAN $=3$, NGASR $=0$

IFA-431 ROO 3 MECHAN $=3, N G A S R=0$

IFA 432 ROD 1 MECHAN $=3, N G A S R=0$

IFA-508 ROD 11 MECHAN $=3, N G A S R=0$

STANDARD BWR MECHAN $=3$, NGASR $=0$

STANDARD PWR MECHAN $=3$, NGASR $=0$

STANDARD PWW MECHAN=3, NGASR $=2$ 
TABLE A.3. Developmental Assessment Microfiche Using PELET/RADIAL

$\frac{\text { Case }}{\text { GC 2-3, } 523-1}$
GC 2-2, $522-4$
GC 2-2, 522-3
GC 2-1, Rod 503
IFA-431, Rod 3
IFA-508, Rod 11
IFA-508, Rod 13
Studsvik, Rod 11

Microf iche Heading

GC 2-3 523-1 MECHAN $=1$, NGASR $=0$

GC $2-2522-4$ MECHAN $=1$, NGASR $=0$

GC 2-2 522-3 MECHAN $=1$, NGASR $=0$

GC 2-1 ROD 503 MECHAN $=1$, NGASR $=0$

IFA 431 ROD 3 MECHAN $=1$, NGASR $=0$

IFA 508 ROD 11 MECHAN $=1$, NGASR $=0$

IFA 508 ROD 13 MECHAN $=1$, NGASP $=0$

STUDVIK ROD 11 MECHAN $=1, N G A S R=0$

H. B. Rovinson, Rod Ka 4

H. B. ROBINSON ROD $K-4$ MECHAN $=1$, NGASR $=0$

IFA-432, Rod 1

PCM-4, Rod 15

IFA-430, Rod 3

IFA-432, Rod 1

IFA-431, Rod 3

Studsvik, Rod 11

IFA 432 ROD 1 MECHAN $=1$, NGASR $=0$

PCM4 ROD 15 MECHAN $=1$, NGASR $=0$

IFA 430 ROD 3 MECHAN=1, NGAAR $=0$

IFA 432 ROD 1 MECHAN $=1$, NGASR $=0$

IFA 431 ROD 3 MECHAN=1, NGASR =

STUDSVIK ROD 11 MECHAN $=1, N G A S R=$ ?

H. B. Robinson, Rod K-4

H. B. ROBINSON ROO K-4 MECHAN $=1, N G A S R=$ ?

IFA-432, Rod 1

IFA 432 ROD 1 MECHAN $=1$, NGASR $=6$

IEA-432, Rod 1

IFA 432 ROD 1 MECHAN $=1, N G A S R=5$ 



\section{DISTRIBUTION}

No. of

Coples

OFFSITE

A. A. Chum

DOE Patent Division 9300 5. Cass Avenue

Argonne, IL 60439

400 U.S. Nuclear Regulatory Commission Division of Technica Information and Document Control

7920 Norfolk Avenue

Bethesda, MD 20014

2 Oot Technical Inf omation Center

4 M. Silberberg

Cnief, Fuel Behavior Research Branch

Division of Reactor Safety Research

U.S. Nuclear Regulatory Commission Washingtor, DC 20555

G. P. Marino

Fuel Behavior Research Branch Division of Reactor Safety Research

U.S. Nuclear Regulatory Commission Washington, DC 20555
No. of

Copies

ONSITE

43 Pacific Northwest Laboratory

w. J. Batley

J. D. Barner

E. R. Bradiey

H. E. Cunninghan

5. K. Edler

M. D. Freshey

R. L. Goodman

R. J. Guenther

C. R. Hant

D. D. Lanning (10)

R. K. Marshall

C. L. Mohr

c. Nealley

F. E. Panisko

W. N. Rausch (10)

R. E. Schrelber

R. E. Willifard

C. $\mathrm{L}$. Wilson

Publeshing Coordination Yo (2)

Technical Information (5) 



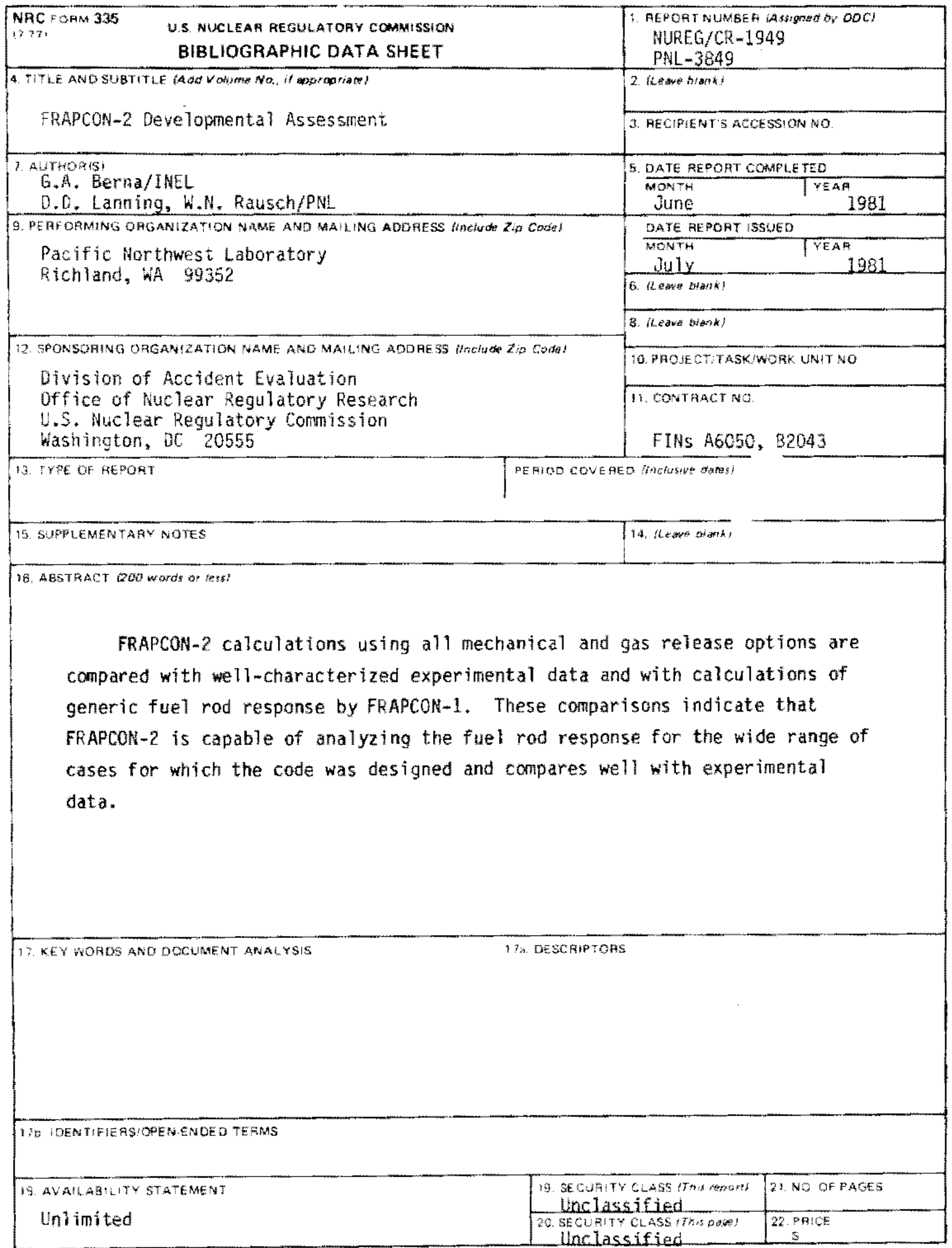


Date Fetruary 7,1903

" FRAPCON-2 User's

From N. Rausch/o, O. Lanning Whe

Subat FRAPCON-2/VMA (NUREG/CR-1949)

This letter describes the changes that have been made to the NRC FRAPCON-2 Fuel performance Code in order to create version 1. Modification 4 (VIMa). The original version was reledsed as HIM2 in lune 1981, and VIM3 was released in April 1982.

Two enclosures accompany this letter:

1) Histing of the pertinent UPDATE-generated output;

2) Sample problen $1 / 0$, to assist users in adding the VIMA UPDATE set to FRAPCON-2/VIM3.

The major modifications to FRAPCON-2 in the update are the following:

- A new version of the FASTQRASS tission gas release subrout ine (developed at AlL) supplants the previous version. The new version includes the effect of fuel microcracking and hyorostatic stress upon the fission gas release mechanisms. Note that FRAPCON-2 still does not have a grain growth model, so this mechanism is not included in the FASTGRASS results.

Note also that the fuel swelling from the modifled limited MATPRO model is used, not that calculated internally by FASTGRASS.

- The gap size lteration algorithn in the fRACAS-11 thermallnechanical subcoge was altered; the iteration is now started at the hot unrelocated gap size, rather than at zero gap size. The consequent change in converged gap size is dramatic in certain cases, and in certain inportant cest cases this has had a significant inpact upon whe predicted fuel temperatures.

- The lower linit on the bulk effective elastic fuel moduli in the PELET subcode was reduced. The modult in the radial direction was additionally sotened. This pertitited creep down to be calculated for lowi-powered PwR rod cases, where. in fact, is observed. 
These changes and their effect upon the code's predictions are discussed below. Other items (of less importance) which have also been changed in V1M4 are listed at the end of the letter.

\section{FASTGRASS}

The new FASTGRASS version, in general, tends to release less gas than the previous version. This is demonstrated by comparative runs with a "standard" prepressurized PWR rod, (a) operated at a constant peak power of $4 \mathrm{l} \mathrm{kW/m}$ to a peak burnup of $17 \mathrm{MWd} / \mathrm{kgM}$. The calculated surface/centerline fuel temperatures at the peak power node are shown for this case in Figure 1. Except for a s]ight rise near beginning of life (discussed below) the fuel temperatures calculated by the two code versions are within 50k. Yet the FASTGRASS gas release model option calculated $8 \%$ end-oflife release in the case of V1M3, and only $1 \%$ in V1M4. The latter result is more reasonable relative to data for low-burnup pressurized PWR rods.

FRACAS-II Gap Size Changes

Figure 1 also reveais the effect of changes to the FRACAS-II gap size calculation. With VIM3 the surface temperature remained essentially constant throughout $\mathrm{I}$ ife, and the slowly decreasing fuel center temperature reflects the ameliorating effect of slowly increasing PCMI upon the initially degraded fuel thermal conductivity. With V1M4, however, there is a rapid rise in surface and center temperature, reflecting fuel densification, and a slow decline in both related to cladding creepdown. Gaps up and down the rod tend to be open in V1M4, whereas they were always closed (thermally) in V1M3. The new version presents a much more realistic fuel temperature response to the various processes in operation during the rod's life.

Figure 2 represents the improvement the latest changes have made in predicting the measured fuel temperatures in Xenon-filled instrumented test rods (which are particularly sensitive to the calculated gap size). FRACAS-II in VIM3 (with its closed thermal gap) seriously underpredicts the fuel temperatures. In V1M4, the gap is estimated to be open at BOL at low power, and the predicted temperatures are much more realistic.

Reduction in PELET Fuel Moduli Lower Limit

The simple reduction in the effective bulk fuel moduli permits a prediction of creepdown by the PELET model for PWR rods which is similar to that actually observed in commercial reactor rods. The effect of this change is demonstrated in Figure 3, where the peak-power node's cladding hoop strain is plotted against peak burnup. Because of the helium fill gas and the relatively high power (equivalent to high PCMI in the PELET model), the effect of

(a) for a complete description of the design/precharacterization parameters used for this rod, see the equivalent case in Reference 1. 
this creepdown upon fuel temperatures is minor, as demonstrated in Figure 4. Nevertheless, the change is in the expected direction (VIM4 temperatures are less than V1M3) and is in fair agreement with both FRACAS-II predictions and the BOL thermal performance of PWR rods, as extrapolated from instrumented Halden tests.

Other changes to the code were also made, and these will now be discussed.

- FRAPCON-2 can now accept up to 200 input power-time steps (increased from the previous limit of 100 time steps).

- A problem from previous versions that was corrected in V1M4 was the time printout for time steps toward the end of very long power histories (over 900 days). The problem appeared to be intermittent and did not affect the engineering calculations of the program. This error was finally traced to an improper use of the time variable in the subroutine calculating the radial power profile from the LASER tables, and has now been fixed.

- A new item has been added to the output for each time step summary. The coefficients for calculating the radial power profile or flux depression. The values of $Z, Y Y$, and $W$ are now printed out and are used as follows:

POWER $=Z+Y Y \star R A O I U S \star \star 2+W \star R A D I U S \star \star 4$.

POWER is normalized to be 1.0 at the center and RADIUS is in meters.

- For the FRACAS options only, the fuel stack axial elongation is now printed out along with the cladding axial elongation. (PELET does not calculate this explicitly).

- The various printouts of cladding stresses and strains have now been adjusted to present consistent information to the user. These values are printed out in the axial node report, the time step summary page, and in the final summary. The former discrepancies were caused by having cladding stress and strain values from both before and after the creep calculation and also from nodes at the inner and outer surfaces of the cladding.

- An error was corrected in the printout of the coolant temperature at the different axial nodes and in the corresponding cladding-coolant heat transfer coefficients. The correction changes the printout values but should not affect the calculations of the code. 
- The PELET/RAOIAL model had previously improperly lumped the dish volume in wh the crack volume when calculating the rod pressure. This has been changed in 1944 with the result being increased volume in the rod but also higher temperatures for the gas in the rod. The final calculated gas pressure appears to have increased slightly (approximately $5 \%$ ).

Spectal Note: Version V1M4 permits a user-finput of asfabricated mean gram size, but does not pass this value to FASTGRASS. A constant 5-micron dianeter grain size is used instead. The following nodification will allow the user supplied value to be a? so used by FASTGRASS:

*IO REVIIMA

$*$ D V144. 106

$$
A(L 20+I-1)=6 \text { RNSI2*1.OE-4 }
$$

These cards wilT supply the user-input grain size (GRNSIz in the WME IST FRPCON) to the FASTGRASS nodel. For most cases, the change is not significant, but it may be desirable for some special circurstances.

1) Berna, Lanning. Rasch, FRAPCon-2 Developmentas Assessment, NUREG/CR-1949, June 1981. 


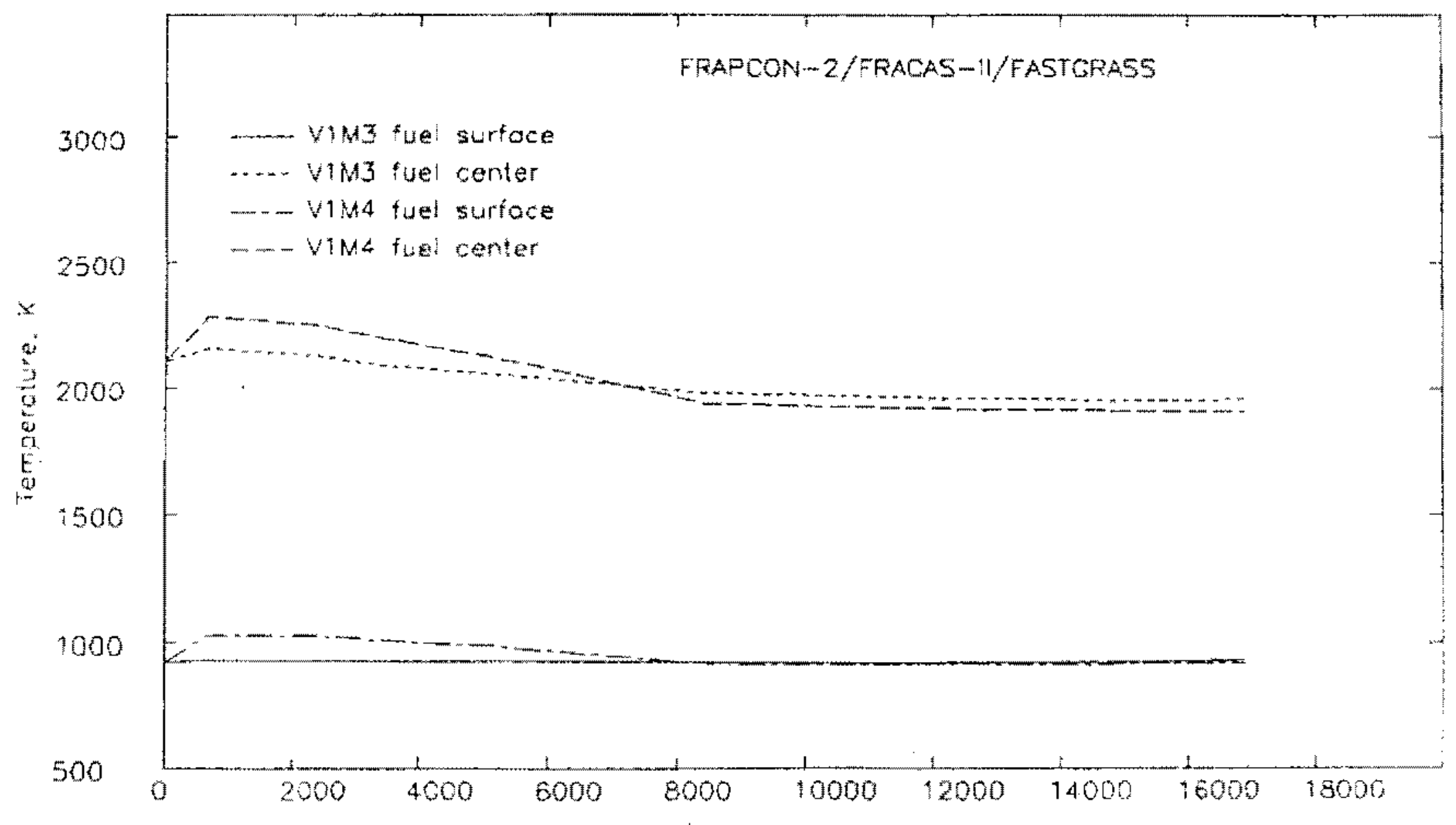

Burnup, MWd MTN

FIGURE 1. FRACAS-IL calculated fuel surface and center temperatures for a 'gerieric PWR rod at a constant $41 \mathrm{~kW} / \mathrm{m}$. 


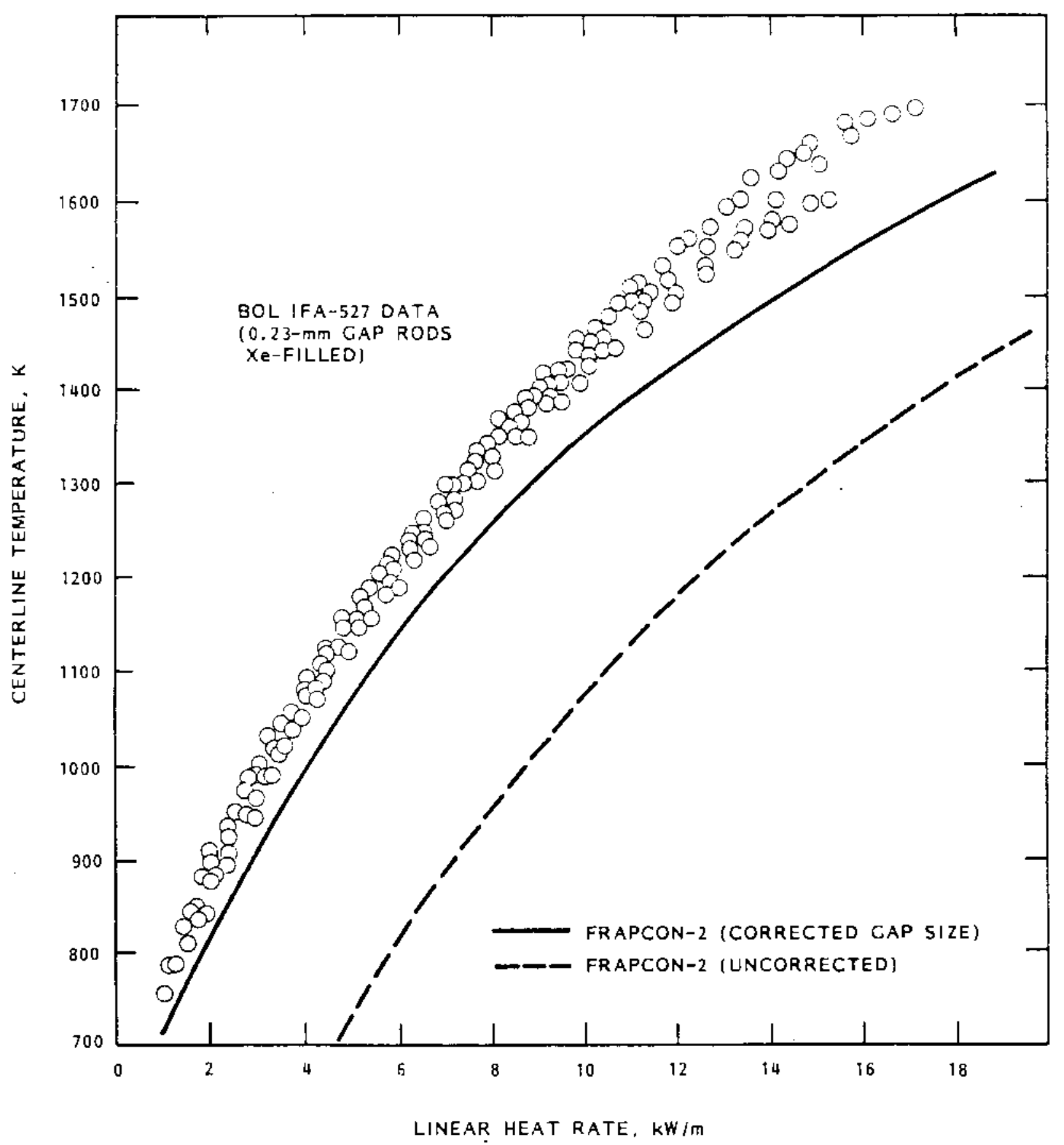

FIGURE 2. Beginning-of-life ramp comparing FRACAS-II Calculation from FRAPCON-2/V1M3 and VIM4. 


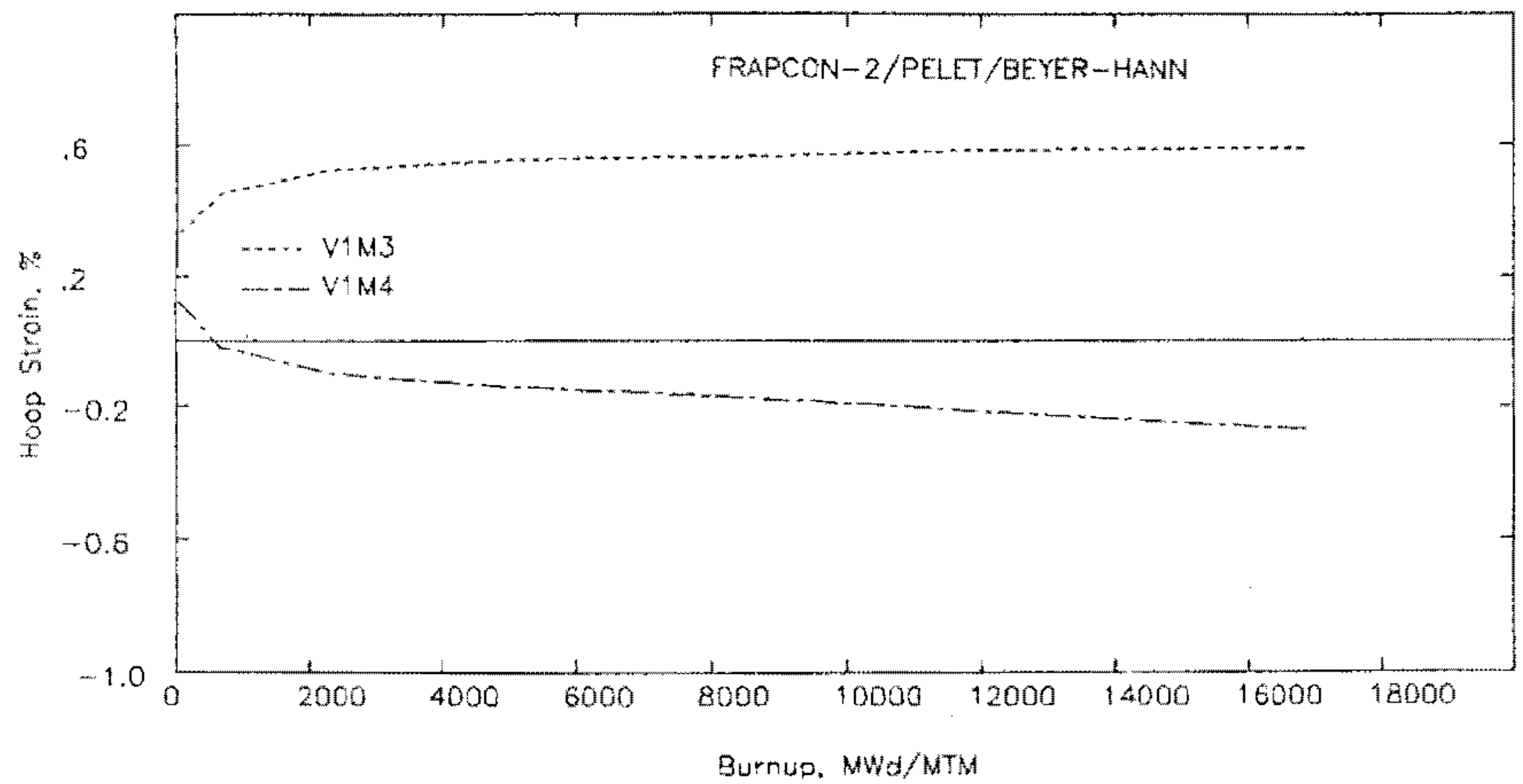

FlGURE 3. PELET calculated cladding creepdown for a generic' PWR rod at a constant $41 \mathrm{kw} / \mathrm{M}$. 


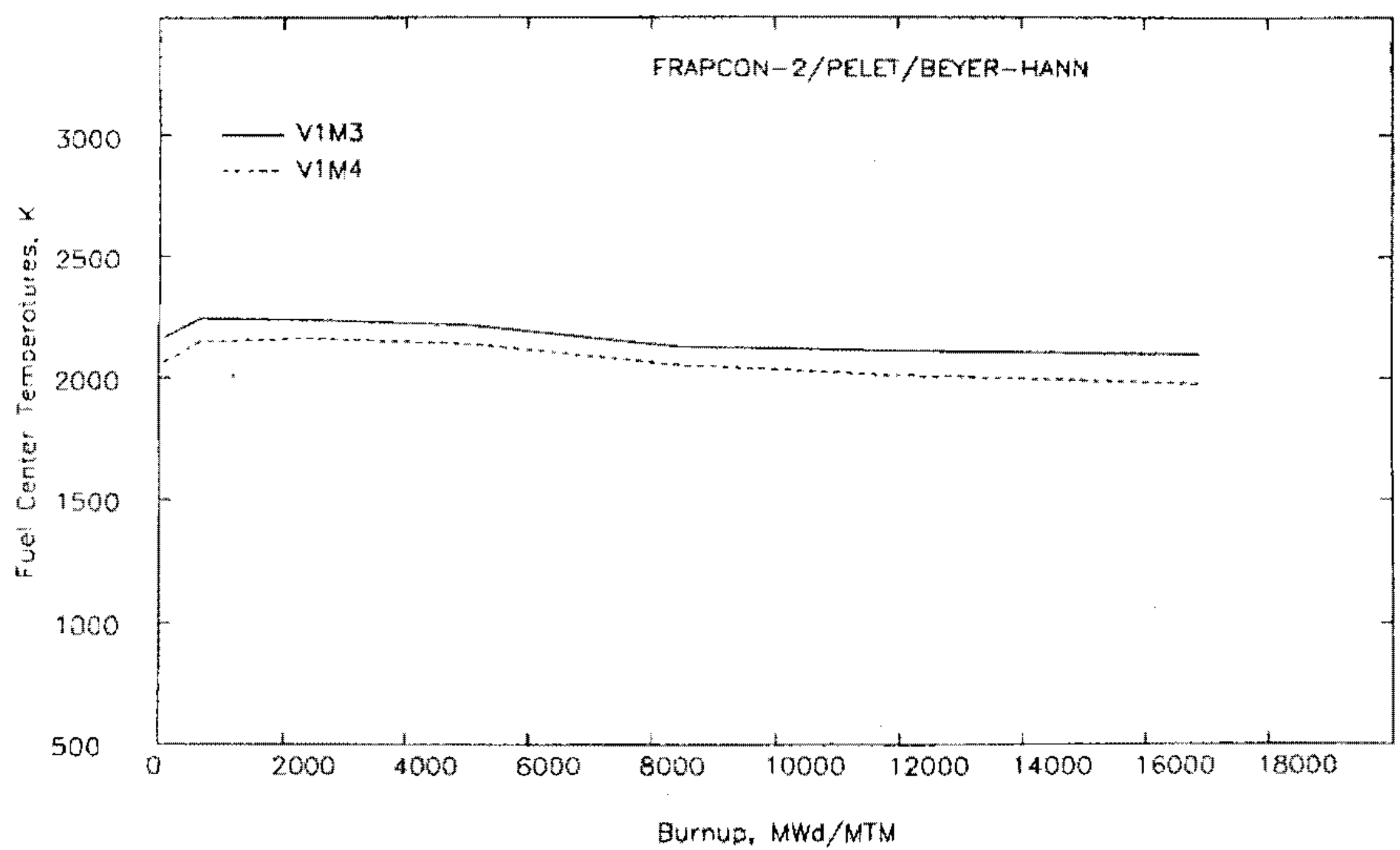

FIGURE 4. PELET calculated tuel center temperatures for a "generic" PWR rod at a constant $41 \mathrm{~kW} / \mathrm{m}$. 


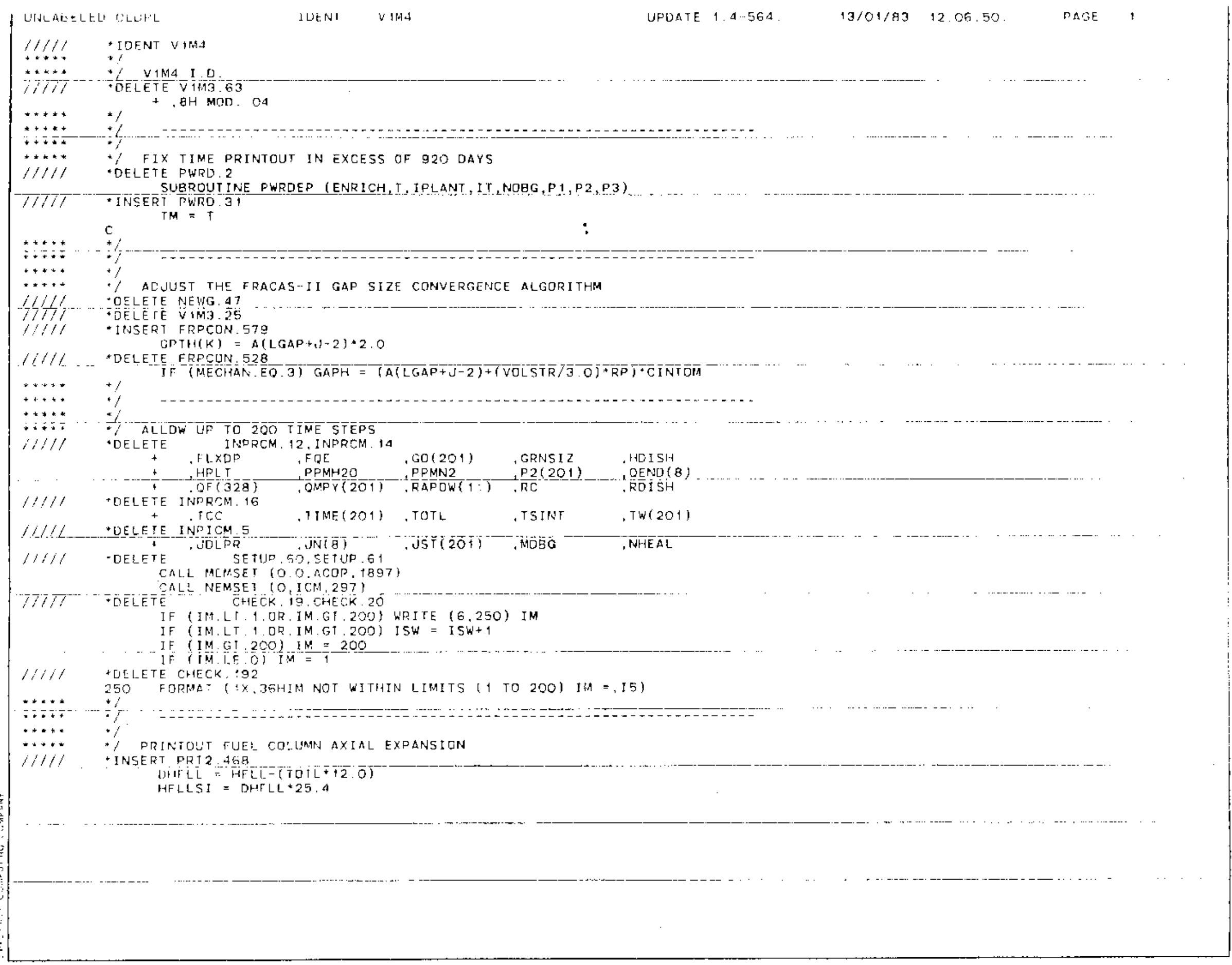




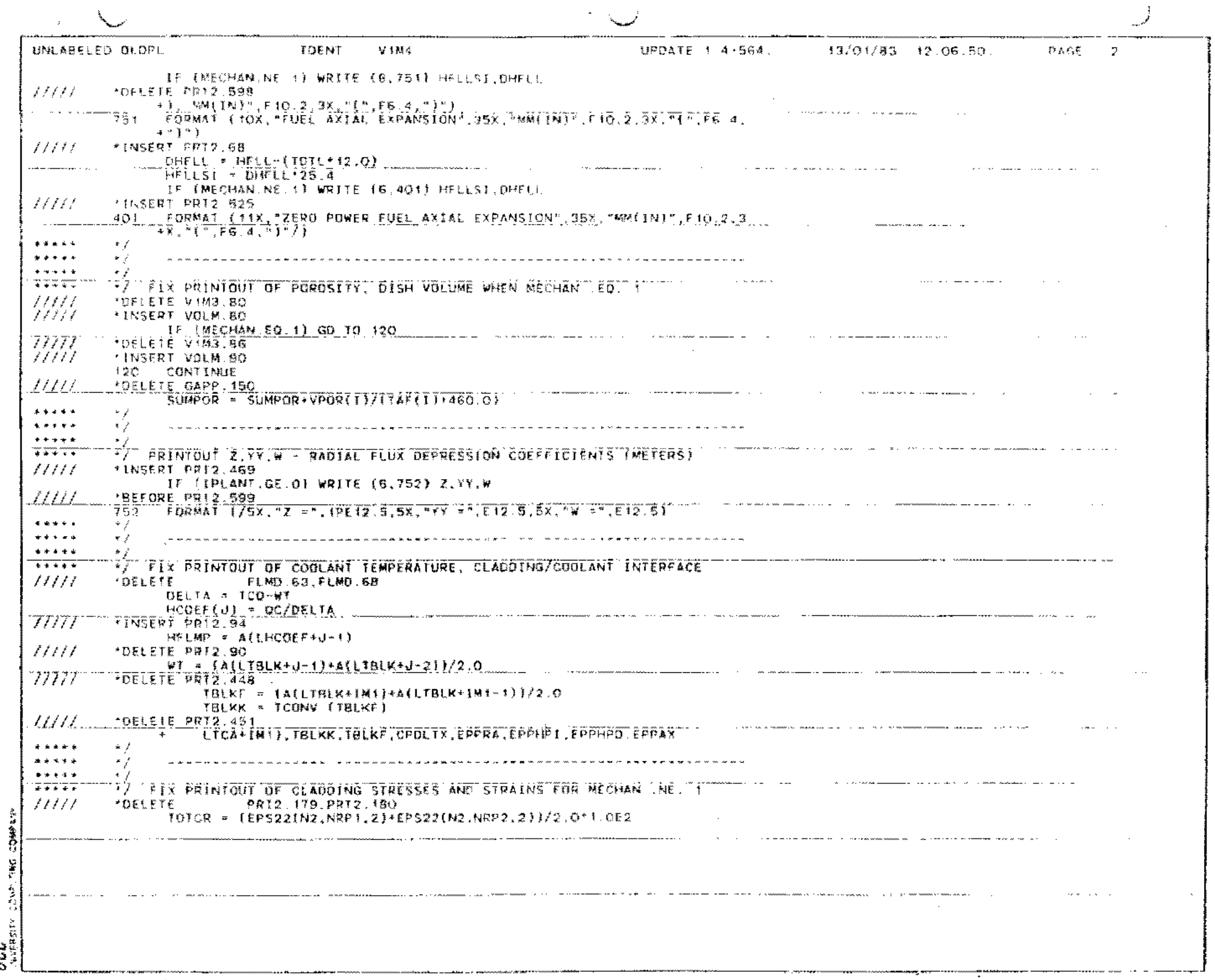




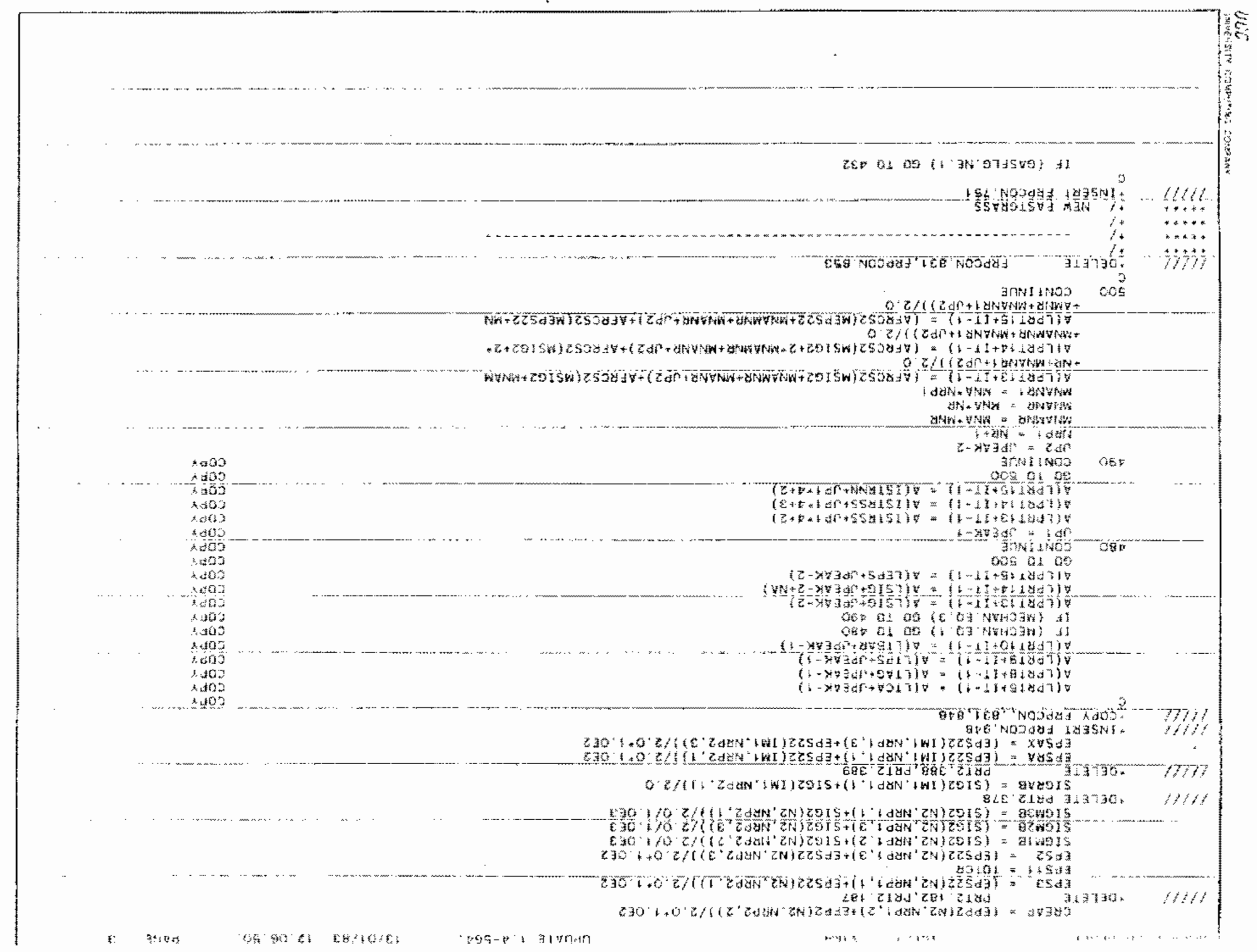




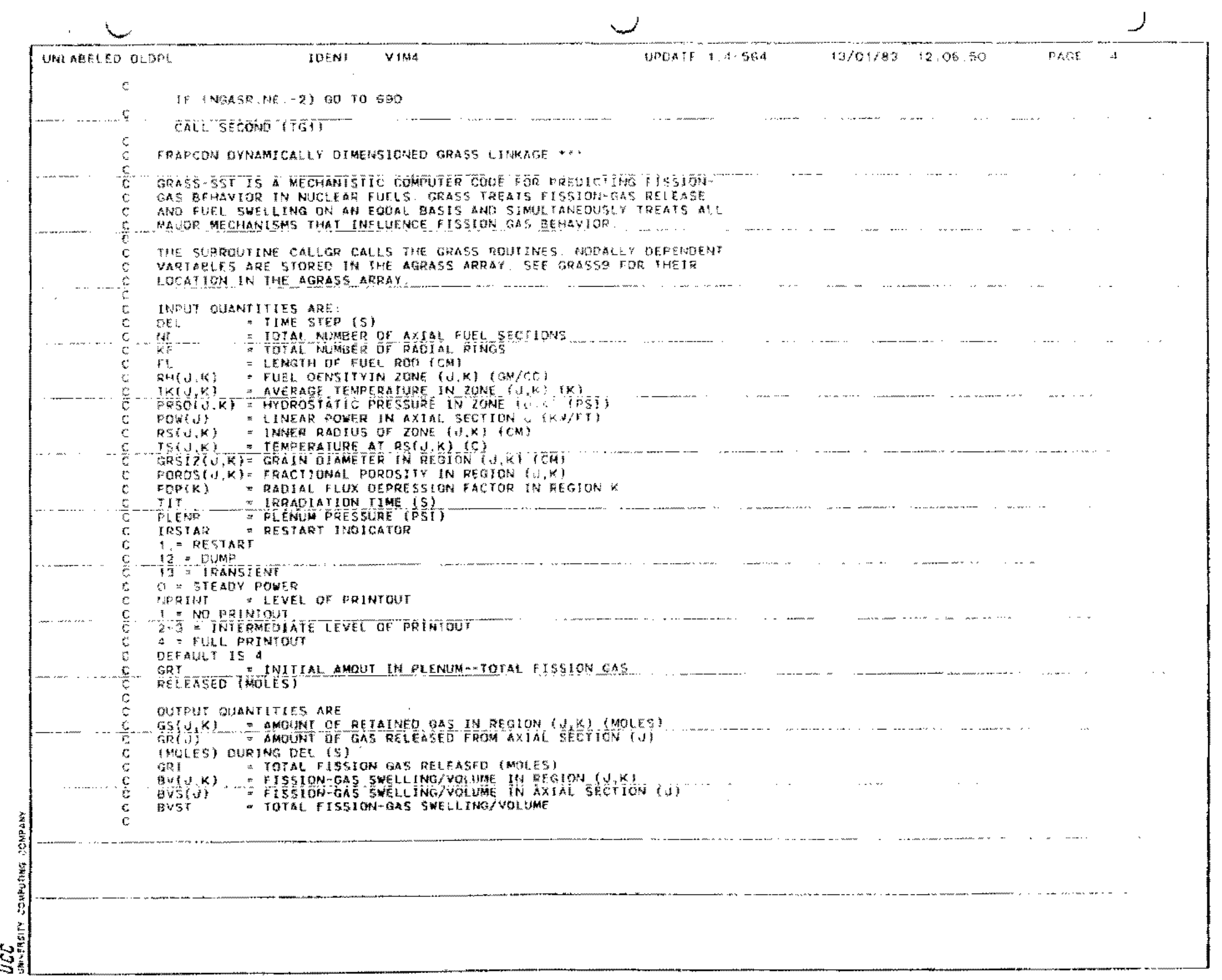




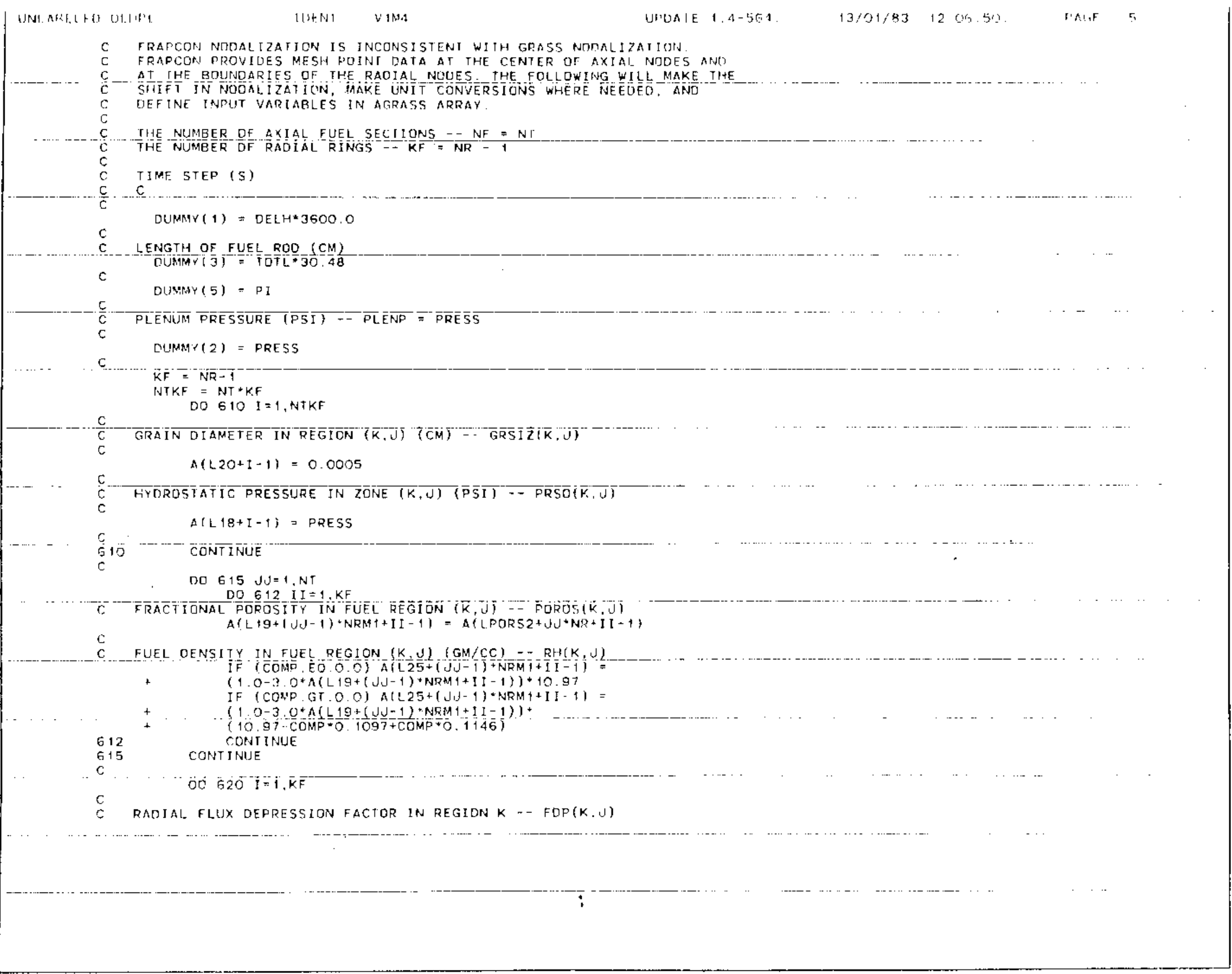




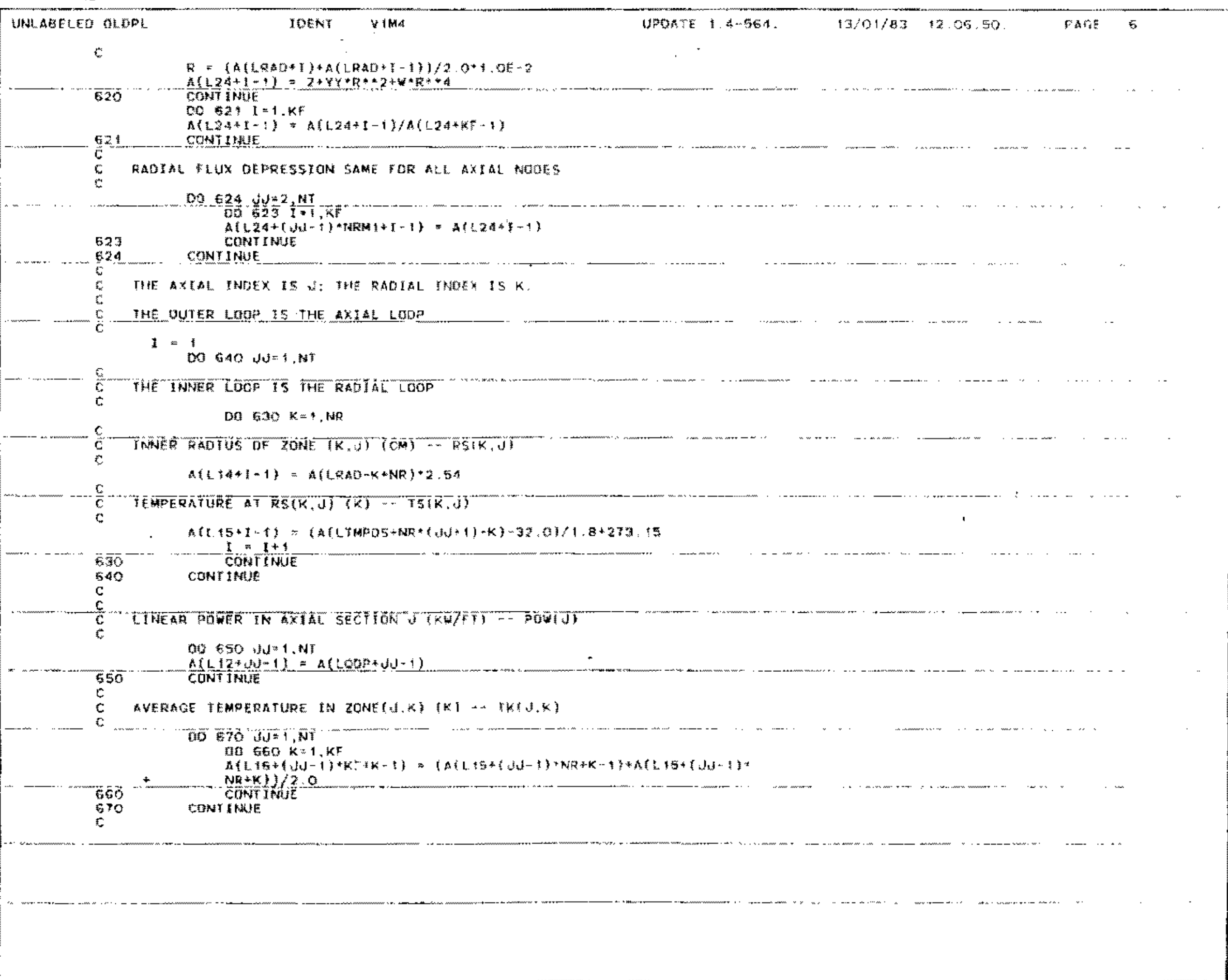




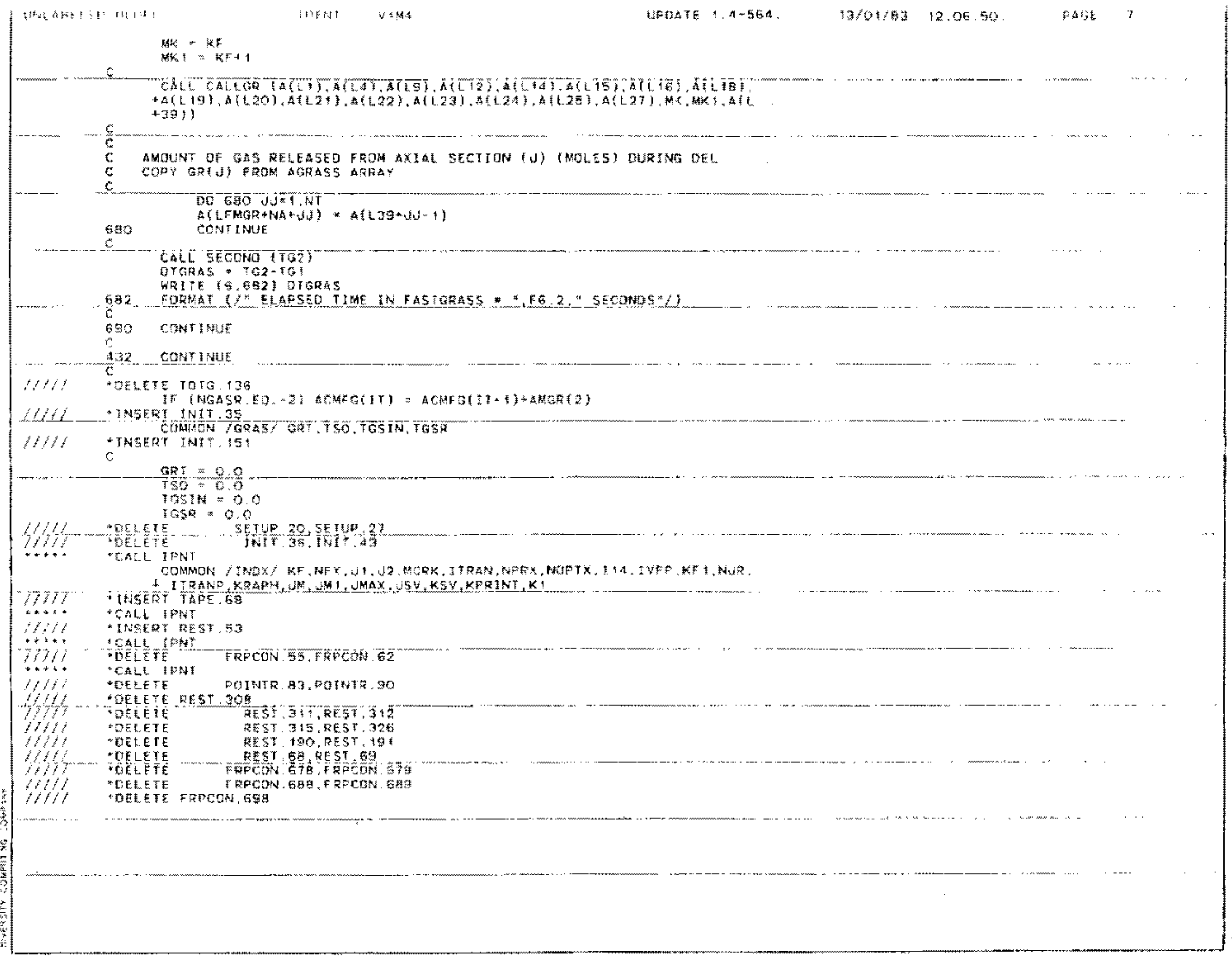




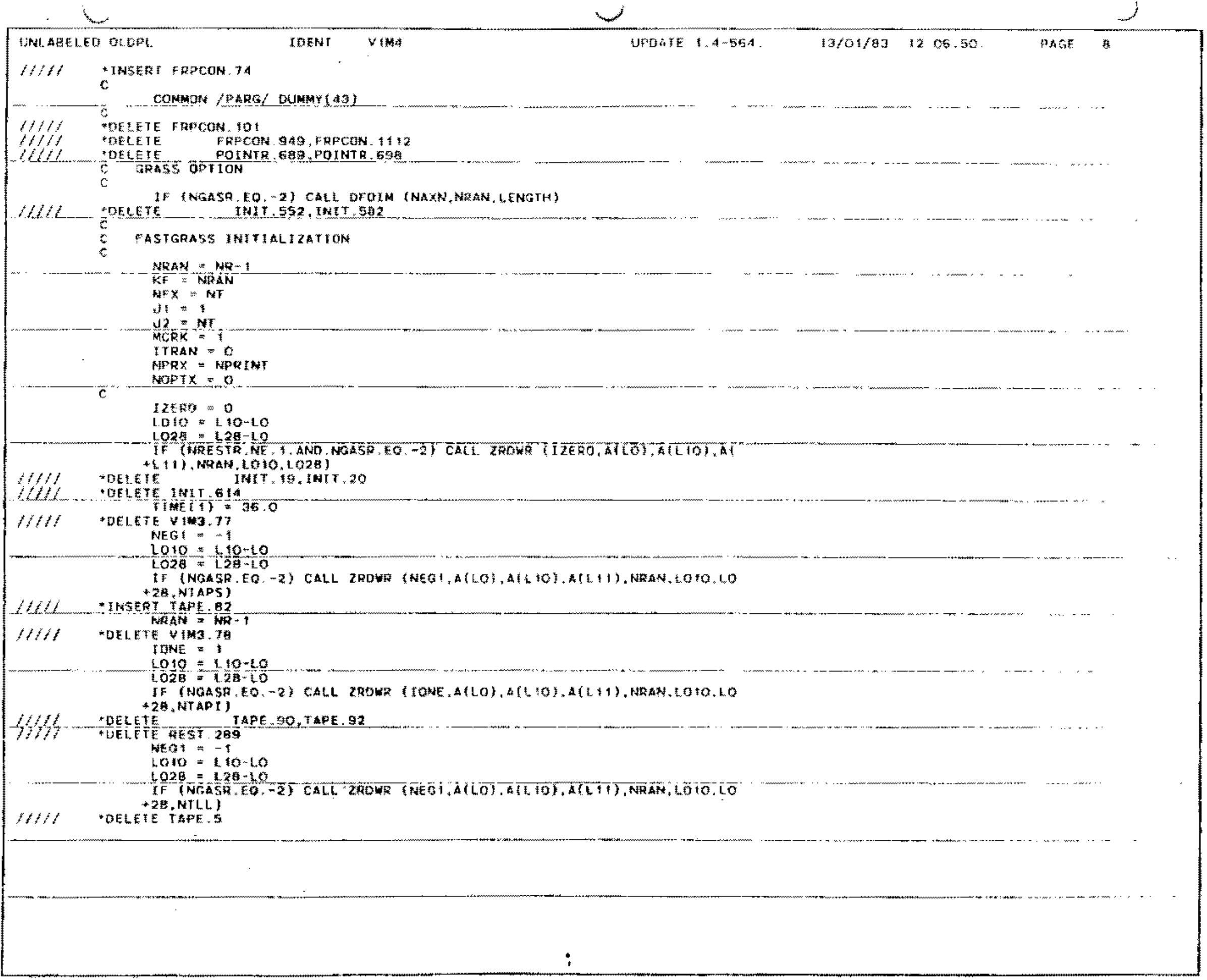




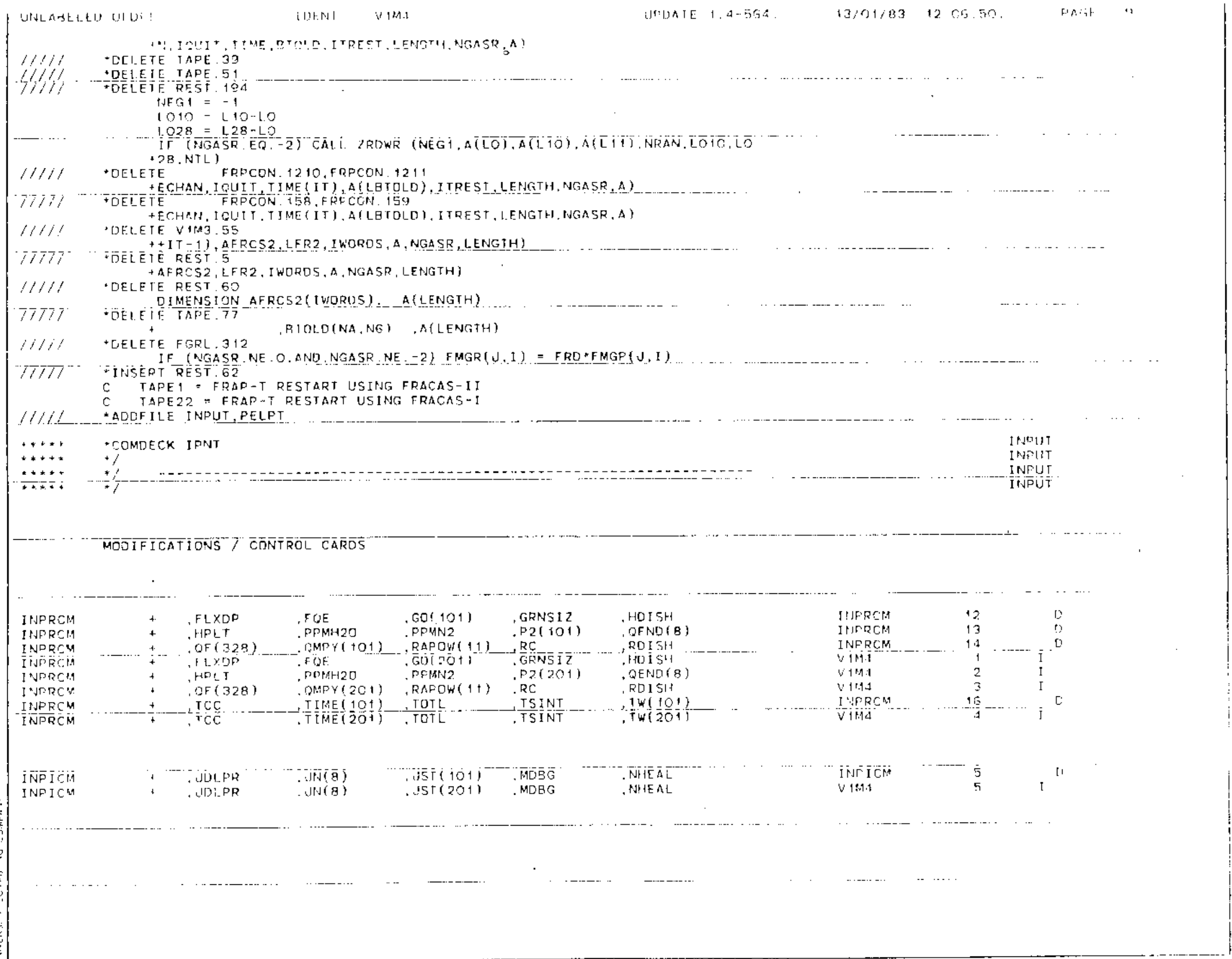




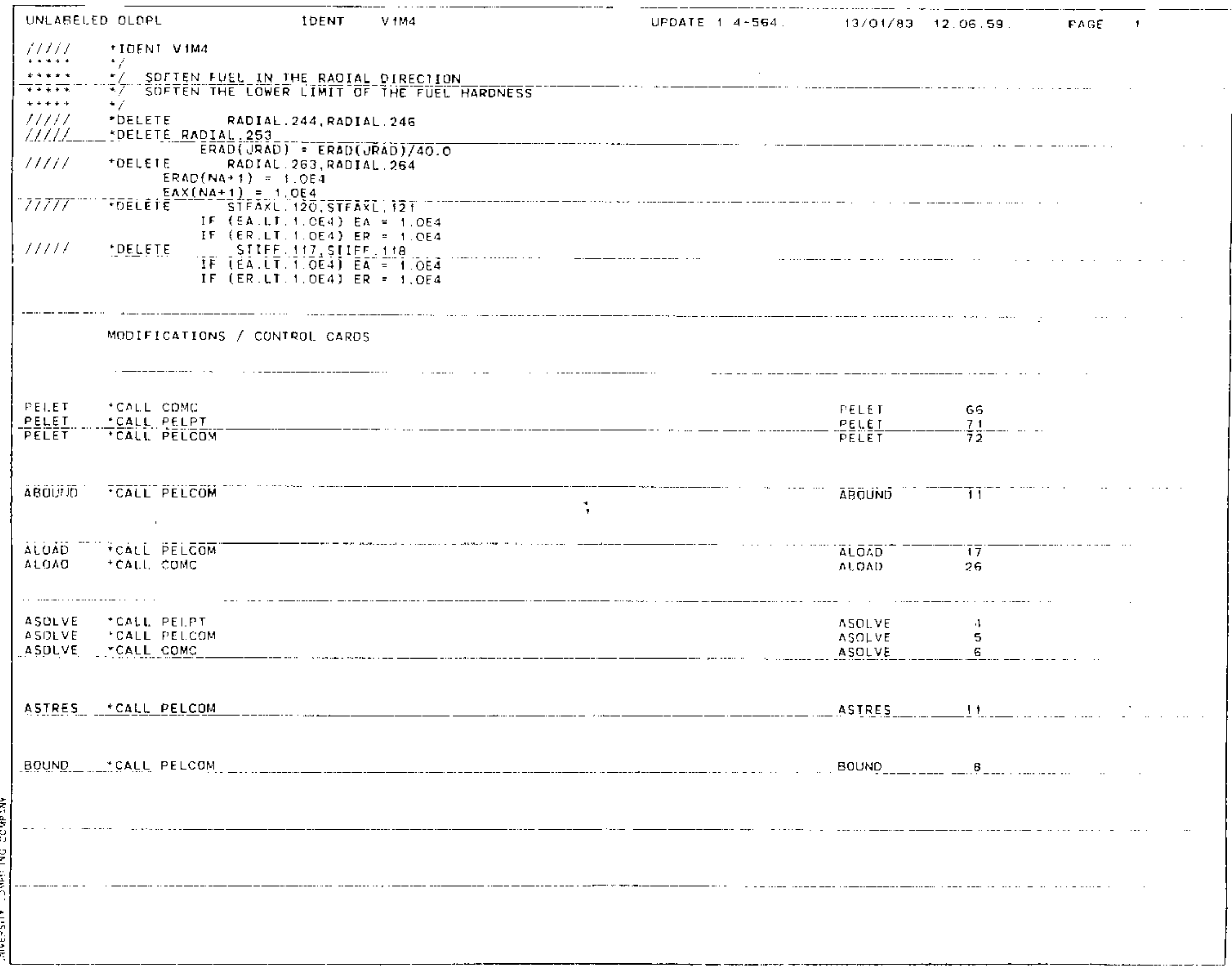




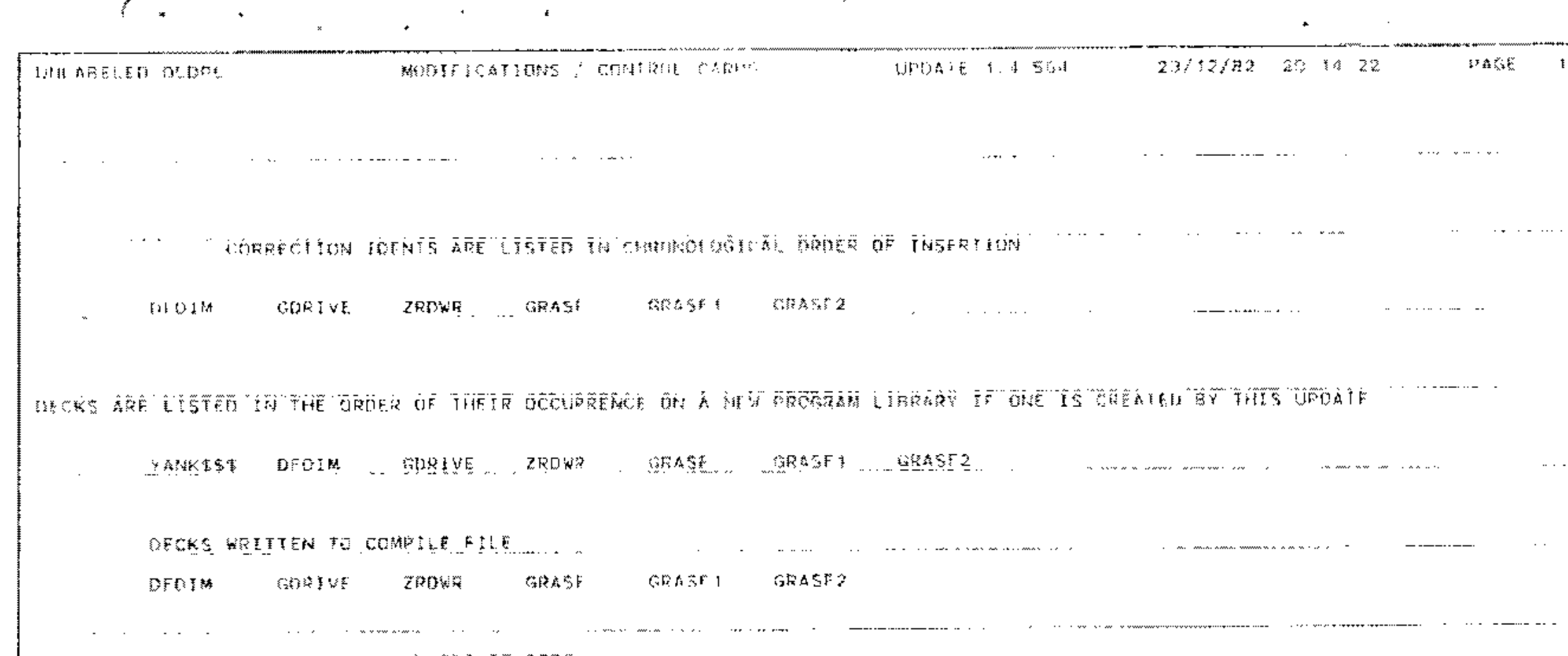

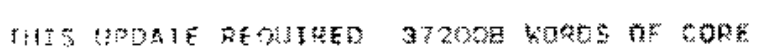




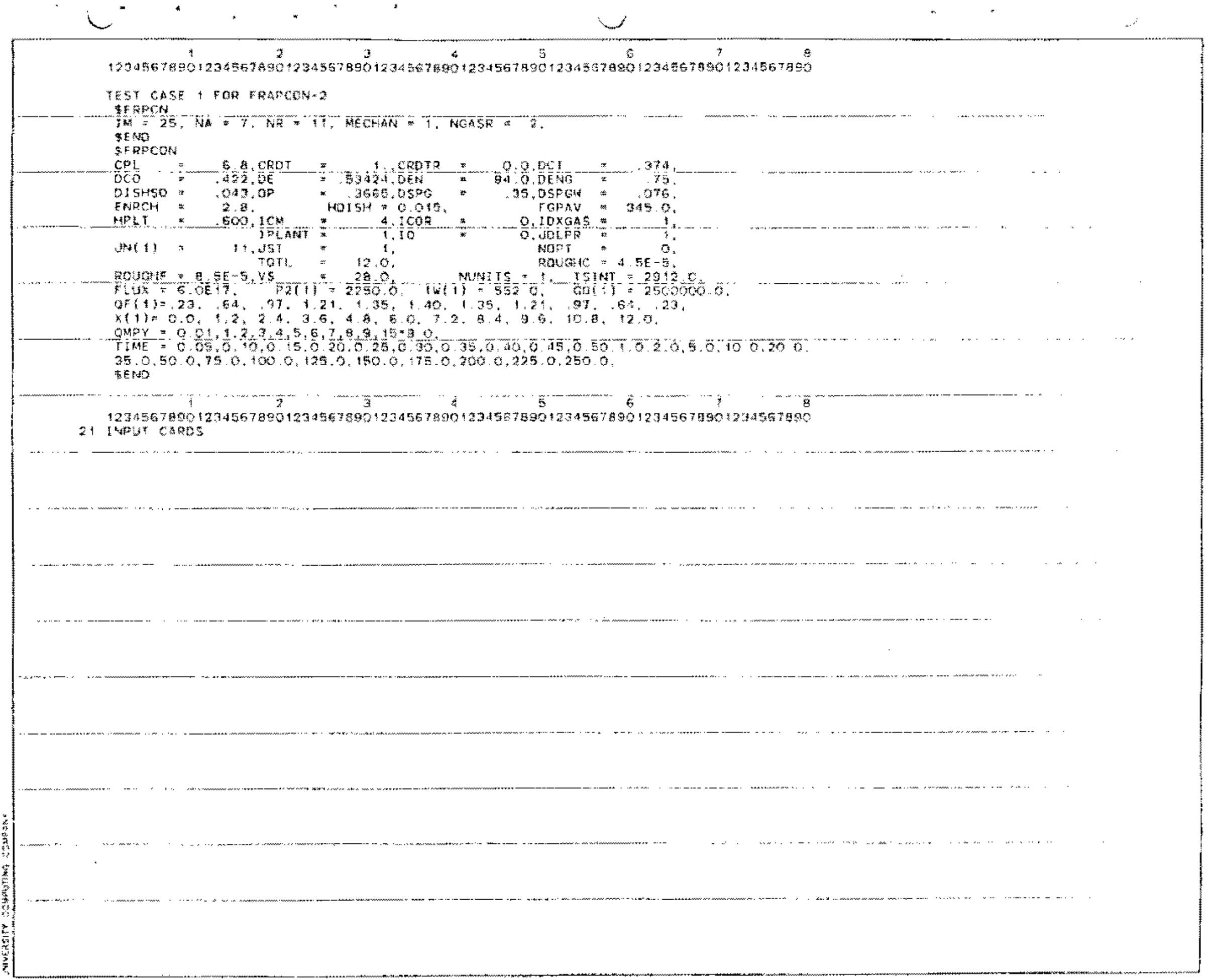




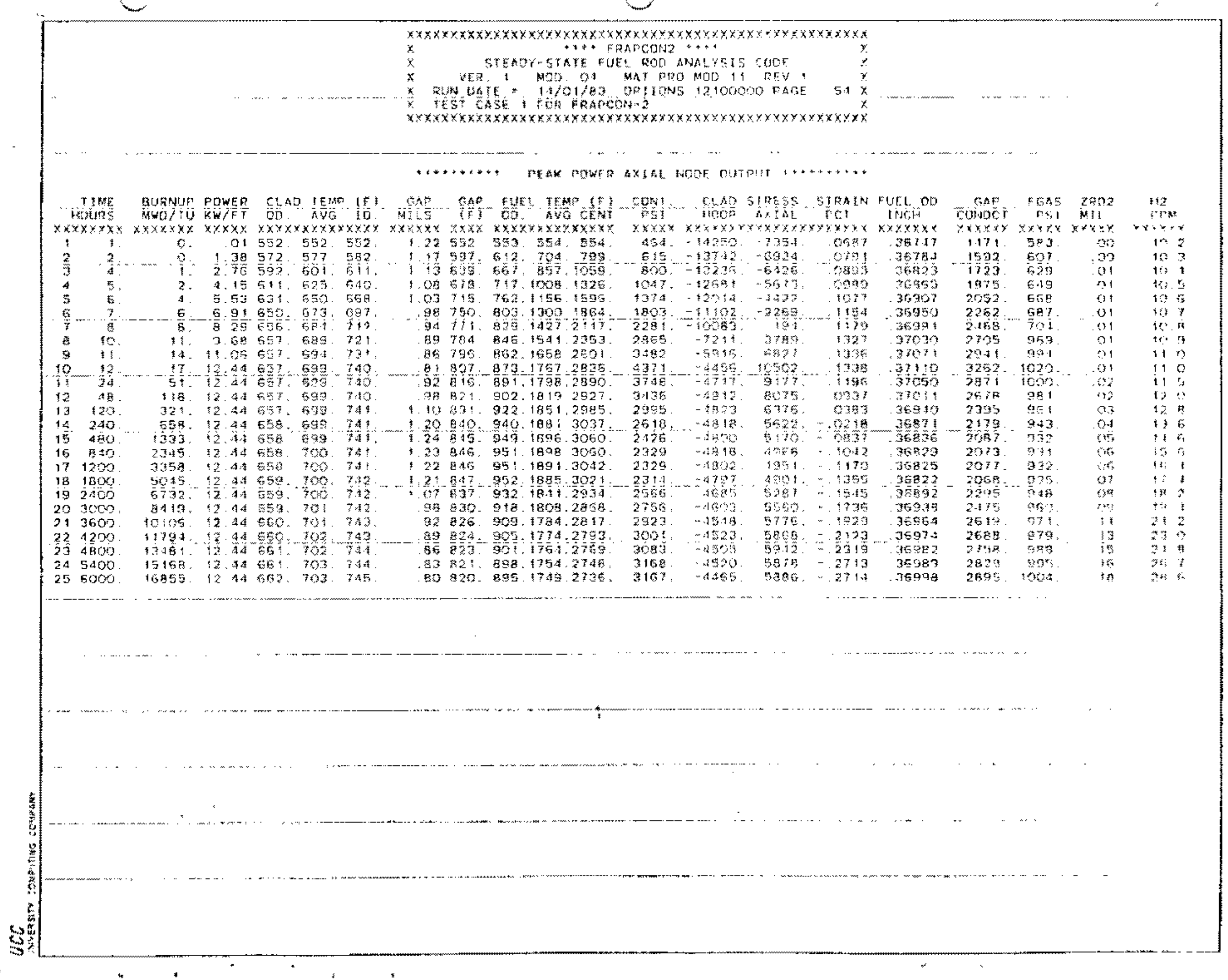




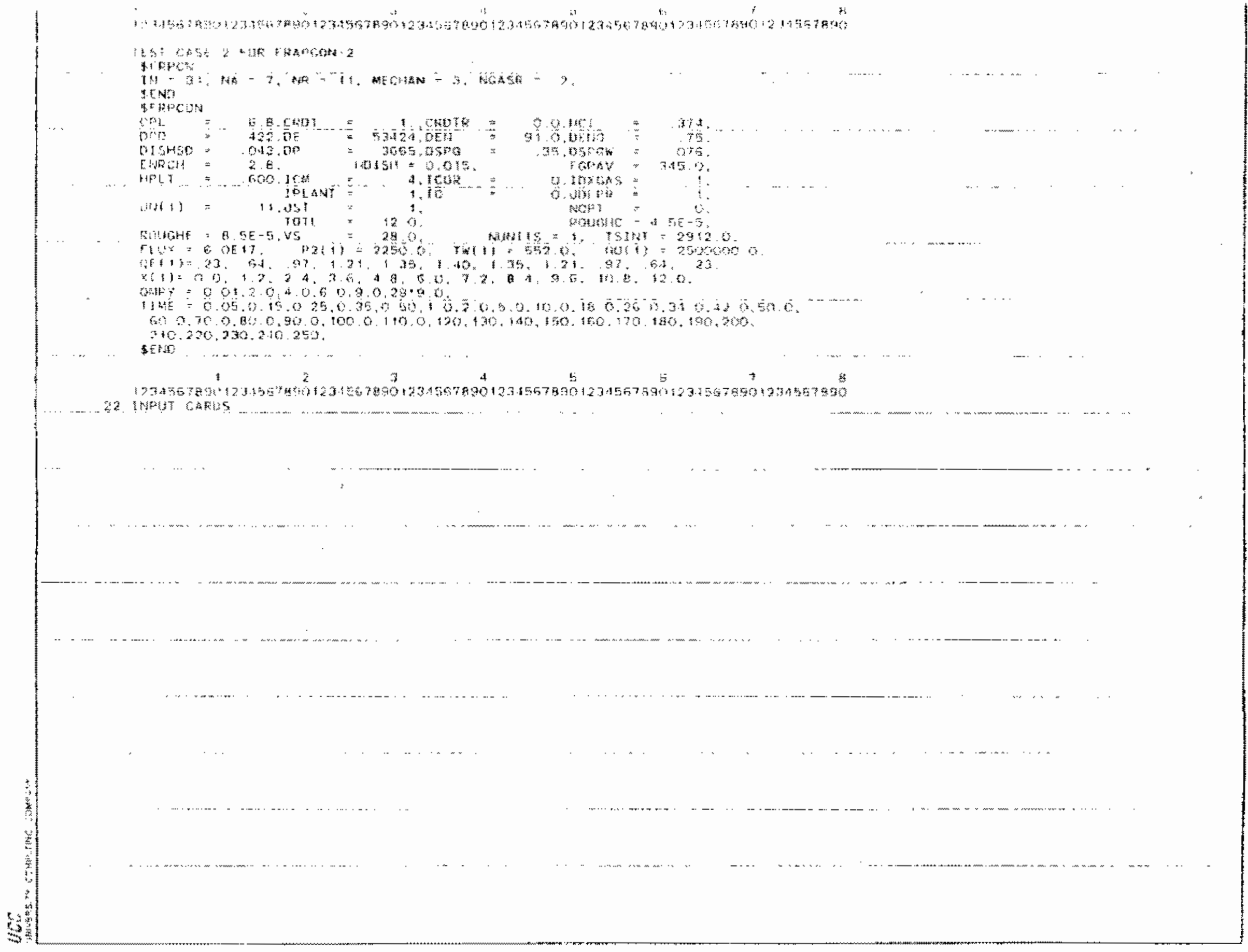




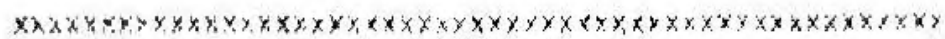
$x$.

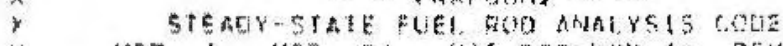

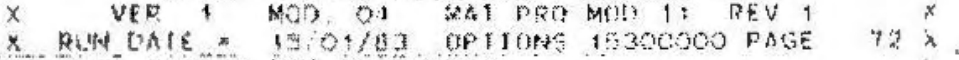

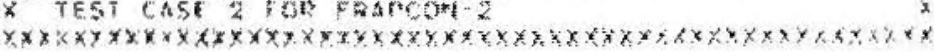

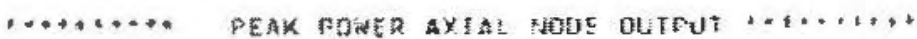

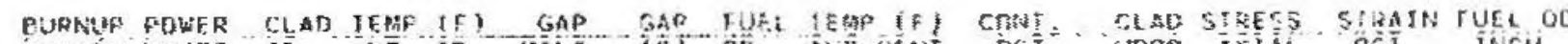

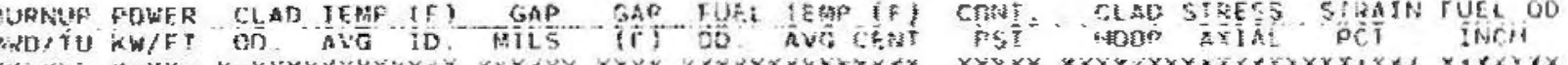

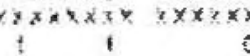
$\begin{array}{ll}\frac{3}{3} & 3 \\ 3 & 5\end{array}$ 48 $\begin{array}{ll}5 & 17 \\ 6 & 24 \\ 6 & 96\end{array}$ $6 \cdot 24$ B 130 92.3 11) 432 . 12 造相, 12 造行 131,7918

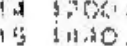

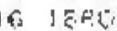
17 19:1 B 2 (t5) 193 2.100 (2) 1 2.8. ?? 3120 2.3 .350

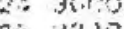

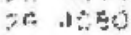
$23 \quad 2.7 \%$

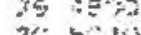

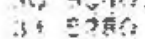

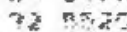

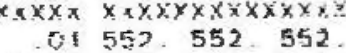

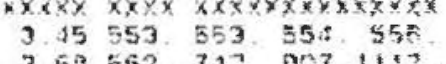

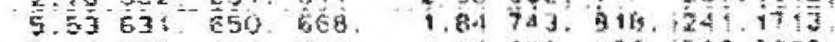

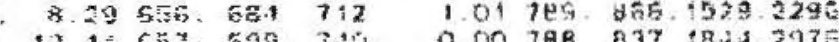
$12-42$ tse : na.

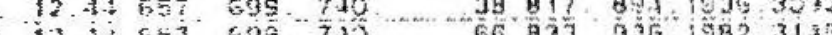

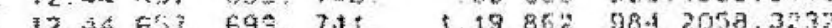

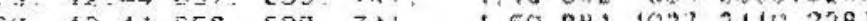

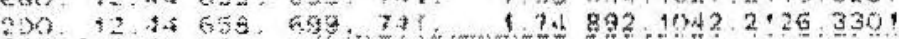

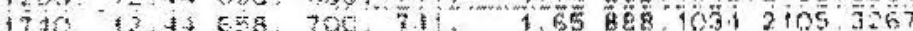
$1243 \leqslant 88.700743+52894.1021 .29 \% 3.3227$

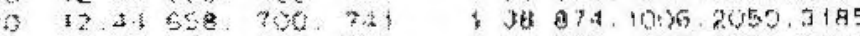
10 700 the 12. -

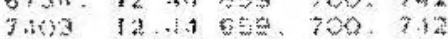

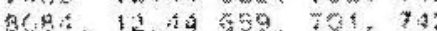

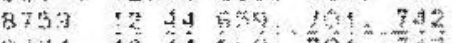

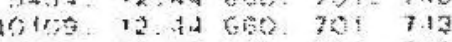
7 a

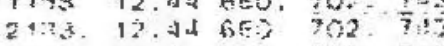

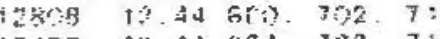

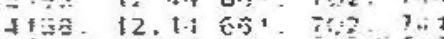

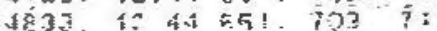

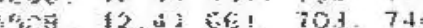

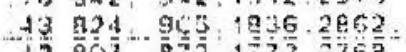
13 00709 Ba 11432\%? on $728.834 \cdot 1709.25 \%$

6. 735.629 .17002560 $0 \times 374.825 .1536$ रेख़ (ax) 18 4. 275 , 1693,2644 (10 78. $824,1591 \quad 2638$ .06 20.9 325.16903\%33

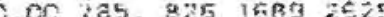
50 185 . 825 , $1637.2 \times 321$

De $735 \quad 327,1987.2621$ 9.

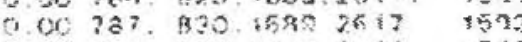
00728 831 3Eग यदा If

c 00 .

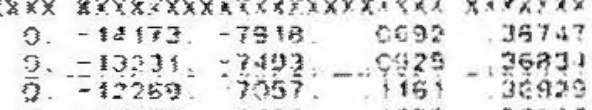
130 $-61,5$ $53 \% 2$

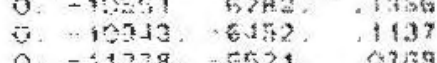

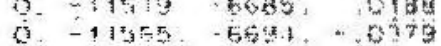

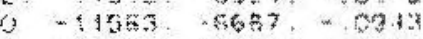

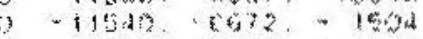
$0-11527 .-56954.2003$ (1)

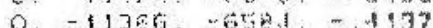

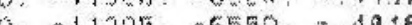
0 - i $120 \%$ w

17

然

5:5

arto

$15 t$

is 12

$x \geqslant i$

8

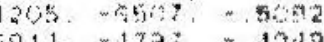

$-2157-2194, \cdots+1856$

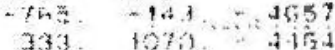

10\%3 $1335-1295$

$939+8+4=418$

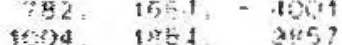

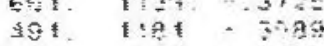

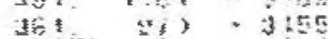
य8 $-715-35-3212$

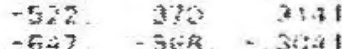

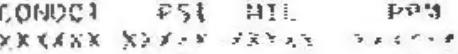

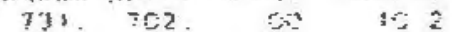
$95 \%$ ans . त

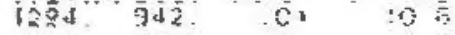
Mus rose or $13+$ $\begin{array}{llll}1521 & 137 \%\end{array}$ 2830 its 11

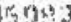
3697 35906 का 140 1492. 1452. HAT ist उㄴำ 70 3 in 365150 3 కi:3.38 34 . उदि? and $3 \% 3 \pi 0$ 34 3653 35004
362504 3691 3593 , $3 \sqrt{3} 39$ 3630 36,95 ? $30,26:$

$3 r 565$

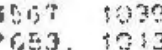

750. is?

1858. 1042

2014 ists?

2igs. then

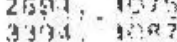

7839 14

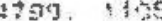
514 1113 5.350 की 13 fits is 530 : 231\% 숭 ร3)

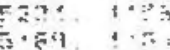
lind $\cdots$ es 